\title{
DEVELOPMENT OF HIGH TEMPERATURE, CORROSION RESISTANT POLYMER CONCRETE FOR USE IN THE STEAM DISTRIBUTION SYSTEM OF THE CONSOLDATED EDISON COMPANY OF NEW YORK - FINAL REPORT
}

R. P. Webster, L. E. Kukacka, W. Reams and C. A. Miller

November 1994
Energy Efficency and Conservation Division
Department of Applied Science
Brookhaven National Laboratory
Upton, New York 11973

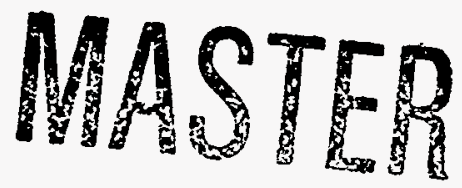

This work was performed under the auspices of the U.S. Department of Energy

Washington, D.C. Under Contract No. DE-AC02-76CH00016

DISTRIBUTIONY OF THIS DUCUMENI IS UNLIMIIEL 


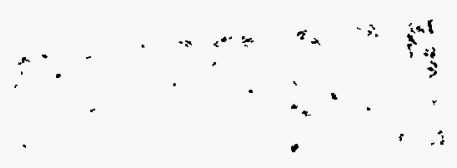




\title{
DISCLAIMER
}

\begin{abstract}
This report was prepared as an account of work sponsored by an agency of the United States Government. Neither the United States Government nor any agency thereof, nor any of their employees, makes any warranty, express or implied, or assumes any legal liability or responsibility for the accuracy, completeness, or usefulness of any information, apparatus, product, or process disclosed, or represents that its use would not infringe privately owned rights. Reference herein to any specific commercial product, process, or service by trade name, trademark, manufacturer, or otherwise does not necessarily constitute or imply its endorsement, recommendation, or favoring by the United States Government or any agency thereof. The views and opinions of authors expressed herein do not necessarily state or reflect those of the United States Government or any agency thereof.
\end{abstract}

\section{PROPRIETARY NOTICE}

This report was prepared as an account of the work done by Brookhaven National Laboratory under contract to the Consolidated Edison Company of New York, Inc. (Con Edison). All information contained in this publication is the exclusive property of con Edison and may not be used or reproduced without the prior written approval of Con Edison. 


\section{DISCLAIMER}

Portions of this document may be illegible in electronic image products. Images are produced from the best available original document. 
. 


\section{TABLE OF CONTENTS}

ABSTRACT •....... . vi

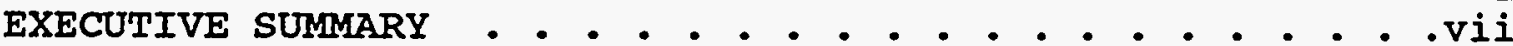

1.0 INTRODUCTION . . . . . . . . . . . . . . . . . . . . . 1

1.1 Background ... . . . . . . . . . . . . . . . 1

1.2 Program Objectives . . . . . . . . . . . . . . . . 4

2.0 IDENTIFICATION AND EVALUATION OF CANDIDATE PC SYSTEMS • • 6

2.1 Temperature Requirements . . . . . . . . . . . 6

2.2 Binder System Selection . . . . . . . . . . . . . 6

2.3 Aggregate System Selection . . . . . . . . . . . 13

2.3.1 Fine aggregate system . . . . . . . . . . 13

2.3.2 Coarse aggregate system . . . . . . . . . 13

2.4 Fiber Reinforcement System . . . . . . . . . . . . 13

2.5 PC Mix Design Formulations . . . . . . . . . . . 15

3.0 LABORATORY TEST PROGRAM . . . . . . . . ........... 17

3.1 Objectives . . . . . . . . . . . . . . . . 17

3.2 Test Methods . . . . . . . . . . . . . . 17

3.2.1 Compressive strength . . . . . . . . . . . 17

3.2.2 Splitting tensile strength . . . . . . . . 17

3.2.3 Flexure strength and flexural modulus

of elasticity . . . . . . . . . . . . 17

3.2 .4 Shear strength .................. 17

3.2.5 Coefficient of thermal expansion . . . . . . 17

3.2.6 Coefficient of thermal conductivity . . . . . 17

3.2.7 Water absorption ............... 18

3.2 .8 Creep characteristics . . . . . . . . . . 18

3.2.9 Bond of conventional reinforcing

steel to PC ................. . 18

3.3 Laboratory Test Results . . . . . . . . . . . . 18

3.3.1 Physical and mechanical properties . . . . . 18

3.3.2 Autoclave exposure tests ... . . . . . . 26

4.0 IN SITU FIELD TEST PROGRAM . . . . . . . . . . . . . . . . 27

4.1 Objectives . . . . . . . . . . . . . . . . . . 27

4.2 Field Test Locations . . . . . . . . . . . . 27

4.3 Test Program ..................... 30

4.4 In Situ Test Results ................. . 31

4.4.1 Effects of field exposure on the properties

of the PC systems .............. . 31

4.4.2 In situ post-curing of a PC system . . . . . . 36

4.4.3 In situ testing of samples made with

4.4.4 In situ load testing of verirt PC beams $\cdot \cdot \cdot 38$

4.4.5 Effects of field exposure on the properties of portland cement concrete systems . . . . 51

5.0 PRELIMINARY DESIGN OF A MANHOLE MADE WITH FIBER-

REINFORCED POLYMER CONCRETE . . . . . . . . . . . . 55

5.1 Introduction . . . . . . . . . . . . . . . 55

5.2 Loading Conditions . . . . . . . . . . . . . 55

5.2 .1 Forces on the roof . . . . . . . . . . . . 56

5.2.2 Forces on the sidewalls . . . . . . . . . 56 


\section{TABLE OF CONTENTS -- continued}

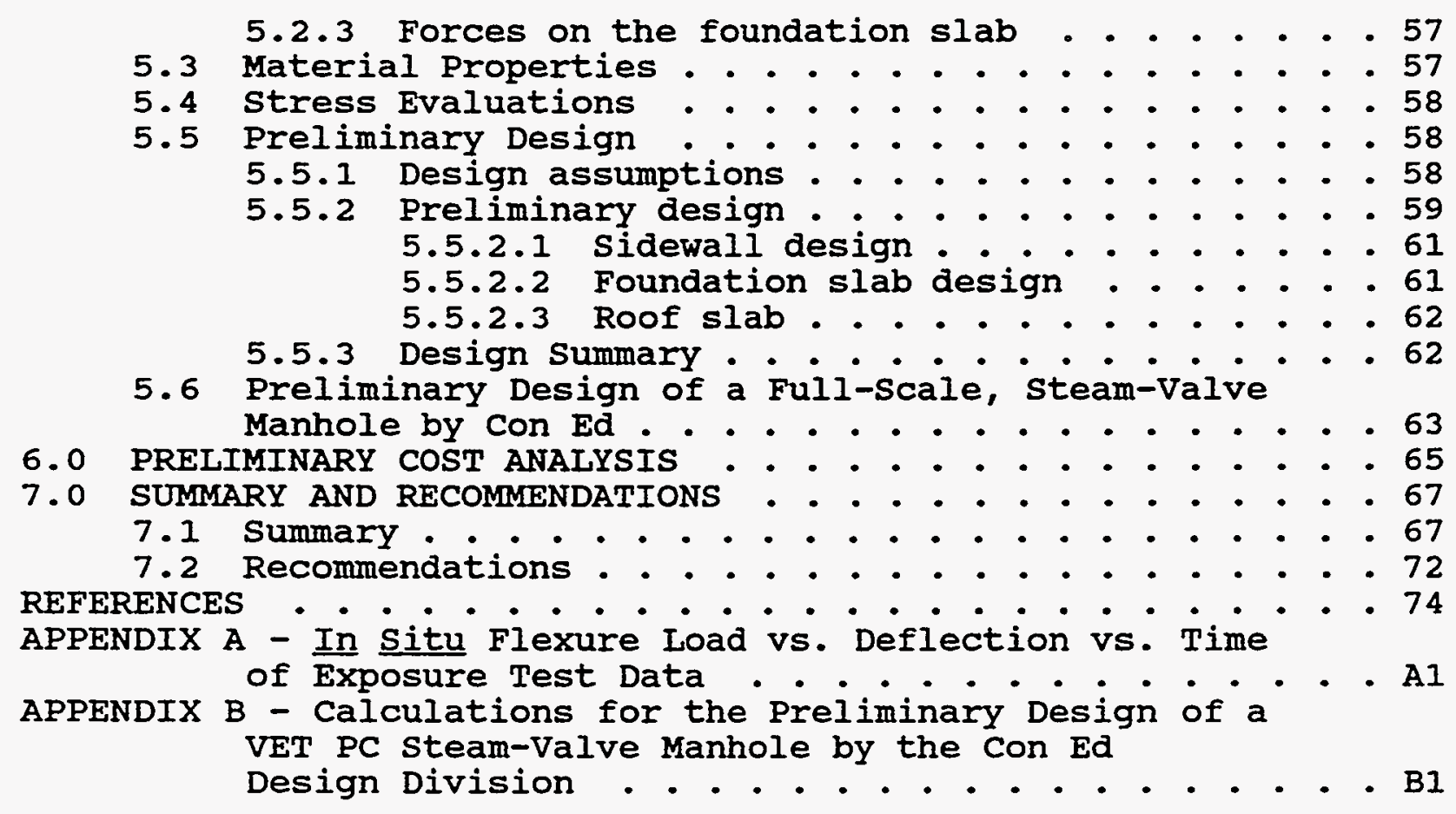




\section{ABSTRACT}

The results of a research program conducted by Brookhaven National Laboratory (BNI) to evaluate and develop polymer concrete (PC) materials, which can be used as an alternative material of construction to conventional steel-reinforced portland cement concrete (PCC) within the steam distribution system of Consolidated Edison Company of New York (Con Ed), are presented. Three fiberreinforced PC systems were identified and evaluated in a series of laboratory and in situ field tests. Based upon the results of these tests preliminary design studies were performed by BNL and the Con Ed Civil Design Division to determine the necessary floor slab, wall and roof thicknesses required to replace a typical steel reinforced PCC manhole with a fiber-reinforced PC manhole. 


\section{EXECUTIVE BUMARY}

The Consolidated Edison Company of New York (Con Ed) operates and maintains a large steam distribution system under the streets of New York City. Over the years several materials relatedproblems have been encountered with the steel-reinforced portland cement concrete (PCC) manholes used to house the system's valves and fittings. The high ambient temperature and humidity within the manholes create an environment which eventually leads to the corrosion of the reinforcing steel in the concrete. The byproducts of the corrosion process increase the volume of the reinforcing steel, creating tensile stresses in the surrounding concrete. As these stresses exceed the tensile strength of the concrete, cracks develop in the concrete which eventually lead to delaminations and/or spalls in the concrete. In addition, condensate leaking from the valves and/or piping system attacks the cement matrix of the concrete which weakens the surface of the concrete thereby making it susceptible to further deterioration. Consequently, many of the manholes in the system are severely deteriorated and need to be replaced.

The manholes are presently being rebuilt using conventional PCC. Since the manholes are located beneath the streets and sidewalks, there is a great emphasis to minimize the time involved in rebuilding the manhole to prevent excessive disruption of traffic. As a result, the manholes are often cast around existing steam mains and are then immediately placed into service. The concrete is therefore only a few days old when it is subjected to the harsh environment of the manholes. In addition, by placing the manhole into service so quickly the concrete is not allowed to fully develop the strength and physical characteristics that it normally would obtain under ideal curing conditions. This can result in the development of a substandard quality of concrete. The combination of quickly casting and placing the new PCC manhole into service and the severe operating conditions to which the manholes are exposed has resulted in a shorter than desired service life.

With the development in recent years of more advanced materials of construction, such as polymer concrete (PC), it may be possible to cast manholes that have a longer service life resulting from the improved physical and mechanical properties of these materials.

The Process Materials Group of the Energy Efficiency and conservation Division, Department of Applied Science at Brookhaven National Laboratory (BNL), Upton, NY has developed numerous PC formulations that display a wide range of physical and mechanical properties. Some of these materials are currently being used in 
commercial applications while others are still undergoing development and evaluation. Based on this experience BNI carried out a program for Con Ed entitled "Development of High Temperature, Corrosion Resistant Polymer concrete for Use in the steam Distribution system of the Consolidated Edison company of New York." The results of this program are described in this report.

The primary objective of the program was to develop a PC system suitable for use as a construction material for steam-valve manholes. Alternate methods of construction would be investigated and the PC formulations would be tailored to meet the needs of the different construction technologies under consideration. During the laboratory-phase of the program a private contractor familiar with the field application of PC systems would be consulted to ensure that the systems under development were adaptable to field installations.

The original program plan called for the development of a PC system which could be used to (a) make precast panels or (b) fabricate cast-in-place manholes. The precast panels would be used as protective stay-in-place forms against which conventional PCC could be cast or they would be used to replace the PCC in its entirety.

The exposure conditions within a typical steam-valve manhole required that any $P C$ system being considered for use exhibit the following characteristics: (a) it should be thermally stable at temperatures up to $275^{\circ} \mathrm{F}$, (b) it should have good strength and stiffness at temperatures up to $275^{\circ} \mathrm{F}$, (c) it should be impermeable to moisture penetration, and (d) it should have good resistance to possible chemical attack.

Evaluation of the candidate systems would be based upon the results of tests done to determine the physical and mechanical properties over a temperature range of $40^{\circ}$ to $275^{\circ} \mathrm{F}$. Properties to be evaluated included: water absorption, shrinkage, compressive strength, flexure strength, tensile strength, and thermal coefficient of expansion. The tests would primarily be done under laboratory conditions. Based upon the results of these tests one or more PC systems would be selected for full-scale evaluation in the field. This work would be done in Phase Two and was beyond the scope of work for this phase of the program.

Before starting the laboratory test program a survey was performed to verify the range of ambient air temperatures typically encountered within the steam-valve manholes. Seven operating manholes were selected at random and surveyed by con Ed personnel. The results indicated that air temperatures within the manholes varied between $214^{\circ}$ and $349^{\circ} \mathrm{F}$ and averaged $297^{\circ} \mathrm{F}$. In addition, it was determined that the temperature of the steam within a steam main is $\approx 380^{\circ} \mathrm{F}$. Based upon this information, con Ed asked that the design service temperature of the PC systems be raised from the 
originally specified value of $275^{\circ}$ to a value of $400^{\circ} \mathrm{F}$. This would ensure that the PC systems were thermally compatible with the range of temperatures found within the steam-valve manholes and it would also ensure that the PC systems would not thermally degrade in the event of a steam main rupture.

The scope of work for the program was revised to reflect the fact that the design service temperature was raised to $400^{\circ} \mathrm{F}$. In addition, it was expanded to include small-scale field testing of the candidate PC systems. These tests were added in order to determine the effects of exposure to actual field conditions on the physical and mechanical properties of PC and PCC systems.

To meet the objectives of the program four tasks were developed to serve as guidelines. They were:

A. Identification and evaluation of candidate PC systems.

B. Laboratory-scale evaluation.

C. Field evaluation.

D. Preliminary design of a typical steam-valve manhole.

The results of the work performed in these tasks are summarized below.

In Task A three PC systems were developed and evaluated. Each system consisted of four components: a polymer binder system, a blended fine aggregate system, a graded coarse aggregate system, and a fiber reinforcement. The fiber reinforcement was added to the PC mix design to improve the strength and ductility of the systems. The primary difference between each system was the monomer/resin system used as the binder. Three binder systems were evaluated: (1) a styrene-trimethylolpropane trimethacrylate (TMPTMA) [ST]-based monomer system, (2) a vinyl ester-TMPTMA [VET]based monomer system, and (3) a phenol formaldehyde [PF] resin system.

One and one-half inch long corrugated, carbon steel fibers were initially selected for use as the reinforcing system. Synthetic fibers, such as graphite and Kevlar aramid fibers, also were evaluated, but the carbon steel fibers were found to provide the best load carrying capacity and ductility. Stainless steel fibers were later evaluated when results of the in situ field tests indicated that corrosion of some of the carbon steel fibers exposed at the surface of the samples was causing some of the PC systems to deteriorate.

Preliminary evaluation of the three candidate systems (Task B) was based upon the results of a series of laboratory-scale tests designed to (a) determine the physical and mechanical properties of each system over a temperature range of $72^{\circ}$ to $400^{\circ} \mathrm{F}$ and (b) determine if exposure to simulated field conditions adversely affected these properties. 
The results of the laboratory-scale tests indicated that the strength properties of each system decreased with increasing temperature. The strength reductions were due to a softening of the polymer binder systems, and not to any physical deterioration of the PC systems. Compressive strengths for the three systems generally varied between 12,220 and $14,270 \mathrm{psi}$ at $72^{\circ} \mathrm{F}$ and between 4,730 and $9,415 \mathrm{psi}$ at $400^{\circ} \mathrm{F}$. The flexural yield strength generally varied between 2,145 and 2,865 psi at $72^{\circ} \mathrm{F}$ and 930 and $1,440 \mathrm{psi}$ at $400^{\circ} \mathrm{F}$. The highest strength values were exhibited by the VET PC system. BY comparison, fiber-reinforced portland cement concrete, which had been cast and cured at room temperature conditions, was found to have a compressive strength of $5115 \mathrm{psi}$ and a flexure strength of 960 psi at $72^{\circ} \mathrm{F}$.

Results of small-scale, short-term, load-deflection tests indicated that the VET PC system was the most rigid system and the ST PC system the most flexible. The test results also indicated that each of the three systems would creep at room temperature conditions under a sustained load.

The coefficients of thermal expansion for the PC systems were

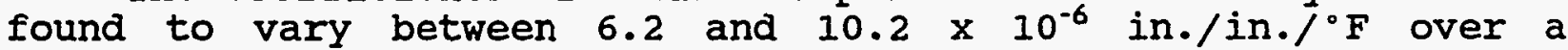
temperature range of $75^{\circ}$ to $425^{\circ} \mathrm{F}$. The coefficient of thermal expansion for conventional PCC normally varies between 4.0 and 7.0 $\mathrm{x} 10^{-6} \mathrm{in.} / \mathrm{in} . /^{\circ} \mathrm{F}$ and has an average value of $5.5 \times 10^{-6} \mathrm{in} . / \mathrm{in} . /^{\circ} \mathrm{F}$. The coefficients for each system varied slightly depending upon the binder and also tended to vary with temperature, generally increasing slightly with increases in temperature. The coefficients of thermal conductivity for the PC systems were found to be within the range of values associated with conventional PCC, i.e. they varied between 0.8 and $2.1 \mathrm{BTU} / \mathrm{hr} / \mathrm{ft} /{ }^{\circ} \mathrm{F}$. Thermal conductivity values were found to vary with the type of binder and with temperature.

Water absorption values for the PC systems were found to be significantly less than those of conventional PCC, which normally varies between 5 and 7 wto. The PC systems had average water absorption values varying between 0.41 and 1.86 wt\%.

Small-scale laboratory tests were done on PC mortar samples under simulated field conditions in an autoclave to evaluate how each system might perform in the field. The tests showed that 12 wh of exposure to simulated field conditions resulted in a slight decrease in compressive strength for the PF system, while the strengths of the VET and ST systems remained relatively constant. Visual examinations of the samples throughout the tests indicated no significant deterioration due to autoclaving. The results suggested that each of the PC systems should perform well in the field.

When the laboratory-scale tests were completed; in situ field tests (Task C) were started. The objectives of the field tests 
were: (a) to evaluate the effects of exposure to actual field conditions on the physical and mechanical properties of PC and PCC systems, (b) to determine if the heat generated within a typical manhole could be used to post-cure a PC system, and (c) to evaluate the long-term creep characteristics of a PC beam under load.

Samples were tested in situ in three operational steam-valve manholes for up to $18 \mathrm{mo}$. The manholes (MH) used in the tests were MH7498, MH7500, and MH15105. The average air temperature within each manhole was as follows: MH7498 - $177^{\circ} \mathrm{F}$, MH7500 - $160^{\circ} \mathrm{F}$, and MH15105 - $194^{\circ} \mathrm{F}$. Three PC systems and two PCC systems were tested in situ. The PC systems were the ST, VET, and PF systems. The PCC systems were a non-reinforced system and a fiber-reinforced system. The specimen placed in test included 2- by 2- by 12-in. long beams and 3 -in. diameter by 6-in. long cylinders.

In general, most of the samples removed within the first 12 mo. of testing were in good physical condition; i.e. no significant deterioration of the surfaces was noted. The exceptions were the ST, PF, and VET samples removed from MH7498 after 6 to 8 mo. of exposure. These samples were beginning to show signs of scaling caused by the rusting of some of the carbon steel fibers located near the surfaces of the samples. An examination of these samples after testing indicated that the rusted fibers were present only in that region located near the surface of the samples and that the rusting had not progressed to the fibers located in the interior of the samples. Analysis of the polymer binders after exposure indicated no evidence of thermal degradation.

Results of the splitting tensile strength and flexure strength tests showed that each of the PC systems exhibited some reduction in strength as a result of exposure to the environment within the manholes. These reductions in strength had been predicted by the results of the laboratory-scale autoclave tests. After 6 to 9 mo. of exposure in the manholes, the flexural yield strength of the PC systems varied between 1590 and $1710 \mathrm{psi}$ at $160^{\circ} \mathrm{F}, 890$ and $1770 \mathrm{psi}$ at $180^{\circ} \mathrm{F}$, and 1410 and $1870 \mathrm{psi}$ at $200^{\circ} \mathrm{F}$; with the VET PC system always exhibiting the highest strengths.

As previously indicated the program plan called for the development of a PC system which could be used to (a) make precast panels or (b) fabricate cast-in-place manholes. Shortly after the start of the field tests a decision was made by Con Ed and BNL to concentrate on the development of a system which could be used in cast-in-place applications. Tests were therefore done to determine the ease with which the PC systems could be cast into formwork. Tests were also done to determine if the heat generated within a manhole could be used to post-cure the PC manhole after it had been put into service.

Results of in situ exposure tests done on ST and VET PC beams and cylinders cast and cured at room temperature indicated that the 
heat generated within the steam-valve manholes can be used to postcure these PC systems. The flexural yield strength of the VET PC system was found to increase 12 percent after $3 \mathrm{mo}$. of exposure in MH15105.

As a result of the problems associated with the rusting of the carbon steel fibers, a series of tests were done to evaluate the use of 430 stainless steel fibers as a replacement for carbon steel fibers. The results of these tests indicated that at $200^{\circ} \mathrm{F}$ the strength properties of the samples made with the stainless steel fibers were very similar to values measured for samples made with the carbon steel fibers. In addition, the stainless steel fibers did not deteriorate. In situ testing of individual fibers in MH15105 indicated that carbon steel fibers began to rust within 1 mo. of being placed in test while the 430 stainless steel fibers exhibited no evidence of rusting after 11 mo. of exposure.

In situ load-deflection (creep) tests were done in MH15105 (at an ambient temperature of $\approx 196^{\circ} \mathrm{F}$ ) using a 2-in. by 8-in. by 6.25 ft. long fiber-reinforced VET PC beam cast at room temperature to determine how the system would behave under a sustained load. When tested for 54 wk at 84 percent of its theoretical design load, the beam was found to deflect approximately $0.748 \mathrm{in}$ at midspan. The rate of creep was calculated over the duration of the test to be approximately $0.010 \mathrm{in./Wk}$.

A second beam was tested to determine if the creep could be controlled with the addition of conventional reinforcing bars. The results of laboratory and in situ load-deflection tests indicated that at $200^{\circ} \mathrm{F}$ the VET PC system continued to creep under a sustained load, i.e. the conventional reinforcing bars did not help control the creep exhibited by the system. In addition, the rebar did not reduce the magnitude of the deflections.

Tests were done on non-reinforced and fiber-reinforced PCC samples to determine the effects of elevated temperatures on the development of strength properties. Results of tests done on fiber-reinforced PCC samples cast for use in the in situ exposure tests showed that the strength properties of concrete cast and cured at elevated temperatures were significantly less than those for concrete cast and cured at room temperature. When tested at $200^{\circ} \mathrm{F}$, there was an average reduction in compressive strength ( $f_{c}$ ) of 36 percent for the samples cast and cured at elevated temperatures ( $f_{c}=3225 \mathrm{psi}$ ) as compared to the samples cast and cured at room temperature $\left(f_{c}=4890 \mathrm{psi}\right)$. Reductions in flexure strength values also were noted.

In situ test results for non-reinforced and fiber-reinforced PCC samples after $3 \mathrm{mo}$. of exposure in MH15105 indicated that the samples were in good condition and that the strength properties had increased slightly. The most significant change noted in either of the PCC systems was that both systems exhibited a loss in weight. 
The weight loss was most likely due to a loss of moisture from the samples and not to any physical deterioration. The continued loss of moisture from the samples may at some point adversely affect the strength development of the system by reducing the rate at which the cement in the matrix hydrates.

A preliminary design study was made by BNL (Task D) to determine the necessary floor slab, wall, and roof thicknesses required to replace a typical reinforced PCC manhole with a castin-place, fiber-reinforced PC manhole. The design approach used classical plate theory by considering the manhole to be a series of plates subjected to loads resulting from soil pressures, highway loading, and dead weight. Designs were performed at two service temperatures, $285^{\circ}$ and $400^{\circ} \mathrm{F}$, for each of the three PC systems under evaluation. The preliminary design analysis indicated that the required wall thicknesses varied between 4.35 and 6.50 in., depending upon the PC system used and the required design temperature. The required thickness of the roof slab varied between 7.80 and 11.70 in. A preliminary design study by the con Ed Civil Design Division produced similar results.

Polymer Construction specialties, Inc. of syosset, NY performed a preliminary cost analysis for BNL to provide a rough estimate of the costs associated with the placement of a 8 ft by 5 ft by $7 \mathrm{ft}$ high cast-in-place PC manhole made with the VET PC system. A comparative estimate also was done for a manhole cast with conventional PCC. The estimates showed that the cost of the cast-in-place PC manhole would be approximately $\$ 32,316$, compared to $\$ 20,800$ for the PCC manhole. It should be noted that the analysis included only the cost of materials and those costs associated with the placement of a PC or PCC manhole. It did not include the cost for excavating and removing the existing manhole or the cost for backfiliing the new manhole and replacement of the pavement surface. The analysis also assumed that the PCC floor of the existing manhole was in good condition and that it could be used as the base slab for the new PC or PCC manhole.

The cost of placing a PC manhole was estimated to be $\approx 50$ percent higher than that for placing a conventional PCC manhole. However, the increased service life of a PC manhole should offset the initial increase in investment.

In general, the results of the laboratory and in situ field tests indicate that the physical and mechanical properties and the corrosion resistance characteristics of the vinyl ester-TMPTMA (VET) PC system are superior to those of the other PC systems evaluated. However, the suitability of using the VET PC system as a structural material in the construction of underground, steamvalve manholes would, at present, appear to be limited by several factors which influence the performance of the system at elevated temperatures. As a result, the program was not carried beyond the design stage and full-scale testing of a PC manhole was not 
performed. The factors influencing this decision included the following:

(a) The VET PC system exhibits outstanding strength properties at $72^{\circ} \mathrm{F}, \mathrm{e.g}$. the system has a compressive strength of 14,270 psi and a flexural yield strength of 2,865 psi. However, test results have shown that the strength properties decrease significantly with increases in temperature. When compared to values measured at $72^{\circ} \mathrm{F}$, the VET PC system exhibits a 20 to 25 percent decrease in strength at $240^{\circ} \mathrm{F}$ and a 50 percent decrease in strength at $400^{\circ} \mathrm{F}$.

(b) Long-term field tests performed on beams made with and without conventional reinforcing bars have indicated that the system exhibits an excessive amount of creep when loaded at 84 percent of its theoretical design capacity. Efforts to solve this problem have, to date, been unsuccessful.

(c) The lack of established design methods makes it difficult to accurately predict how the system will perform in the field, particularly at elevated temperatures. Conventional reinforced concrete design theory was used in the design studies performed in this program. It was also used to design the in situ creep tests. The results of the creep indicate that the assumptions made during the design of the experiments did not adequately predict the results which were obtained.

Based upon the results presented in this report it is concluded that the PC systems evaluated in this program are not, at this time, ready for use as a construction material for steam-valve manholes. Additional work will need to be done to address the limitations of the materials at elevated temperatures before they are ready for use in the field. Suggested areas of research include the following:

(a) Because the use of PC as a structural material is still relatively new there are, at present, no established design standards which will accurately predict actual field performance, particularly at elevated temperatures. As a result, additional laboratory and field tests need to be done to completely define the behavior of PC at ambient and elevated temperature conditions. One area in particular which needs to be addressed is creep. Tests results have shown that under the presently selected design loads the creep exhibited by the system is excessive. A more extensive series of load tests needs to be done to fully define the creep characteristics and to identify acceptable design limitations.

(b) Before a full-scale steam-valve manhole is built and put into service, at least one small-scale (one-quarter or 
one-half scale) model should be load tested to verify the analysis used in the design of the manhole.

(c) Long-term in situ testing of PC samples should be done to gather as much information as possible about the performance and durability of the PC systems under actual field conditions.

(d) The VET PC system may be best suited for use in applications in which the maximum ambient temperature is less than $150^{\circ} \mathrm{F}$. When compared to values measured at $72^{\circ} \mathrm{F}$, the VET PC system exhibits only a 5 to 9 percent reduction in strength at $150^{\circ} \mathrm{F}$ as compared to a 20 to 25 percent decrease in strength at $240^{\circ} \mathrm{F}$ and a 50 percent decrease in strength at $400^{\circ} \mathrm{F}$. Work should be done to more fully define the physical and mechanical properties of the VET PC system at temperatures of $150^{\circ} \mathrm{F}$, of less. 


\section{DEVELOPMENT OF HIGH TEKPERATURE, CORROBION RESISTANT POLYMER CONCRETE FOR UBE IN THB BTEAY DIBTRIBUTION BYSTEM OF CONSOLIDATED EDISON COMPANY OF NY}

\subsection{IXTRODUCTION}

\subsection{Background.}

The Consolidated Edison (Con Ed) Company of New York operates and maintains a large steam distribution system under the streets of New York city. over the years several materials related problems have been encountered with the steel-reinforced portland cement concrete (PCC) manholes used to house the system's valves and fittings. The high ambient temperature and humidity within the manholes create an environment which eventually leads to the corrosion of the reinforcing steel in the concrete. The byproducts of the corrosion process increase the volume of the reinforcing steel, creating tensile stresses in the surrounding concrete. As these stresses exceed the tensile strength of the concrete, cracks develop in the concrete which eventually lead to delaminations and/or spalls in the concrete. In addition, condensate from steam leaks in the valves and/or piping system attacks the cement matrix of the concrete which weakens the surface of the concrete thereby making it susceptible to further deterioration. Consequently, many of the manholes in the system are severely deteriorated and need to be replaced (Figures 1 and 2).

The manholes are being rebuilt using conventional PCC. Since the manholes are located beneath the streets and sidewalks, there is a great emphasis to minimize the time involved in rebuilding the manhole to prevent excessive disruption of traffic. As a result, the manholes are often cast around live steam mains and are immediately placed into service. The concrete is therefore only a few days old when it is subjected to the harsh environment of the manholes. In addition, by placing the manhole into service so quickly the concrete is not allowed to fully develop the strength and physical characteristics that it normally would obtain under ideal curing conditions. This can result in the development of a substandard quality of concrete. The combination of quickly pouring and placing the newly cast PCC manhole into service and the severe operating conditions to which the manholes are exposed invariably results in a shorter than desired service life.

with the development in recent years of more advanced materials of construction, such as polymer concrete (PC), it may be possible to cast manholes that have a longer maintenance-free 


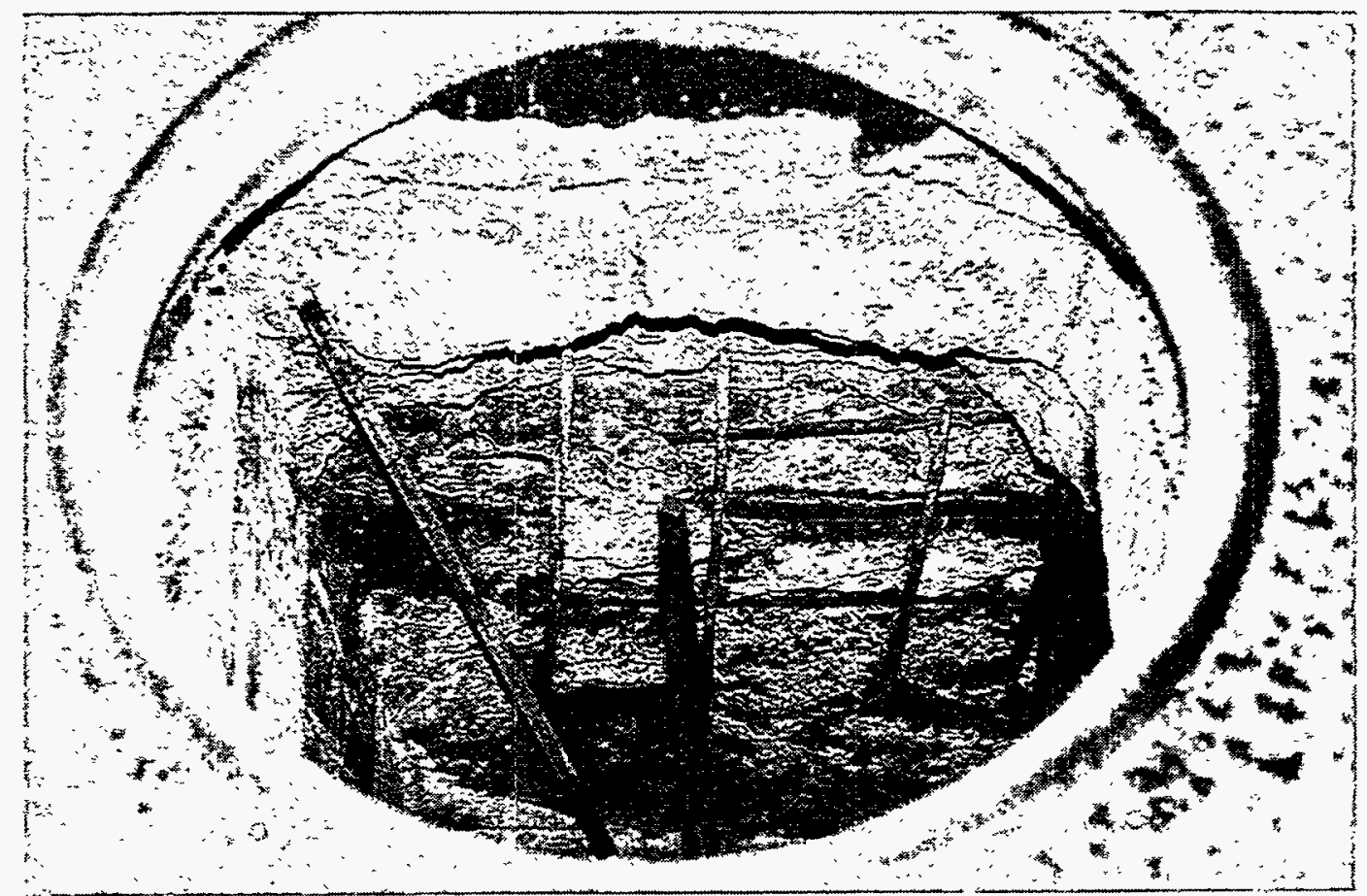

(a)

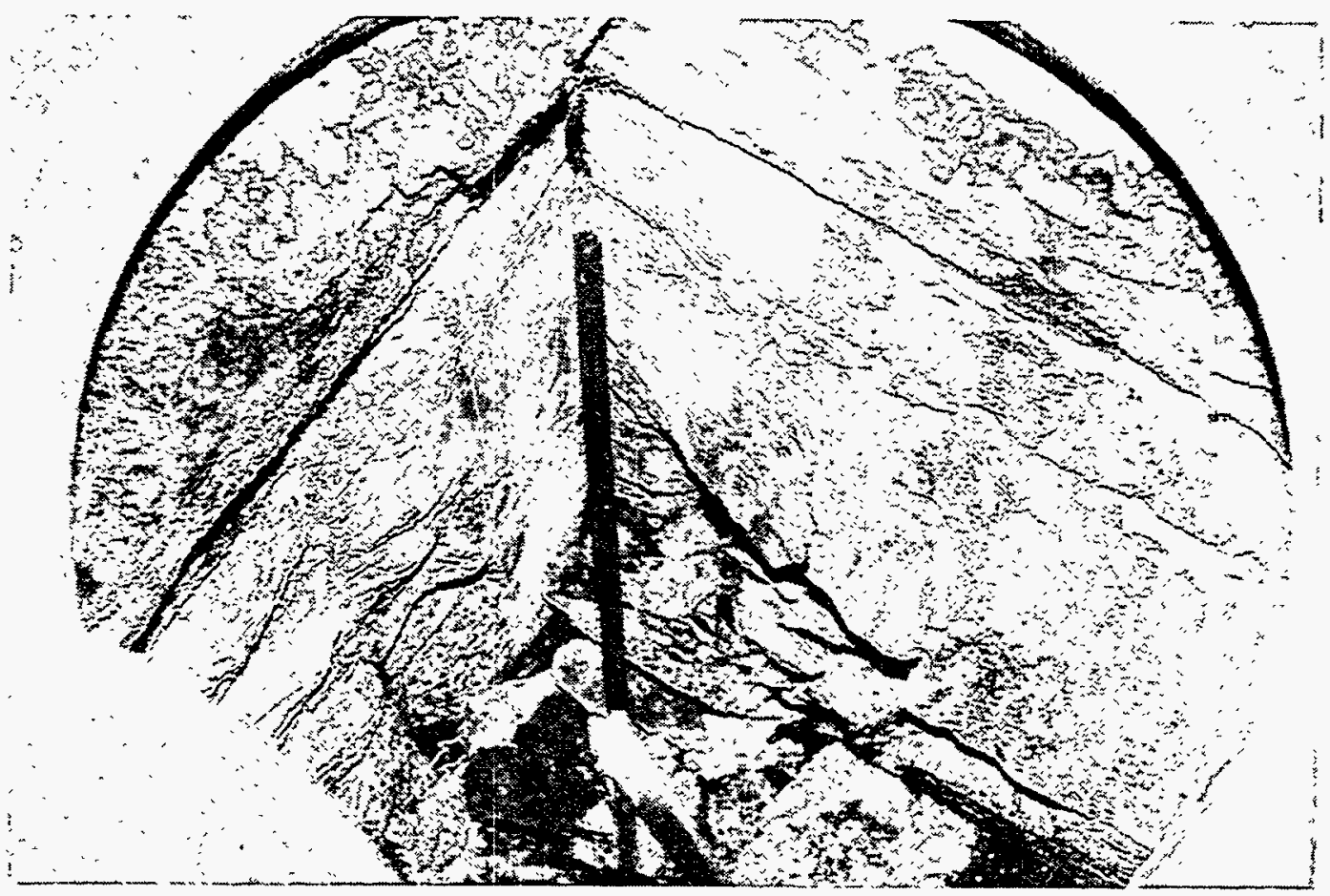

(b)

Figure 1. Interior views of two Con Ed steam manholes, from the street level, illustrating the extent to which the concrete walls in some of the manholes have deteriorated. 


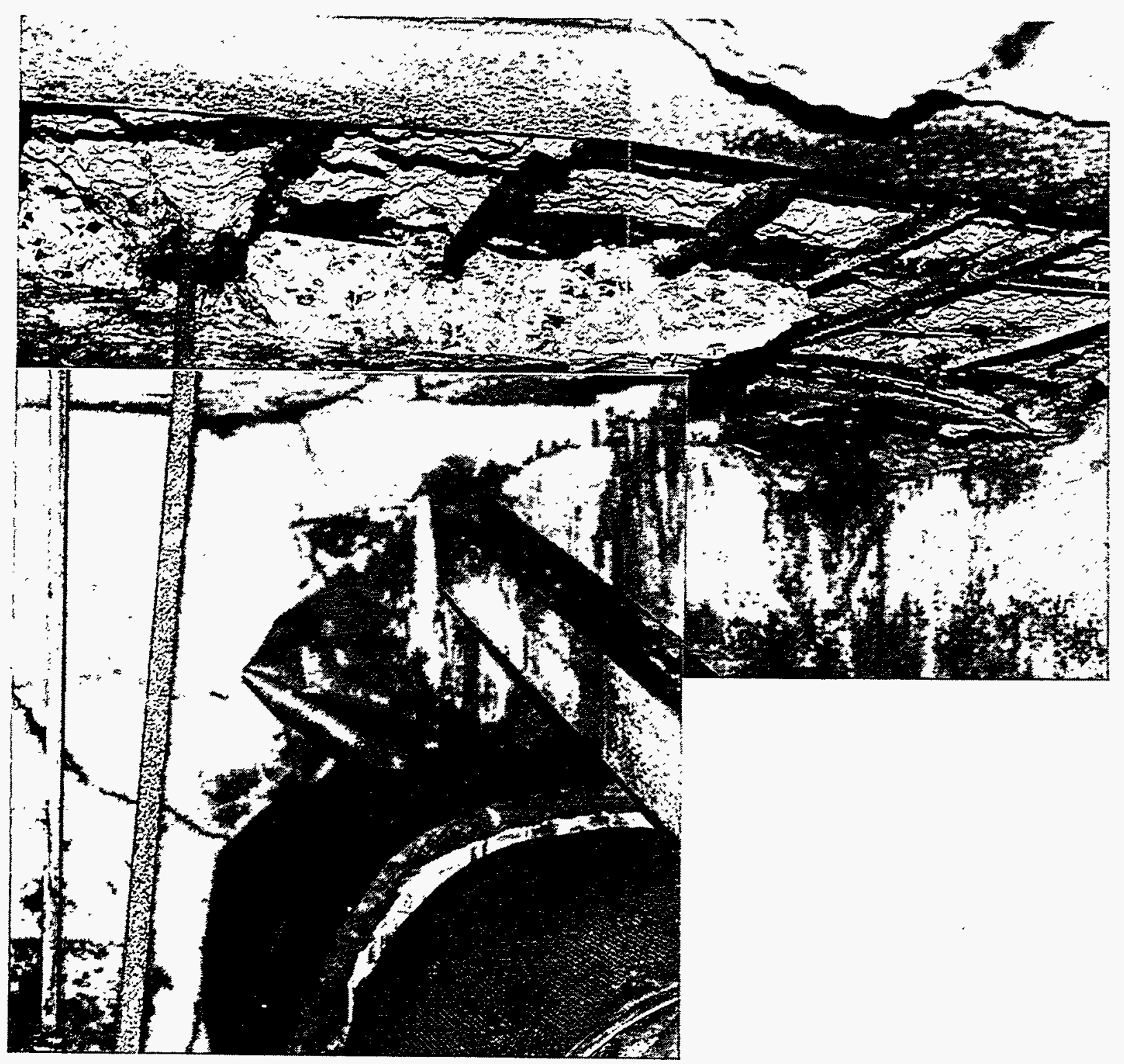

Figure 2. Interior view of Manhole (MH) 7500 (looking north) illustrating the extent of deterioration present in some of the concrete manholes. Note that the cover over the reinforcing steel in the ceiling has fallen off exposing the steel, which has begun to rust. The end wall is also severely cracked. 
service life resulting from the improved physical and mechanical properties of these materials ${ }^{[1]}$.

The Process Materials Group of the Energy Efficiency and Conservation Division, Department of Applied Science at Brookhaven National Laboratory (BNL), Upton, NY has developed numerous PC formulations that display a wide range of physical and mechanical properties ${ }^{[2-4]}$. Some of these materials are being used in commercial applications while others still are undergoing development and evaluation. Based on this experience BNL carried out a program for Con Ed entitled "Development of High Temperature, Corrosion Resistant Polymer concrete For Use In The steam Distribution system of the Consolidated Edison Company of New York".

\subsection{Program objectives.}

The primary objective of the program was to develop a PC system suitable for use as a construction material for steam-valve manholes. Alternate methods of construction would be investigated and the PC formulations would be tailored to meet the needs of the different construction technologies under consideration. During the laboratory-phase of the program a private contractor familiar with the field application of PC systems would be consulted to ensure that the systems under development were adaptable to field installations.

The original program plan called for the development of a PC system which could be used to (a) make precast panels or (b) fabricate cast-in-place manholes. The precast panels would be used as protective stay-in-place forms against which conventional PCC could be cast or they would be used to replace the PCC in its entirety.

The exposure conditions within a typical steam-valve manhole required that any PC system being considered for use exhibit the following characteristics: (a) it should be thermally stable at temperatures up to $275^{\circ} \mathrm{F}$, (b) it should have good strength and stiffness at temperatures up to $275^{\circ} \mathrm{F}$, (c) it should be impermeable to moisture penetration, and (d) it should have good resistance to possible chemical attack.

Based upon the results of a survey performed by con Ed personnel at the start of the program, the design service temperature which the PC systems would have to withstand was raised from the originally specified value of $275^{\circ}$ to a value of $400^{\circ} \mathrm{F}$ (refer to section 2.1). The original scope of work for the program was revised to reflect the fact that the design service temperature was raised to $400^{\circ} \mathrm{F}$. In addition, it was expanded to include small-scale field testing of the candidate PC systems. These tests were added in order to determine the effects of exposure to actual 
field conditions on the physical and mechanical properties of PC and PCC systems.

Evaluation of the candidate systems would be based upon the results of tests done to determine the physical and mechanical properties over a range of temperatures. Properties to be evaluated included: water absorption, shrinkage, compressive strength, flexure strength, tensile strength, and thermal coefficient of expansion. Based upon the results of the laboratory and field tests one or more PC systems would be selected for fullscale evaluation in the field. This work would be done in Phase Two and was beyond the scope of work for this phase of the program.

To meet the objectives of the program, the following series of tasks were developed to serve as guidelines:

A. Identification and evaluation of candidate PC systems.

B. Laboratory-scale evaluation.

C. Field evaluation.

D. Preliminary design of a typical manhole. 


\subsection{IDENTIFICATION AND EVALUATION OF CANDIDATE PC BY8TEMS}

\subsection{Temperature Requirements.}

Before starting the laboratory test program a survey was performed to verify the range of ambient air temperatures typically encountered within the steam-valve manholes. Seven operating manholes were selected at random and surveyed by Con Ed personnel. The results, which are summarized in Table 1, indicated that air temperatures within the manholes varied between $214^{\circ}$ and $349^{\circ} \mathrm{F}$ and averaged $297^{\circ} \mathrm{F}$. In addition, it was determined that the temperature of the steam within a steam main is $\approx 380^{\circ} \mathrm{F}$. Based upon this information, Con Ed asked that the design service temperature of the PC systems be raised from the originally specified value of $275^{\circ}$ to a value of $400^{\circ} \mathrm{F}$. This would ensure that the PC systems were thermally compatible with the range of temperatures found within the steam-valve manholes and it would also ensure that the PC systems would not thermally degrade in the event of a steam main rupture.

\subsection{Binder System Selection.}

In general, polymer concrete (PC) is a composite material formed by polymerizing a monomer/resin system with an aggregate system. The monomer/resin system acts as the binder for the composite. The PC systems developed for this program consist of four components: a binder system, a blended fine aggregate system, a graded coarse aggregate system, and a fiber reinforcement.

The procedure used to cast the PC samples was as follows. The PC was mixed by first blending the fine and coarse aggregates together in a mixer. The binder system, which is a liquid, was then added to the mix. Finally the fiber reinforcement was added. After the mix was completely blended, it was poured into the molds or formwork and consolidated by vibration. The binder systems used were formulated such that they would allow the mix to initially cure, i.e. harden, at room temperature. After the PC had cured the cast section was demolded, and then post-cured in a constant temperature oven to fully develop the strength properties of the system and to ensure that the binder system had been completely reacted.

The primary difference between the PC systems developed for evaluation was the monomer/resin system used for the binder. Three monomer/resin systems were selected for evaluation: a styrenetrimethylolpropane-trimethacrylate (TMPTMA) [ST] based monomer system, a vinyl ester resin-TMPTMA [VET] based system, and a phenol 
Table 1. Ambient air temperatures within various con Ed steam manholes.

\begin{tabular}{||c|c|c||}
\hline MANHOLE NO. & \multicolumn{1}{|c|}{ IOCATION } & $\begin{array}{c}\text { AMBIENT AIR } \\
\text { TEMPERATURE, }{ }^{\circ} \mathrm{F}\end{array}$ \\
\hline \hline 15105 & 41st Street \& Ist Avenue & 349 \\
7887 & 44th Street \& Lexington Ave. & 299 \\
8603 & Madison Ave. between 47th & 320 \\
& and 48th Streets & 272 \\
6120 & Madison Ave. so. of 59th St. & 214 \\
7185 & 5th Ave. south of 75th St. & 332 \\
7301 & 7th Avenue \& 49th Street & 290 \\
\hline
\end{tabular}

formaldehyde [PF] resin system. The mix formulations of each binder system are summarized in Table 2 .

The ST based system is a low viscosity monomer system that was developed by BNL, which, when polymerized produces a polymer which has very good stability at temperatures up to $572^{\circ} \mathrm{F}$. Much of the work done with the ST based system was done using the version of the system developed by BNL. However, the ST based system was later modified by adding poly (methyl methacrylate) (PMMA) to the system. The PMMA in the styrene-TMPTMA-PMMA (STP) system helps improve the film forming characteristics of the system by reducing the rate of evaporation of monomer from the surface before polymerization. The improved film resulted in a harder finish to the surface of the $P C$ and also helped to reduce the water absorption characteristics of the system.

The base resin used in the VET system is a vinyl ester resin manufactured by Dow Chemical Co. called Derakane 470-45. According to Dow Chemical's "Chemical Resistance and Engineering Guide," this resin "combines good corrosion resistance characteristics with superior retention of properties at high temperatures, superior oxidation resistance, and resistance to mixtures of chemicals." The resin system was modified by adding TMPTMA to improve the strength properties of the resin at temperatures above $300^{\circ} \mathrm{F}$.

The PF resin system is a developmental resin manufactured by Borden Chemical Co. called Durite SI-618A. According to Borden, the cured phenolic system has excellent resistance to heat, hydrolysis, strong acids, and organic solvents.

Thermogravimetric analysis (TGA) data for each polymer system, show that each system is thermally stable at $400^{\circ} \mathrm{F}$ (Figures $3-6$ ). 
Table 2. Formulations of the Binder systems

A. Styrene-TMPTMA (ST) monomer system.

54.0 wtq styrene monomer

4.5 wto polystyrene beads

39.0 wt: TMPTMA monomer

1.0 wto $A-174$ silane coupling agent

1.0 wto dimethyl aniline (DMA) promoter

0.5 wto di-tert-butyl peroxide (DTBP) initiator

with 4.0 wto BFF-50 benzoyI peroxide (BPO) initiator

B. Styrene-TMPTMA-PMMA (STP) monomer system.

53.0 wto styrene monomer

4.3 wt: polystyrene beads

38.2 wto TMPTMA monomer

2.0 wto poly (methyl methacrylate)

1.0 wto A-174 silane coupling agent

1.0 wt? DMA promoter

0.5 wto DTBP initiator

with 4.0 wt\% BPO initiator

c. Vinyl ester-TMPTMA (VET) resin system.

78.2 wto Derakane 470-45 vinyl ester resin

20.0 wt: TMPTMA monomer

1.0 wt: $A-174$ silane coupling agent

0.1 wt: DMA promoter

0.5 wto DTBP initiator

with 4.0 wt: BPO initiator

D. Phenol formaldehyde (PF) resin system.

71.0 wt: Durite SL-618A phenol formaldehyde resin

1.0 wto methanol

1.0 wto $\mathrm{A}-187$ silane coupling agent

1.1 wto 10 wt aqueous solution of ammonium bifluoride

8.1 wto water

17.8 wto Durite RC-204A hardener

with 8.7 wt: Durite RC-495A activator

(blended in with the fine aggregate) 


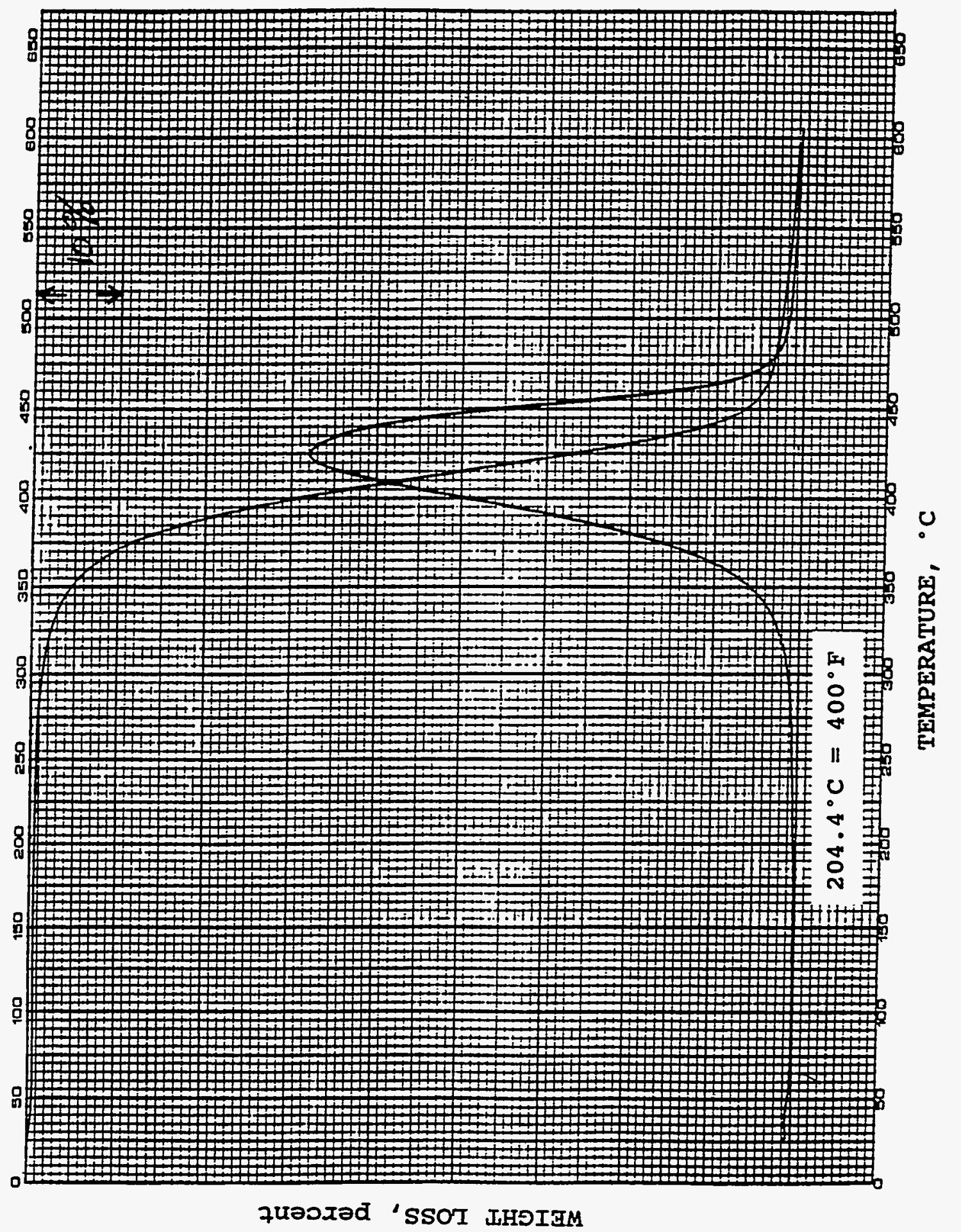

Figure 3. TGA data for the VET monomer system. 


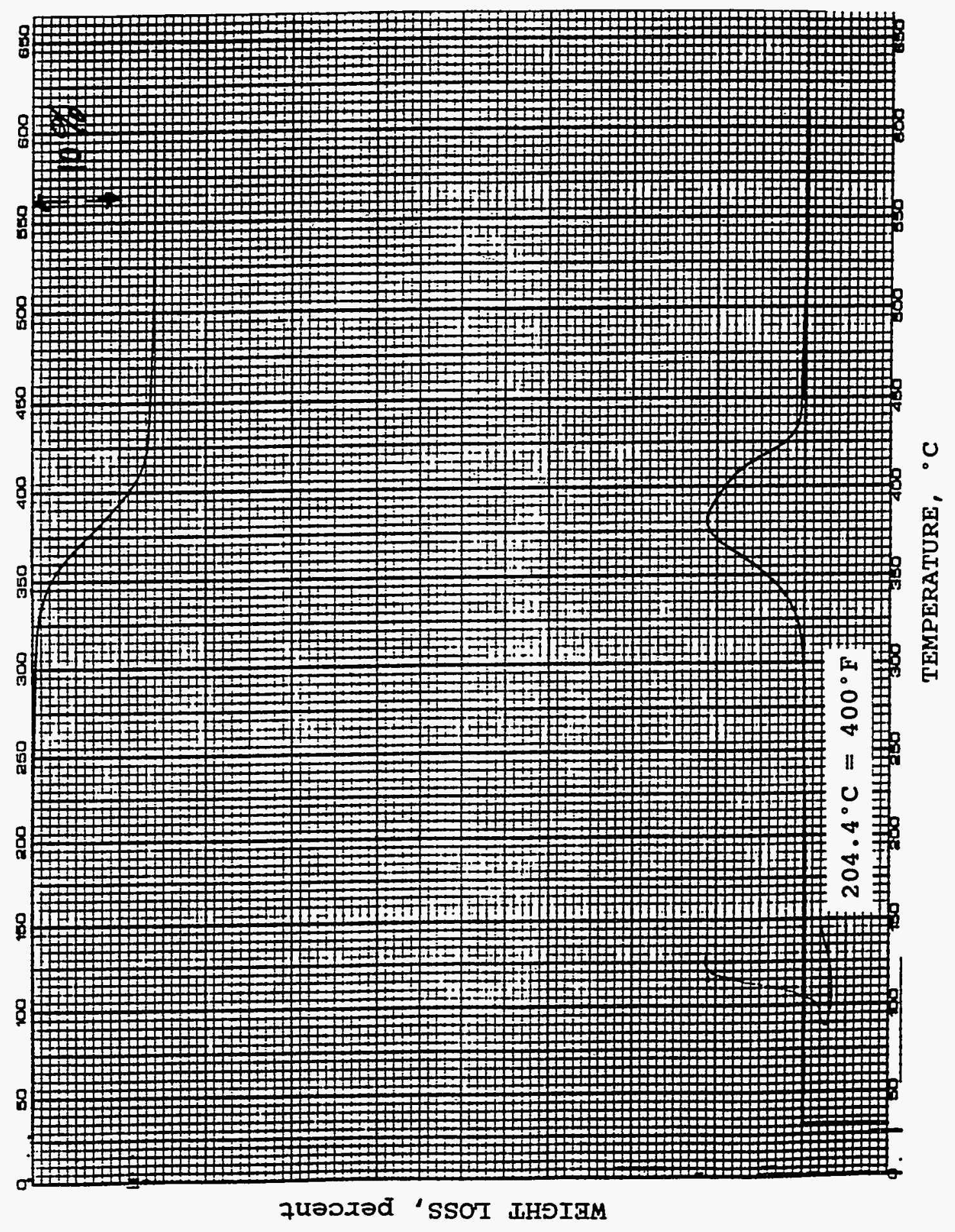

Figure 4. TGA data for the ST mortar system. 


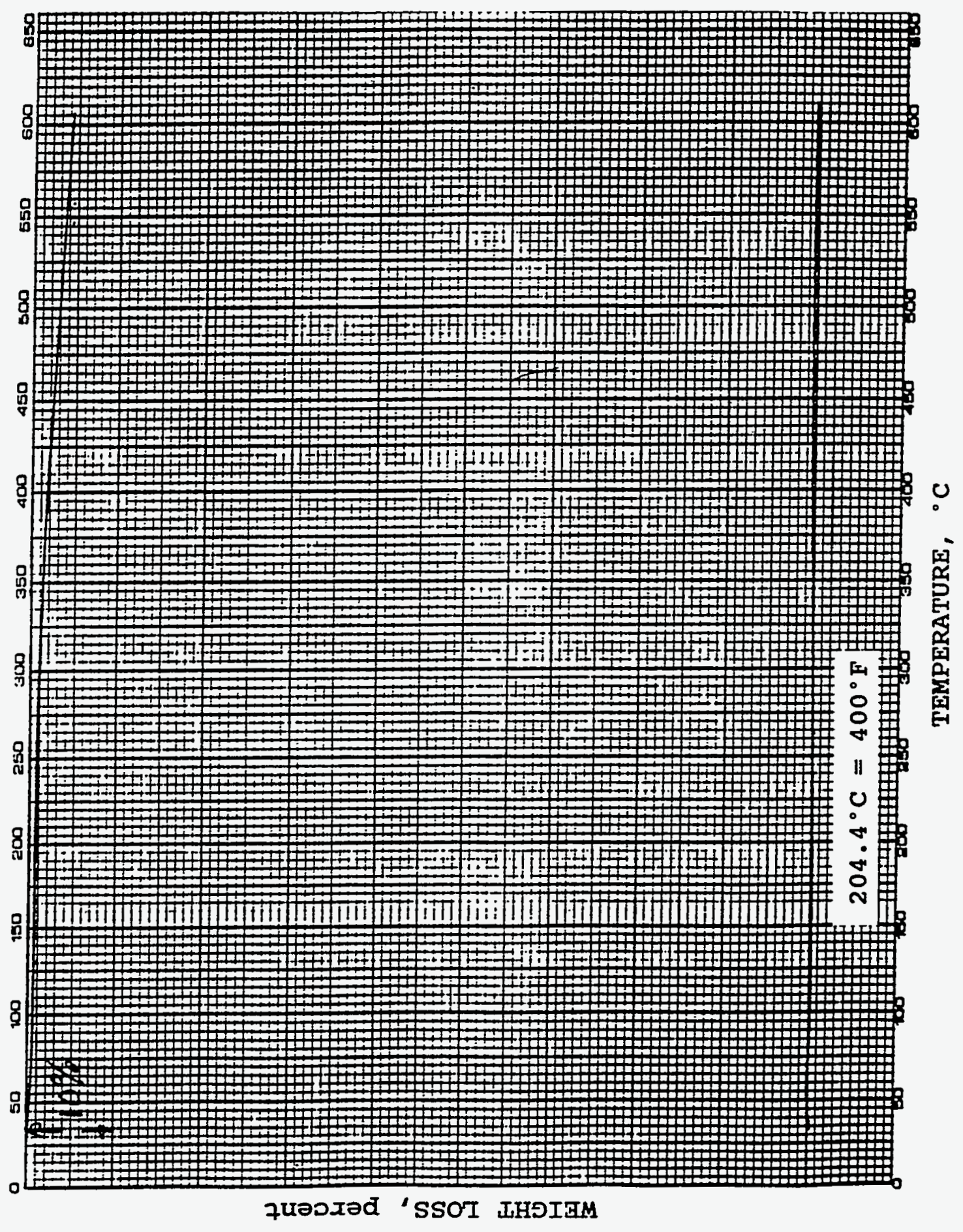

Figure 5. TGA data for the PF mortar system. 


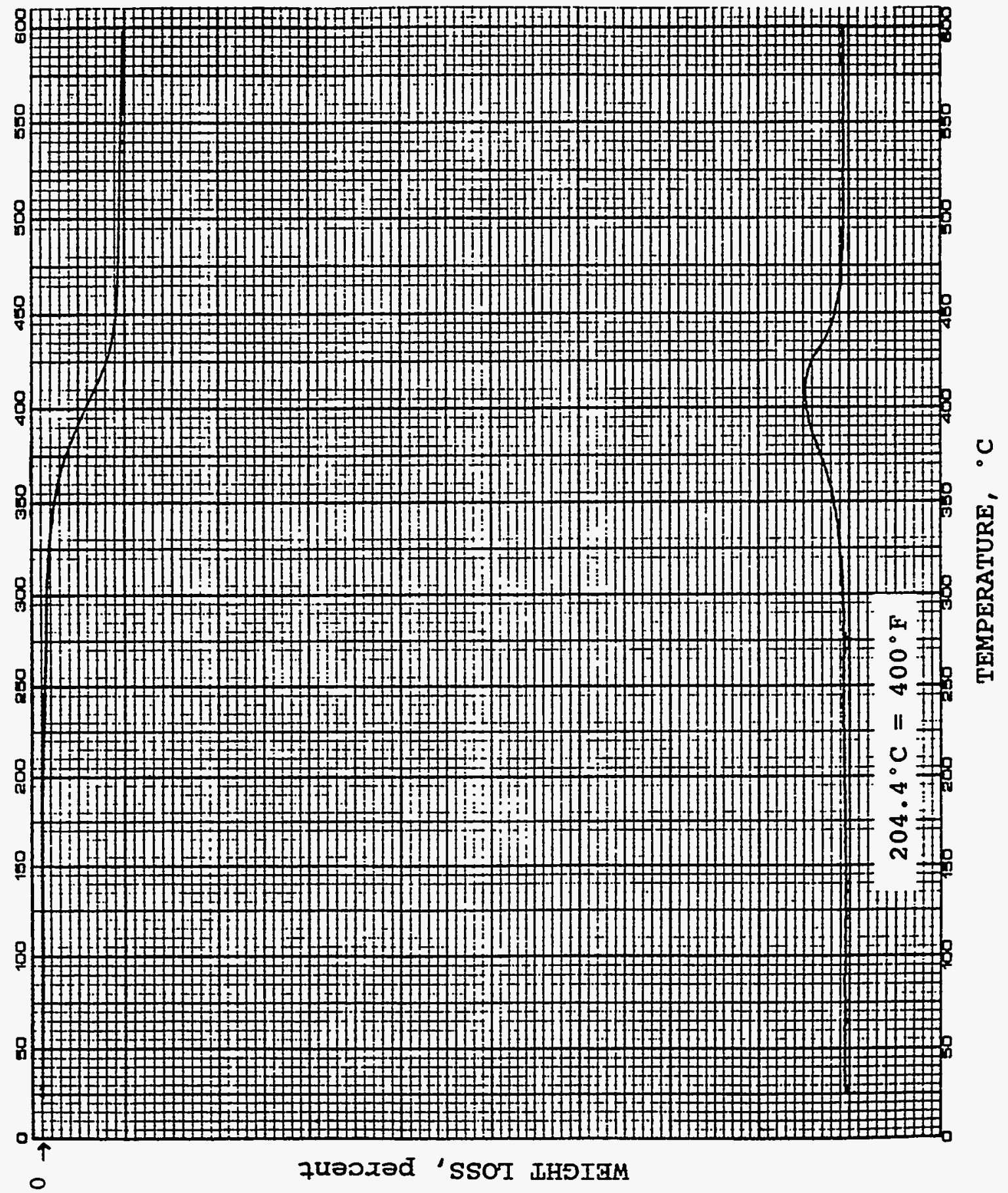

Figure 6. TGA data for the STP PC system. 


\subsection{Aggregate System Selection.}

2.3.1 Fine aggregate system. The fine aggregate system for the ST, STP, and VET systems consists of dry, blended silica sand, flour sand, Type III portland cement, and a liquid surfactant (Surfynol s-440). Table 3 presents the formulation of the fine aggregate system. The Type III cement is added to the system to improve the hydrothermal stability of the PC system by improving the chemical bonding between the monomer and aggregate systems. The surfactant is added to the system to improve the wetting characteristics of the aggregate and to help limit the amount of dust generated during mixing. Table 4 shows a sieve analysis of the blended silica sand and the flour sand.

The fine aggregate system for the PF system consists of dry, blended silica sand, flour sand, and a powdered activator (Durite RC-495A).

2.3.2 coarse aggregate system. The coarse aggregate used in all PC systems was a washed and dried, 3/8-in. crushed siliceous gravel. Table 4 presents a sieve analysis.

\subsection{Fiber Reinforcement System.}

Research performed by BNL has shown that the ductility of PC composites can be improved by adding steel fibers to the $\operatorname{mix}^{[5]}$. Therefore tests were done to evaluate the flexure strength of steel fiber-reinforced PC. Synthetic fibers, such as graphite and Kevlar aramid fibers, also were evaluated because they are less likely to be subjected to corrosion in humid environments than are the steel fibers. Chopped stainless steel fibers also were evaluated.

Table 3. Formulations of the fine aggregate systems.

A. Fine aggregate system for the ST, STP, and VET PC systems.

71.5 wt: blended silica sand

8.0 wto silica flour sand

20.0 wt: $\%$ Type III portland cement

0.5 wto surfynol 440 surfactant

B. Fine aggregate system for the PF PC system.

81.0 wto blended silica sand

17.0 wto silica flour sand

2.0 wt\% Durite RC-495A activator 
Table 4. Sieve analysis data.

A. Typical sieve analysis of blended silica sand. (J. S. Morie \& Sons, Inc. blend TC-4727-81)

\begin{tabular}{|c|c|}
\hline $\begin{array}{l}\text { U.S. Standard } \\
\text { Sieve Size }\end{array}$ & $\begin{array}{l}\text { Percent Passing } \\
\text { (cumulative) }\end{array}$ \\
\hline No. 6 & 100 \\
\hline No. & 100 \\
\hline No. & 60 \\
\hline No. & 48 \\
\hline No. & 28 \\
\hline No. 50 & 26 \\
\hline No. 70 & 15 \\
\hline No. 100 & 3 \\
\hline No. 140 & 1 \\
\hline No. 200 & $<1$ \\
\hline
\end{tabular}

B. Typical sieve analysis of silica flour sand.

\begin{tabular}{cc}
\hline $\begin{array}{c}\text { U.S. Standard } \\
\text { Sieve Size }\end{array}$ & $\begin{array}{c}\text { Percent Passing } \\
\text { (cumulative) }\end{array}$ \\
\hline No. 120 & 100 \\
No. 140 & 96 \\
No. 200 & 90 \\
No. 270 & 82 \\
No. 325 & 73 \\
\hline
\end{tabular}

c. Typical sieve analysis of the siliceous gravel.

\begin{tabular}{cc}
\hline $\begin{array}{c}\text { U.S. Standard } \\
\text { Sieve Size }\end{array}$ & $\begin{array}{c}\text { Percent Passing } \\
\text { (cumulative) }\end{array}$ \\
\hline I/2-in. & 99 \\
$3 / 8-i n$. & 88 \\
No. 4 & 8 \\
No. 8 & 1 \\
No. 16 & $<1$ \\
\hline
\end{tabular}

Note: This grading is very close to the No. 8 Grading specified in ASTM D 448-86. 
A preliminary series of flexure strength tests were done to compare the performance of the various types of fibers under consideration. The tests were performed using 2- by 2- by 12-in. long beams and were done in accordance with test method c78-84 of the American Society for Testing and Materials (ASTM).

Five types of fibers were evaluated: 1.5 in. long corrugated carbon steel fibers (Novocon International)

1.50 in. long Kevlar 49 aramid fibers (DuPont)

1.00 in. long Kevlar 49 aramid fibers (DuPont)

0.25 in. long Magnamite AS graphite fibers (Hercules)

0.30 in. long TD-700 304 stainless steel fibers (Brunswick)

Samples were cast using the ST and VET systems and tested in flexure at room temperature $\left(72^{\circ} \mathrm{F}\right)$. For comparison, non-reinforced beams cast with the VET system also were tested. The results are shown in Figures 7 and 8 . The greatest improvements in load carrying capacity and ductility were obtained using the 1.5 in. long corrugated steel fibers. Based upon these results, all subsequent work was done using the steel fiber reinforced PC systems.

2.5 PC Mix Design Formulations.

Table 5 gives formulations for the ST, STP, VET and PF polymer concrete systems.

Table 5. PC mix design formulations.

A. Mix design for the ST, STP and VET PC systems.

52.0 wto blended fine aggregate

34.5 wto coarse aggregate

6.5 wto binder system

7.0 wt: corrugated steel fibers

B. Mix design for the PF PC system.

49.5 wto blended fine aggregate

32.5 wto coarse aggregate

11.5 wto phenol formaldehyde resin

6.5 wt: corrugated steel fibers 


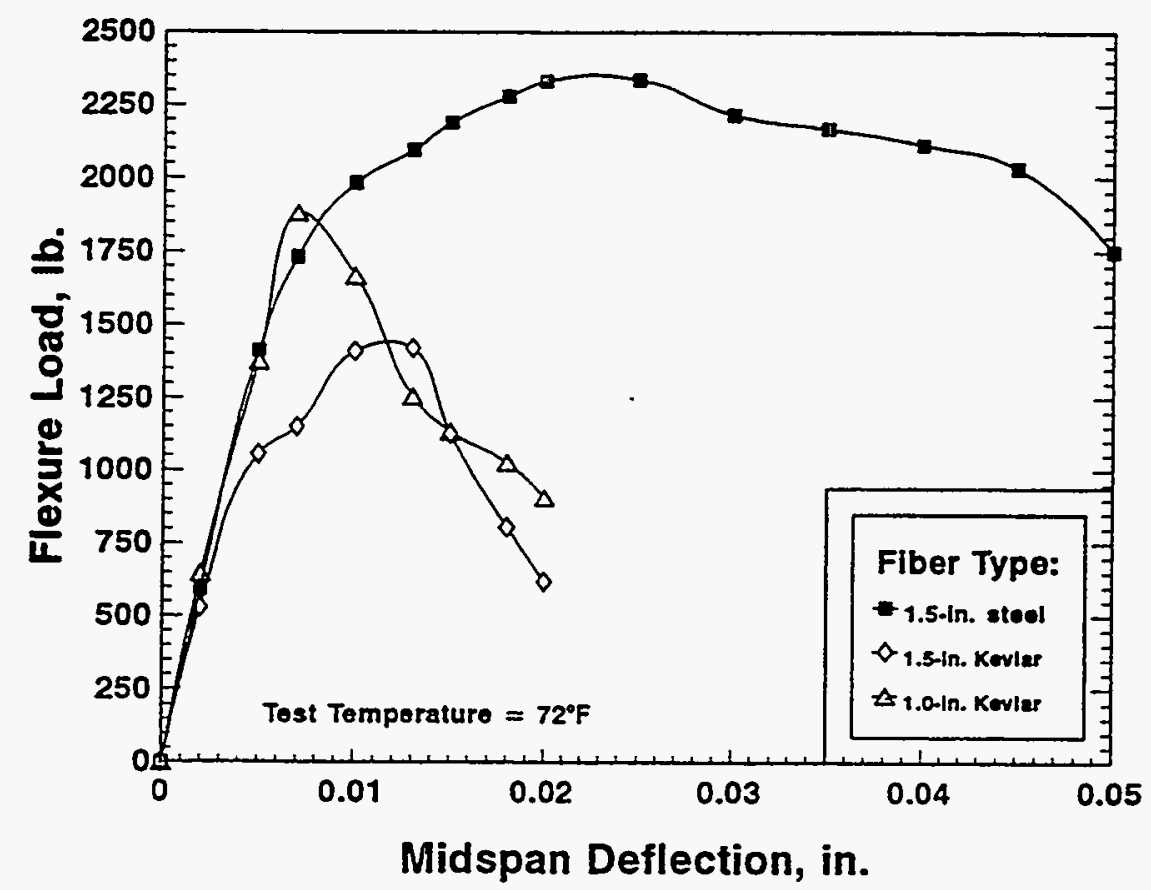

Figure 7. Flexure load vs. deflection data for the ST PC system made with various types of fibers.

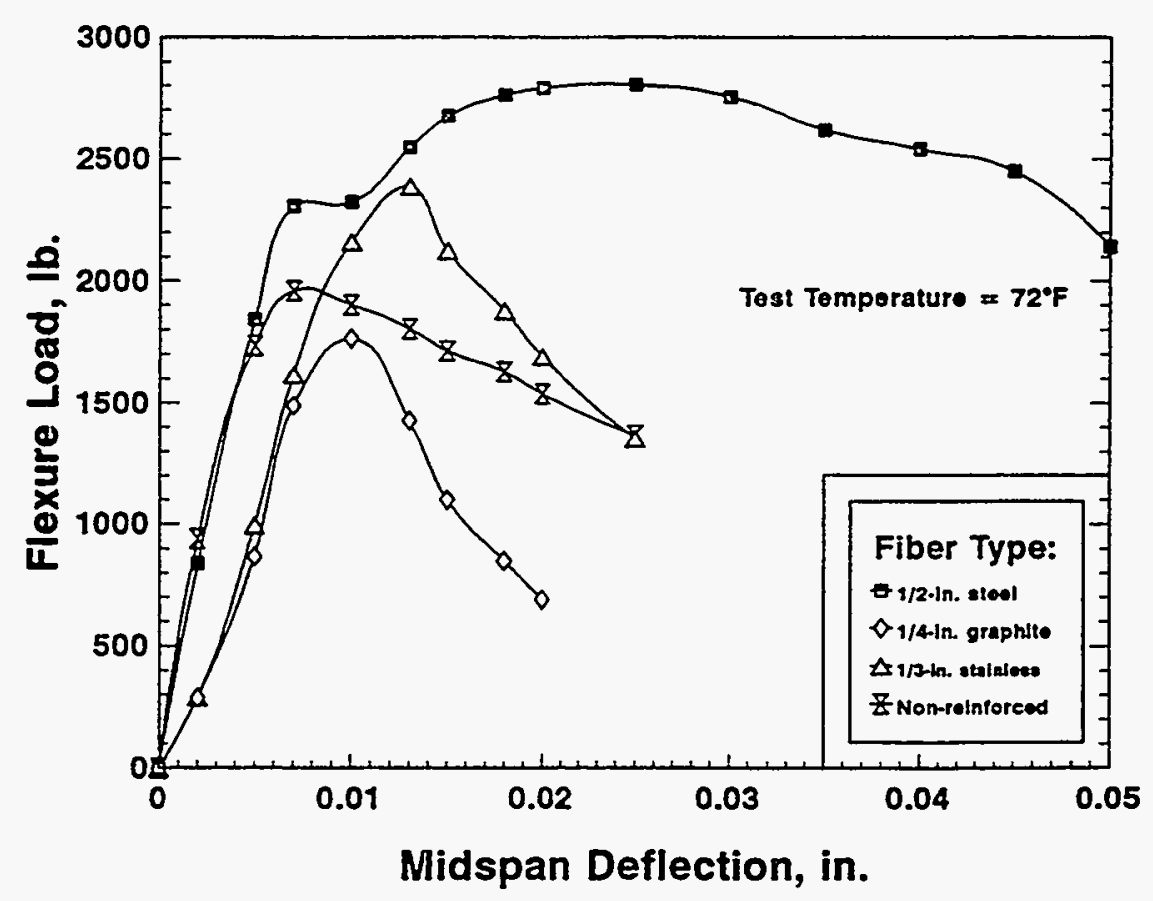

Figure 8. Flexure load vs. deflection data for the VET PC system made with various types of fibers. 


\subsection{LABORATORY TEST PROGRAY}

\section{1 objectives.}

The primary objectives of the laboratory tests were: (a) to experimentally determine the physical and mechanical properties of the PC systems over a temperature range of $40^{\circ}$ to $400^{\circ} \mathrm{F}$ and (b) to determine if exposure to simulated field conditions deteriorated these properties.

\subsection{Test Methods.}

The physical and mechanical properties measured included compressive strength, splitting tensile strength, flexure strength, flexural modulus of elasticity, shear strength, coefficient of thermal expansion, coefficient of thermal conductivity, and water absorption values. The strength properties were measured at $40^{\circ}$, $72^{\circ}, 150^{\circ}, 240^{\circ}, 320^{\circ}$ and $400^{\circ} \mathrm{F}$. The test methods used to evaluate each property are discussed below.

3.2.1 Compressive strength. Compressive strengths were determined in accordance with ASTM test method C 39-86 "Compressive Strength of Cylindrical Concrete specimens" using 3-in. diameter by 6-in. long cylinders. Compressive strength tests on PC mortars were done using 1-in. diameter by 2-in. long cylinders.

3.2.2 Splitting tensile strength. splitting tensile strengths were determined in accordance with ASTM test method $C$ 496-90 "Splitting Tensile strengths of Cylindrical concrete specimens" using 3-in. diameter by 6-in. long cylinders.

3.2.3 Flexure strength and flexural modulus of elasticity. Flexural properties were determined in accordance with ASTM test method C 78-84 "Flexural strength of Concrete (Using Simple Beam with Third-Point Loading) using 2 - by 2- by 12-in. Iong beams.

3.2 .4 Shear strength. Shear strengths were determined using a guillotine shear test developed by BNL. The tests were done using 3 -in. diameter by 6-in. long cylinders.

3.2.5 Coefficient of thermal expansion. The coefficients of therma.l expansion were measured using 2- by 2- by 12-in. Iong beams and were done using ASTM test method C 531-85 "Linear Shrinkage and Coefficient of Thermal Expansion of Chemical-Resistant Mortars, Grouts, and Monolithic Surfaces" as a guide.

3.2.6 Coefficient of thermal conductivity. The coefficients of thermal conductivity were measured using a shotherm QTM Thermal 
Conductivity Meter. The tests were done using 2- by 8- by 7-in. plaques.

3.2.7 Water absorption. The water absorption characteristics of the PC systems were measured using 2-in. cubes cut from the flexure tests beams after they had been tested to failure. The tests were done using ASTM test method C 20-87 "Apparent Porosity, Water Absorption, Apparent Specific Gravity, and Bulk Density of Burned Refractory Brick and Shapes by Boiling Water" as a guide.

3.2.8 creep characteristics. The behavior of the PC systems under sustained loading was evaluated by applying a concentrated load at the centerpoint of a simply supported beam. Deflection measurements were taken at the quarterpoints of the span length. The tests were done using 1-in. high by 3 -in. wide by 30-in. Iong beams.

3.2.9 Bond of conventional reinforcing steel to $P C$. The bond strength of conventional reinforcing steel to PC was determined in accordance with ASTM C 234-86 "Comparing Concretes on the Basis of the Bond Developed with Reinforced Steel."

\subsection{Laboratory Test Results.}

3.3.1 Physical and mechanical properties. Tables $6-8$ summarize the mechanical properties of ST, VET and PF PC systems at $72^{\circ}, 150^{\circ}, 240^{\circ}, 320^{\circ}$, and $400^{\circ} \mathrm{F}$. Test data for the VET PC system at $40^{\circ} \mathrm{F}$ also is included in Table 7. The data show that the mechanical strength of each system decreases with increasing temperature. However, this trend is not unexpected because the polymer binders of each system soften with increasing temperature. As previously noted, the softening of the polymers should not be considered detrimental, because the decomposition temperatures of the polymers are above $482^{\circ} \mathrm{F}$.

The properties of the PC systems that will be primarily used in the structural design of a manhole are the flexural yield strength (FYS) and the ductility of the material when subjected to flexural loads (see section 5.3). Figure 9 shows a comparison of the FYs values for each PC system. The VET system exhibits the highest FYS values over the range of $72^{\circ}$ to $400^{\circ} \mathrm{F}$. However, this system also shows the greatest reduction in strength over this range of temperature. The PF system shows the least reduction in strength over this range.

A comparison of the splitting tensile and flexure strength data shows that it may be possible to use splitting tensile strength test data to predict the flexural yield strength of the PC systems under evaluation. 
Table 6. Strength properties of the ST PC system.

\begin{tabular}{|c|c|c|c|c|c|}
\hline \multirow[b]{2}{*}{ Property } & \multicolumn{5}{|c|}{ Test Temperature, ${ }^{\circ} \mathrm{F}$} \\
\hline & 72 & 150 & 240 & 320 & 400 \\
\hline $\begin{array}{l}\text { Compressive strength, } \\
\text { psi }\end{array}$ & 12,220 & 11,790 & 9,305 & 7,020 & 4,730 \\
\hline $\begin{array}{l}\text { splitting Tensile } \\
\text { strength, psi }\end{array}$ & 2,150 & 2,035 & 1,775 & 1,280 & 965 \\
\hline $\begin{array}{l}\text { Flexural Yield } \\
\text { strength, psi }\end{array}$ & 2,145 & 2,020 & 1,720 & 1,545 & 930 \\
\hline $\begin{array}{l}\text { Ultimate Flexure } \\
\text { strength, psi }\end{array}$ & 2,690 & 2,800 & 2,670 & 1,950 & 1,100 \\
\hline $\begin{array}{l}\text { Flexural Modulus } \\
\text { of Elasticity, } \\
\text { psi } \times 10^{6}\end{array}$ & 3.43 & 3.04 & 1.86 & 1.30 & 0.64 \\
\hline Shear strength, psi & 3,370 & 2,640 & 2,410 & 1,595 & 1,275 \\
\hline
\end{tabular}

Table 7. Strength properties of the VET PC system.

\begin{tabular}{|lrrrrrrr|}
\hline & \multicolumn{7}{c|}{ Test Temperature, ${ }^{\prime}$ F } \\
\cline { 2 - 7 } \multicolumn{1}{c}{ Property } & 40 & 72 & 150 & 240 & 320 & 400 \\
\hline $\begin{array}{l}\text { Compressive } \\
\text { Strength, psi }\end{array}$ & 15,870 & 14,270 & 13,570 & 11,220 & 8,740 & 6,530 \\
$\begin{array}{l}\text { Splitting Tensile } \\
\text { Strength, psi }\end{array}$ & 2,490 & 2,585 & 2,450 & 2,170 & 1,695 & 1,385 \\
$\begin{array}{l}\text { Flexural Yield } \\
\text { Strength, psi }\end{array}$ & 2,760 & 2,865 & 2,745 & 2,205 & 1,965 & 1,440 \\
$\begin{array}{l}\text { Ultimate Flexure } \\
\text { Strength, psi }\end{array}$ & 2,920 & 3,335 & 3,035 & 3,035 & 2,745 & 1,795 \\
$\begin{array}{l}\text { Flexural Modulus } \\
\text { of Elasticity, } \\
\text { psi x 106 }\end{array}$ & 4.43 & 4.07 & 3.50 & 2.54 & 1.74 & 0.88 \\
$\begin{array}{l}\text { Shear Strength, } \\
\text { psi }\end{array}$ & 2,610 & 4,515 & 3,870 & 3,210 & 2,735 & 2,570 \\
\hline
\end{tabular}


Table 8. Strength properties of the PF PC system.

\begin{tabular}{|c|c|c|c|c|c|}
\hline \multirow[b]{2}{*}{ Property } & \multicolumn{5}{|c|}{ Test Temperature, ${ }^{\circ} \mathrm{F}$} \\
\hline & 72 & 150 & 240 & 320 & 400 \\
\hline $\begin{array}{l}\text { Compressive strength, } \\
\text { psi }\end{array}$ & 13,410 & 11,025 & 11,045 & 10,270 & 9,415 \\
\hline $\begin{array}{l}\text { Splitting Tensile } \\
\text { strength, psi }\end{array}$ & 2,165 & 1,850 & 1,745 & 1,535 & 1,505 \\
\hline $\begin{array}{l}\text { Flexural Yield } \\
\text { strength, psi }\end{array}$ & 2,175 & 1,805 & 1,665 & 1,580 & 1,390 \\
\hline $\begin{array}{l}\text { Ultimate Flexure } \\
\text { strength, psi }\end{array}$ & 2,290 & 2,395 & 2,040 & 1,900 & 1,830 \\
\hline $\begin{array}{l}\text { Flexural Modulus } \\
\text { of Elasticity, } \\
\text { psi } \times 10^{6}\end{array}$ & 2.66 & 2.17 & 1.64 & 1.30 & 1.19 \\
\hline Shear strength, psi & 3,925 & 4,040 & 3,425 & 3,090 & 2,875 \\
\hline
\end{tabular}

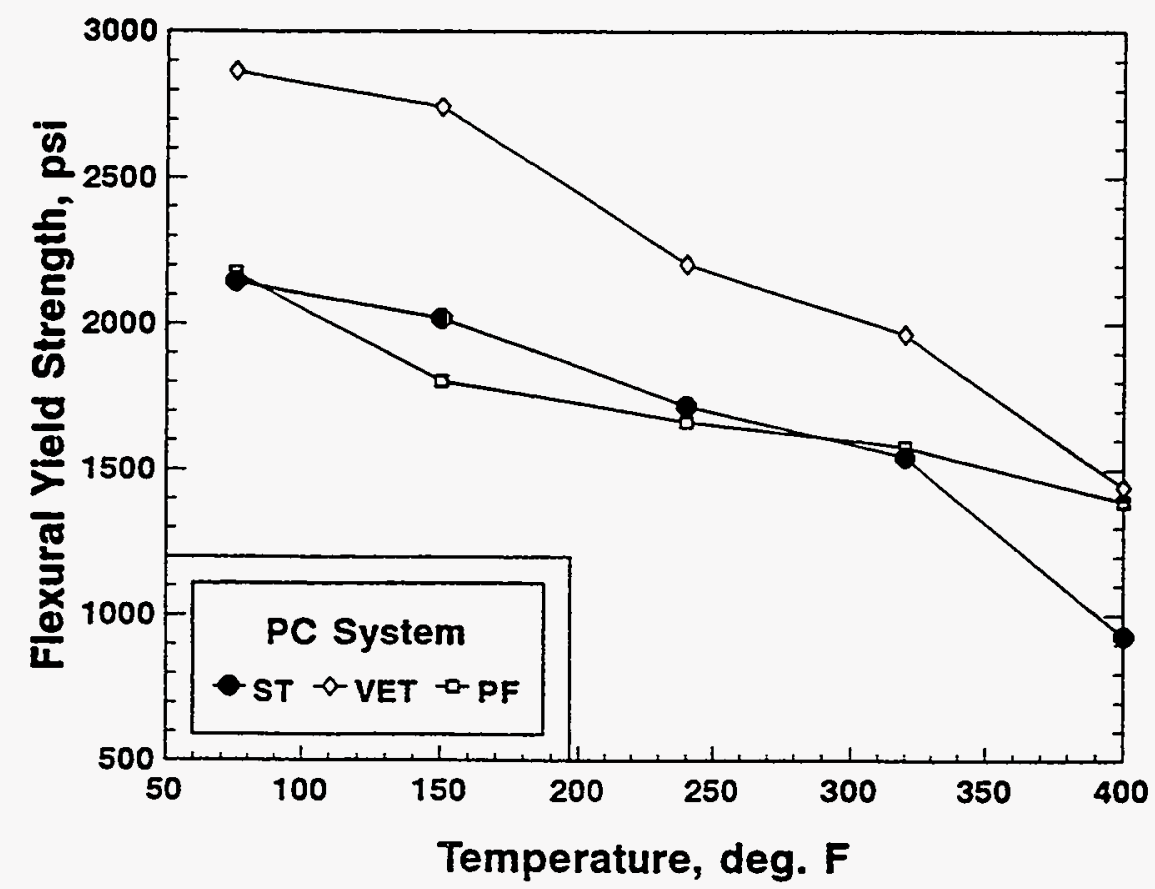

Figure 9. Variation of the flexural yield strength with temperature for the VET, ST, and PF PC systems. 
Figures 10 - 12 illustrate the flexure load vs. deflection characteristics of each PC system over a temperature range of $72^{\circ}$ to $400^{\circ} \mathrm{F}$. The data show that the FYs (the stress corresponding to the load at the end of the linear portion of the load vs deflection curve) and the ultimate flexure strength (the stress corresponding to the maximum load) decrease with increasing temperature.

Deflection tests done on simply supported beams at room temperature indicate that the VET PC system is the most rigid system and that the ST PC system is the most flexible (Figure 13). The VET PC system deflected $0.013 \mathrm{in}$. upon initial loading, while the ST PC system deflected $0.030 \mathrm{in}$. Deflection vs. time (i.e. creep) tests indicate that each system will creep under sustained loading. After 5 weeks under load, the midspan deflection of the VET system increased to 0.023 in., and the midspan deflection of the ST system increased to 0.046 in.

Results of the laboratory tests done to evaluate the bond strength developed between conventional reinforcing steel and the VET PC system at $72^{\circ}, 200^{\circ}$, and $400^{\circ} \mathrm{F}$ are summarized in Table 9. Reference data for portland cement concrete (PCC) is included for comparison.

In general, the results indicate that the pullout strength decreased with increasing temperature. At $72^{\circ} \mathrm{F}$ the VET PC system had a pullout strength of $44,500 \mathrm{lb}$ while at $400^{\circ} \mathrm{F}$ the system had a pullout strength of $26,6001 \mathrm{~b}$.

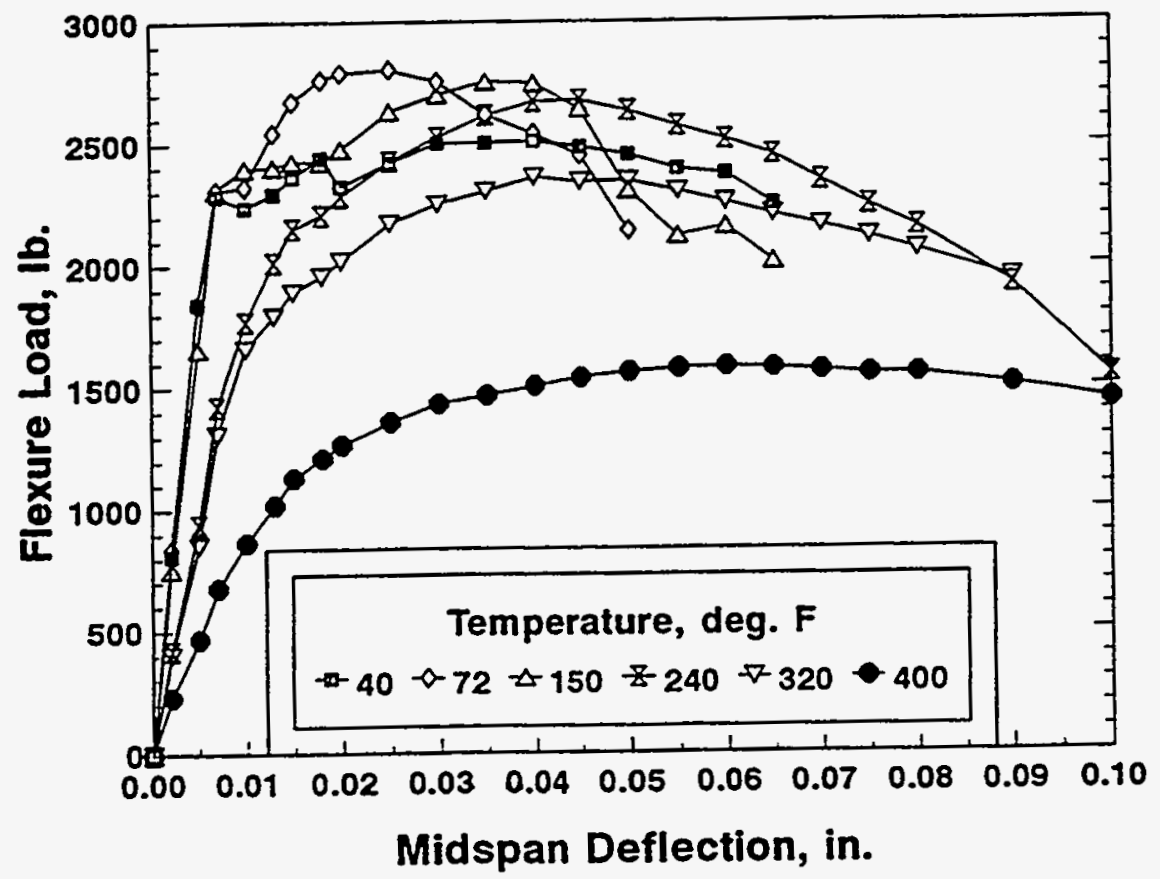

Figure 10. Variation of flexure load vs deflection characteristics with temperature for the VET PC system. 


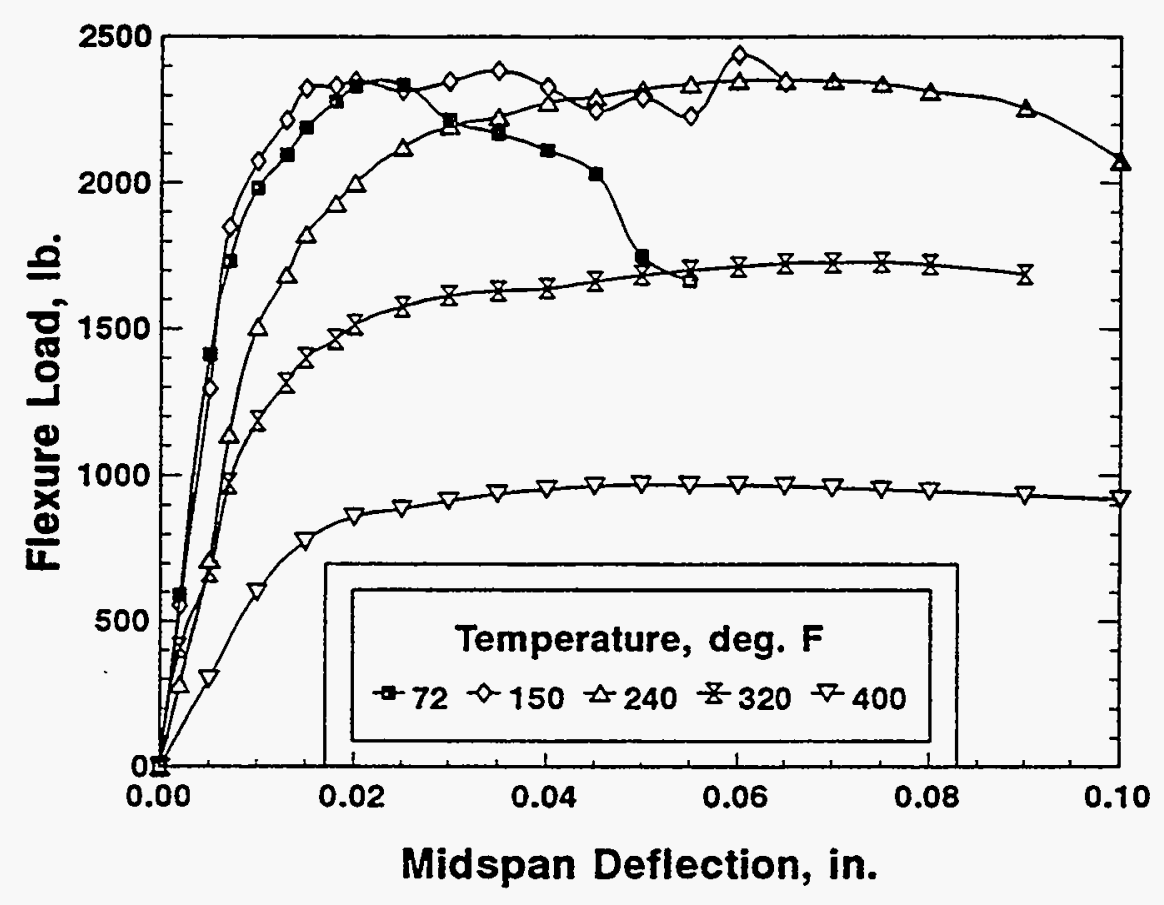

Figure 11. Variation of flexure load vs deflection characteristics with temperature for the ST PC system.

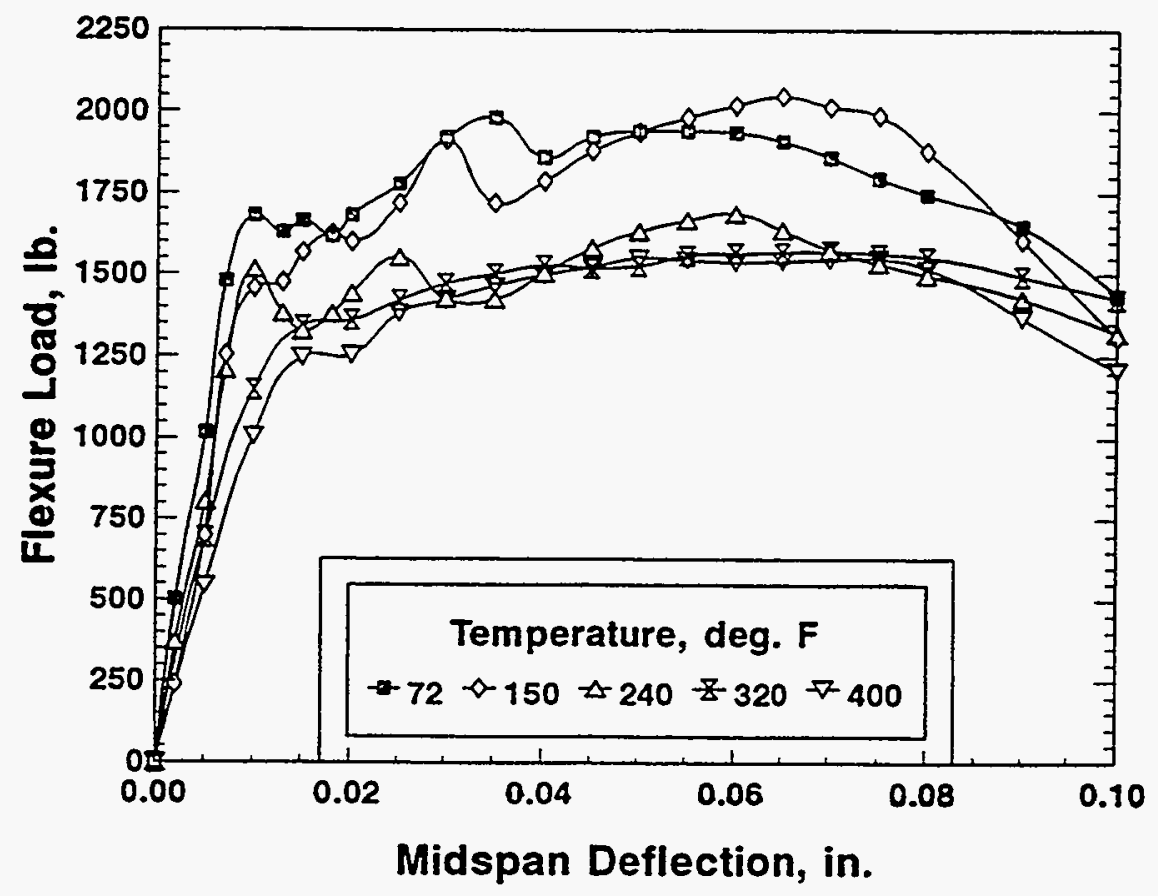

Figure 12. Variation of flexure load vs deflection characteristics with temperature for the PF PC system. 


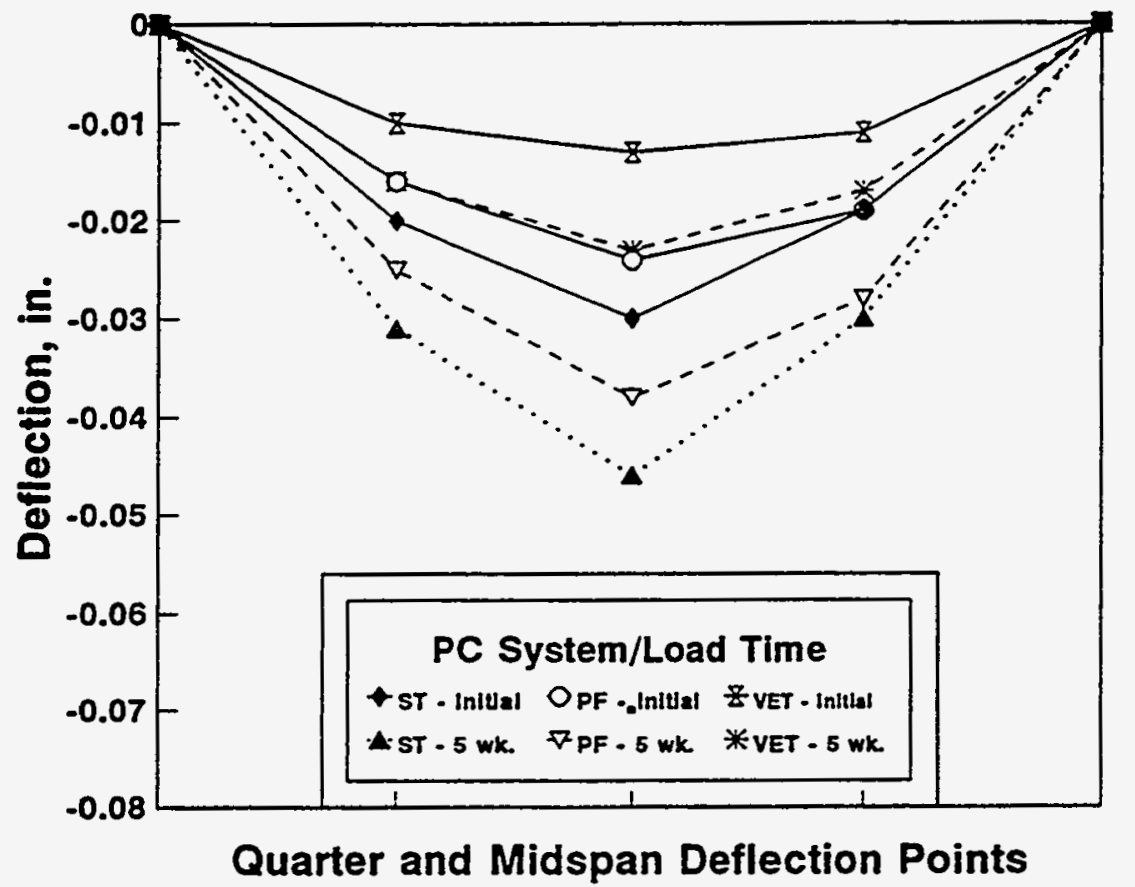

Figure 13. Comparison of deflection test data for the VET, ST, and PF PC systems.

Table 9. Rebar Pullout Test Results.

\begin{tabular}{|c|c|c|c|c|}
\hline System & Temperature & $\begin{array}{c}\text { Compressive } \\
\text { Strength }\end{array}$ & $\begin{array}{c}\text { Pullout } \\
\text { Strength }\end{array}$ & $\begin{array}{c}\text { Failure } \\
\text { Mode }\end{array}$ \\
\hline \hline VET PC & $72^{\circ} \mathrm{F}$ & $14,270 \mathrm{psi}$ & $44,500 \mathrm{Ib}$ & Rebar \\
\hline VET PC & $200^{\circ} \mathrm{F}$ & $12,875 \mathrm{psi}$ & $37,675 \mathrm{Ib}$ & Rebar \& PC \\
\hline VET PC & $400^{\circ} \mathrm{F}$ & $6,530 \mathrm{psi}$ & $28,705 \mathrm{Ib}$ & PC \\
\hline PCC & $72^{\circ} \mathrm{F}$ & $9,830 \mathrm{psi}$ & $26,600 \mathrm{Ib}$ & PCC \\
\hline
\end{tabular}

An examination of the test specimen after failure indicated the failure mechanism changed with temperature. At $72^{\circ} \mathrm{F}$ the failure occurred completely in the rebar, i.e. the rebar failed in tension. At $200^{\circ} \mathrm{F}$ failure generally occurred in the rebar and occasionally in the PC, indicating that the ability of the PC to bond to the rebar was beginning to decrease. At $400^{\circ} \mathrm{F}$ the failure occurred at the interface between the steel and the PC, indicating 
that the bond between the PC and the steel was not sufficient to fully develop the load carry capacity of the rebar.

Published data indicates that at room temperature conditions PCC, with a compressive strength of 9,830 psi, has a pullout strength of $26,600 \mathrm{lb}$ and that the failure mechanism is at the interface between the PCC and the rebar. ${ }^{[5]}$

Figures 14 and 15 illustrate the variation in the coefficients of thermal expansion and thermal conductivity for each PC system over a range of temperatures.

The coefficient of thermal expansion for each of the PC systems is higher than that for conventional PCC, which normally varies between 4.0 and $7.0 \times 10^{-6} \mathrm{in.} / \mathrm{in.} /{ }^{\circ} \mathrm{F}$ and averages $5.5 \times 10^{-6}$ in./in./ ${ }^{\circ} \mathrm{F}$. The coefficients for each system vary slightly depending upon the polymeric binder used in the system. The PF system exhibits the lowest range of values: 6.2 to $8.3 \times 10^{-6}$ in./in. $/{ }^{\circ} \mathrm{F}$. The ST and VET systems exhibit very similar values: 8.4 to $10.2 \times 10^{-6} \mathrm{in.} / \mathrm{in.} /{ }^{\circ} \mathrm{F}$. The coefficients also were found to vary with temperature, generally increasing slightly with increases in temperature.

The coefficients of thermal conductivity are within the range of values associated with conventional PCC, the thermal conductivity of which generally ranges between 0.8 and 2.1 $\mathrm{BTU} / \mathrm{hr} / \mathrm{ft} /{ }^{\circ} \mathrm{F}$ depending upon its composition and moisture content. The values measured for the PC system varied between 1.40 and 2.03 $\mathrm{BTU} / \mathrm{hr} / \mathrm{ft} /{ }^{\circ} \mathrm{F}$. The thermal conductivity varies slightly with the type of polymer binder, with the PF system showing the lowest values and the VET system showing the highest values. The conductivity values for each were found to vary slightly with temperature. The conductivity appears to remain relatively constant up to about $246^{\circ} \mathrm{F}$ beyond which it decreases slightly with increasing temperature.

The water absorption values for the PC systems are well below those of conventional PCC. PCC normally has a water absorption value varying between 5 and 7 wto. The water absorption values measured for the PC systems are summarized in Table 10.

Table 10. Water Absorption Test Results.

\begin{tabular}{|ccc|}
\hline PC System & $\begin{array}{c}\text { Water Absorption } \begin{array}{c}\text { Value, wt: } \\
\text { Range }\end{array} \\
\text { Average }\end{array}$ \\
\hline ST & $1.00-1.83$ & 1.36 \\
VET & $0.19-0.71$ & 0.41 \\
PF & $1.57-2.15$ & 1.86 \\
\hline
\end{tabular}




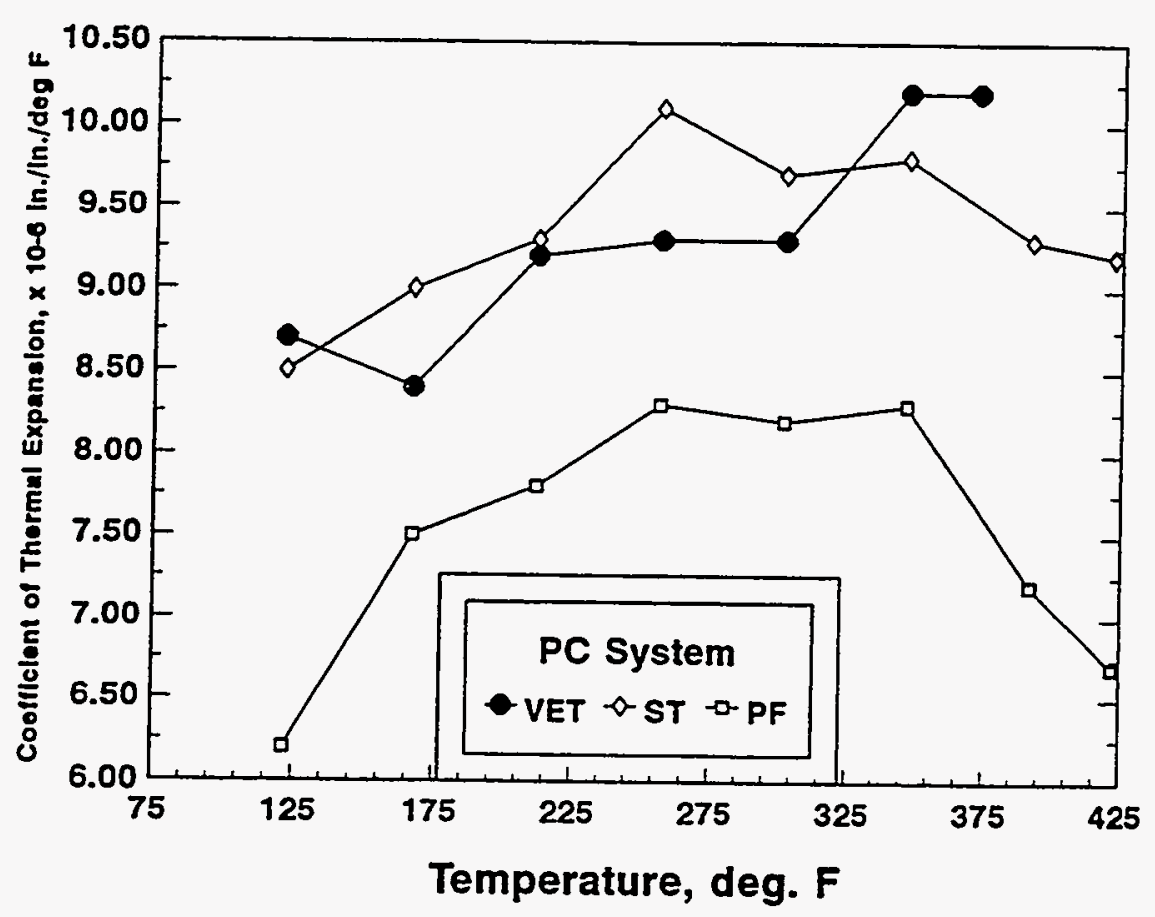

Figure 14. Variation in the coefficient of thermal expansion with temperature for the VET, ST, and PF PC systems.

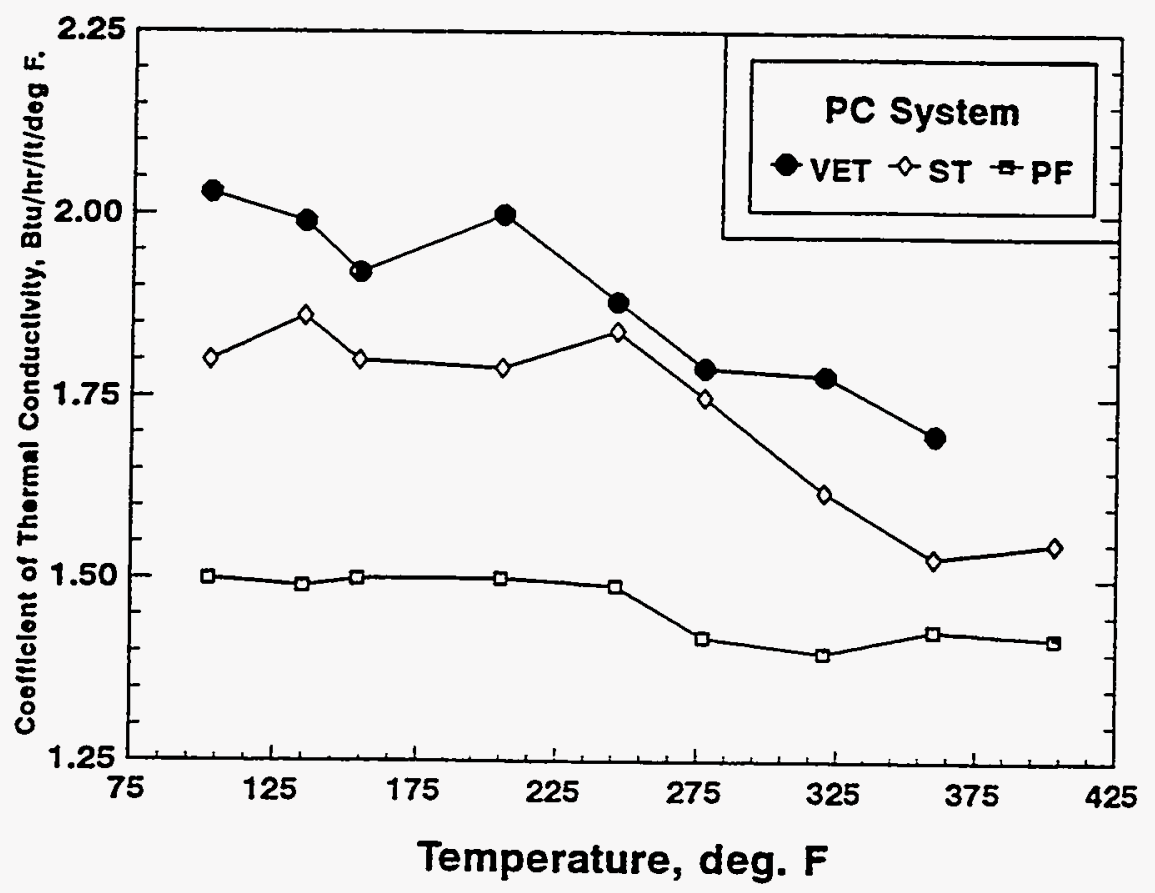

Figure 15. Variation in the coefficient of thermal conductivity with temperature for the VET, ST, and PF PC systems. 
3.3.2 Autoclave exposure tests. Tests were done under simulated field conditions in an autoclave to evaluate how each PC system might perform in the field. Due to space limitations in the autoclave, the tests were done using 1-in. diameter by 2-in. long PC mortar cylinders. The evaluation of each system was based upon visual examinations, and the results of compressive strength tests done after $1,2,4,8$ and 12 wk of exposure to steam at $400^{\circ} \mathrm{F}$. Figure 16 summarizes compressive strength test results for each PC mortar system.

The data indicates that the compressive strength of the ST and VET mortars, measured at $400^{\circ} \mathrm{F}$, remained relatively constant during the test. However, the strength of the PF mortar decreased significantly after one week of exposure, after which the strength remained relatively constant. Visual examinations of the samples throughout the test showed no significant deterioration due to the autoclaving.

The test results suggest that each of the PC systems, particularly the ST and VET systems, should perform well in the field. However, it should be emphasized that the results can only be used to get an indication of how each system might perform in the field. Because the tests were done with mortars, the results do not accurately show how the total composite system containing coarse aggregate and steel fibers might perform.

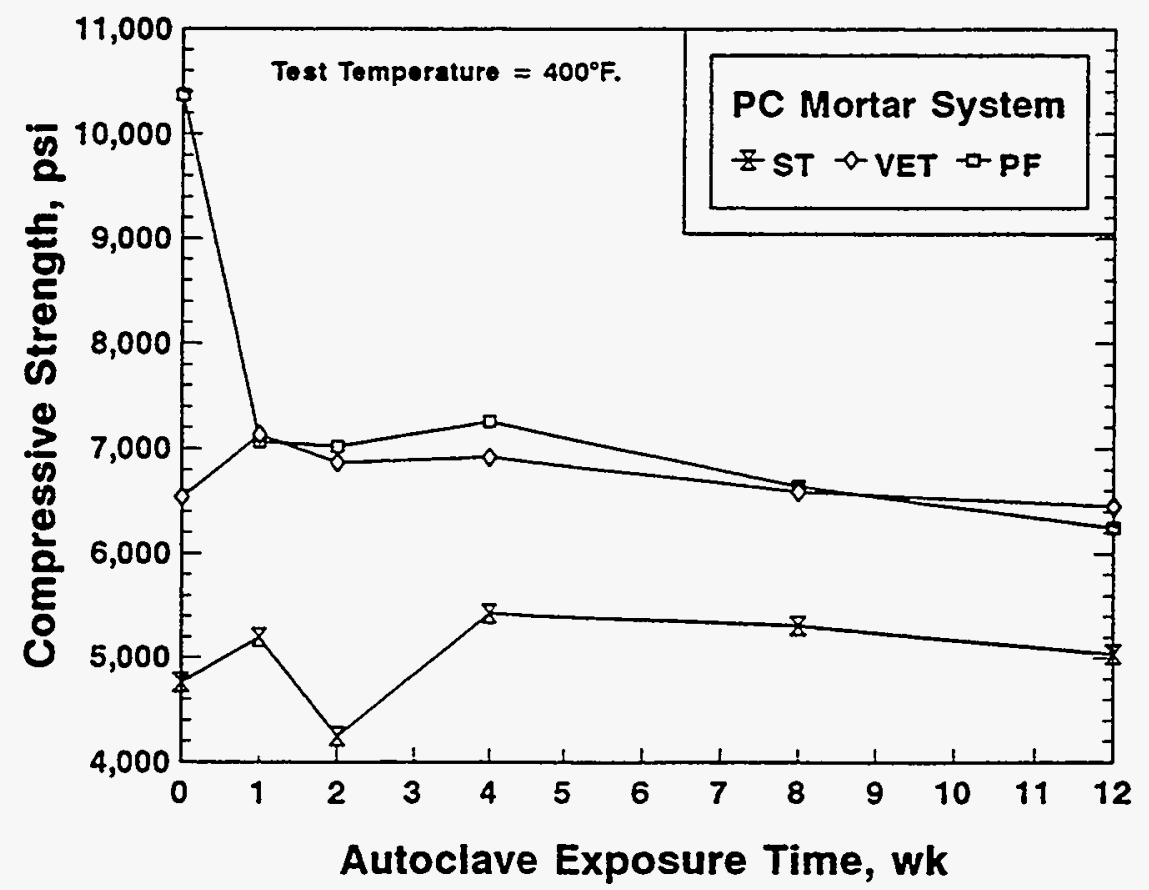

Figure 16. Variation of compressive strength with autoclave exposure time for the VET, ST, and PF mortar systems. 


\subsection{IN SITU FIELD TEBT PROGRAM}

\subsection{Objectives.}

As previously noted, the results of the laboratory-scale autoclave tests suggested that each of the PC systems might perform well in the field. To verify these results, in situ field tests were made.

The objectives of the in situ field tests were: (a) to evaluate the effects of exposure to actual field conditions on the physical and mechanical properties of PC and PCC systems, (b) to determine if the heat generated within a typical manhole could be used to post-cure a PC system, and (c) to evaluate the long term creep characteristics of a PC beam under load.

\subsection{Field Test Locations.}

Six proposed test sites were inspected and evaluated; three sites were selected for the in situ exposure tests. Selection was primarily based upon the ambient air temperature within the manhole and the amount of area within the manhole available for placing test specimen. These three manholes are described below.

Manhole (MH) 7498 -- an expansion joint manhole located beneath the sidewalk on the north corner of 85 th Street and Central Park West. The manhole is approximately $10 \mathrm{ft}$ by $6.5 \mathrm{ft}$ by $6.5 \mathrm{ft}$ in height and contains a 24-in. diameter, insulated steam main. Air temperature within the manhole was measured at $183^{\circ} \mathrm{F}$. An internal inspection of the manhole found it to be in fair condition. The walls were cracked in a few locations, but were intact. Most of the concrete cover over the reinforcing steel in the ceiling had delaminated and fallen onto the floor of the manhole (Figure 17). The exposed reinforcing steel was severely deteriorated, and in many cases had fallen from the ceiling onto the floor. The rest of the ceiling was intact.

MH7500 -- a main valve manhole located beneath the sidewalk on the south corner of $86 \mathrm{th}$ street and Central Park West. The manhole is approximately $18.5 \mathrm{ft}$ by $8 \mathrm{ft}$ by $9 \mathrm{ft}$ in height and contains a 24-in. diameter, insulated main and a 3-in. diameter, insulated bypass line. Air temperature within the manhole was measured to be between $159^{\circ}$ and $164^{\circ} \mathrm{F}$. An internal inspection of the manhole found it to be in a condition similar to that of MH7498, i.e. the walls of the manhole were cracked but intact and the concrete cover over the reinforcing steel in the ceiling had delaminated, and in some cases had fallen to the floor (see Figure 2). At the time of the inspection there was about $1 \mathrm{ft}$ of standing 


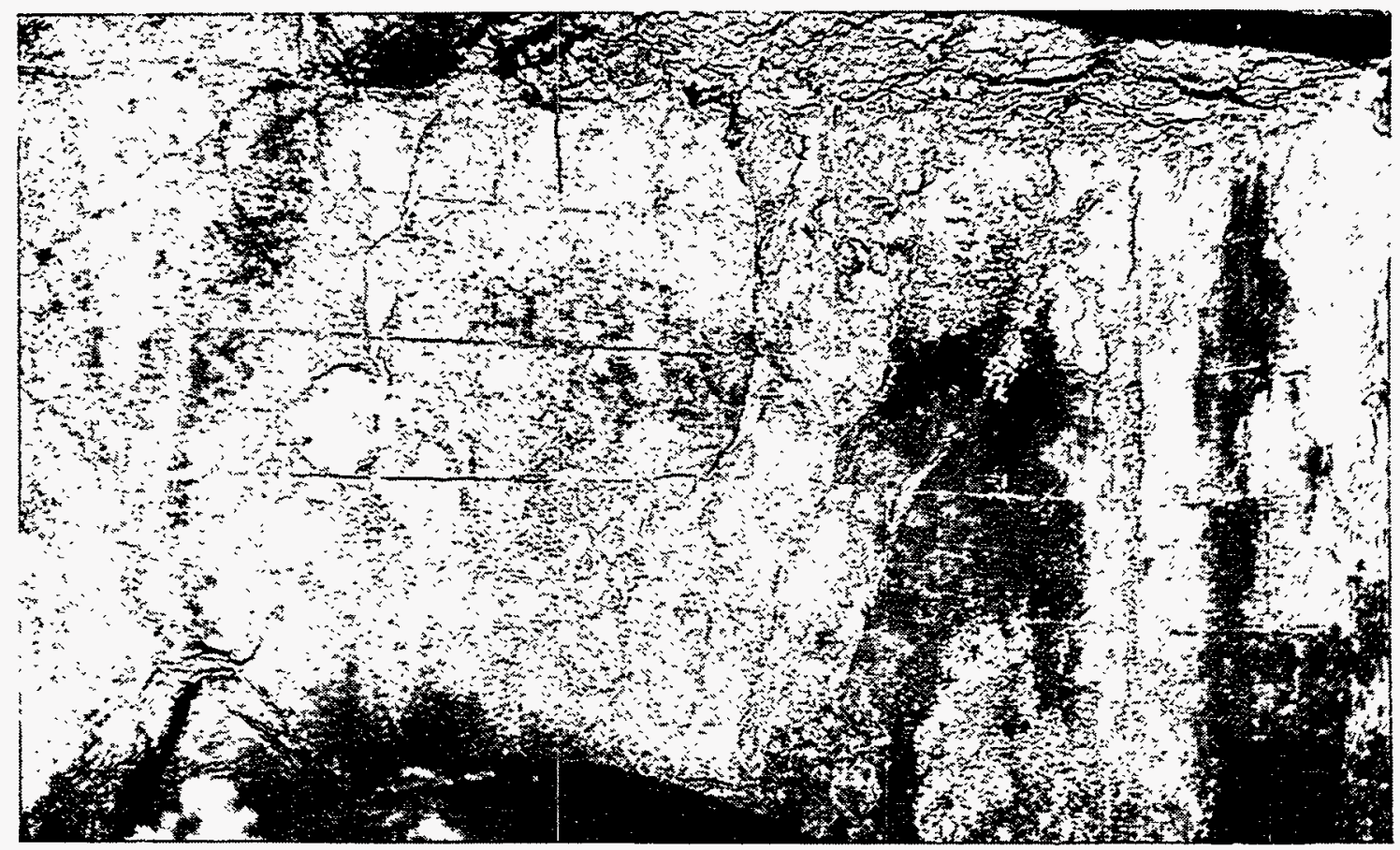

(a)

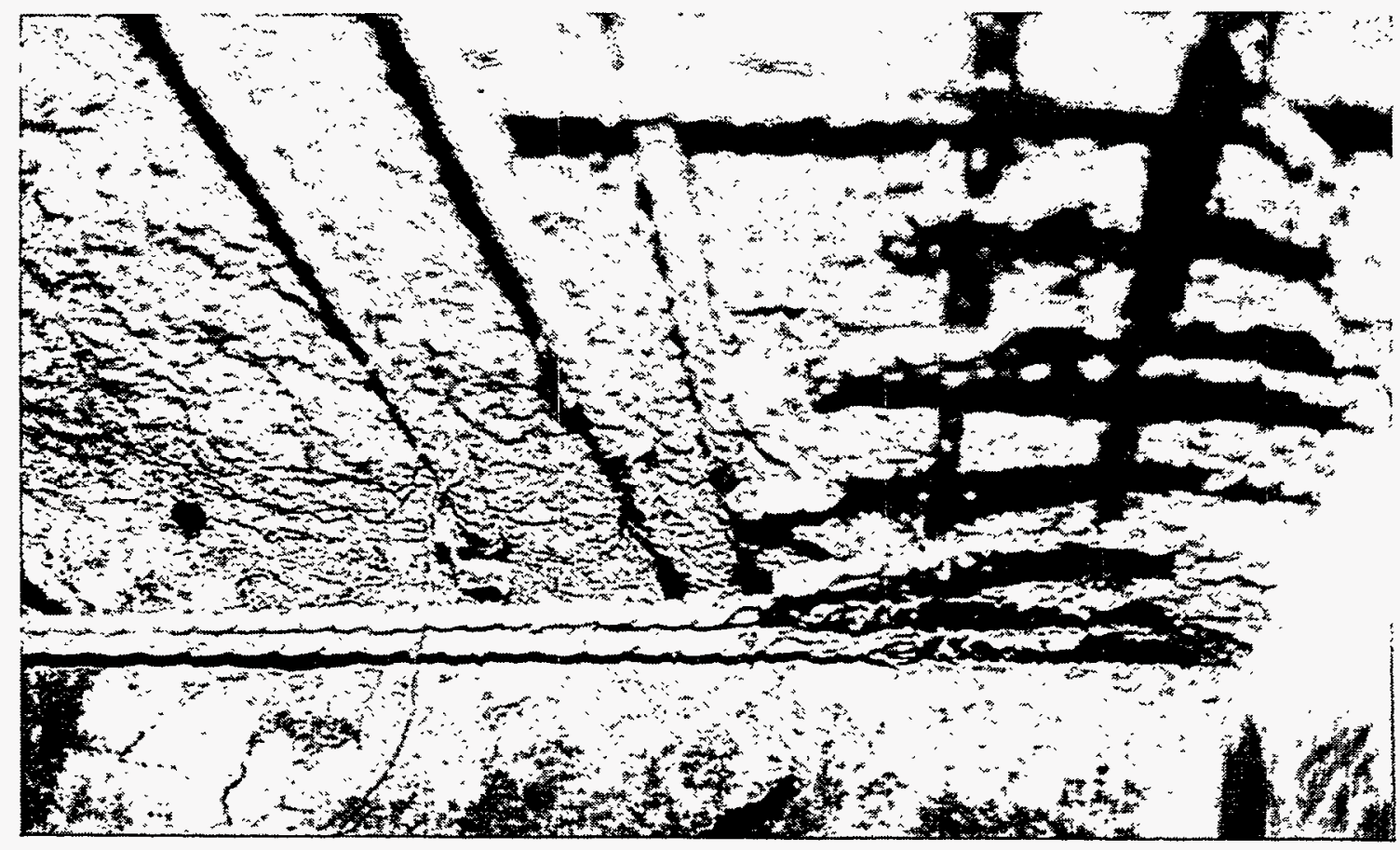

(b)

Figure 17. Interior views of MH7498 showing the extensive deterioration of the concrete walls (a) and ceiling (b). Note the exposed reinforcing in the ceiling. 
water on the floor of the manhole. The water disappeared by the time the in situ tests were started.

MH15105 -- a main valve manhole located beneath the sidewalk at 4 lst street and 1st Avenue. The manhole is approximately $25 \mathrm{ft}$ by $20 \mathrm{ft}$ by $7 \mathrm{ft}$ in height and contains two 30-in. diameter, insulated mains. The manhole was generally in good condition. Some cracking was evident in the walls (Figure 18), but the ceiling was in good condition and appeared to have been cast within the last few years. Air temperature within the manhole was measured to be about $205^{\circ} \mathrm{F}$.

Profiles of the air temperature in MH7498, MH7500, and MH15105 over the duration of the field tests are shown in Figure 19.

Monitoring of sample temperatures within MH15105 indicated that the temperatures of the samples were generally higher than the air temperature measured within the manhole, and that the sample temperatures increased as the distance from the floor of the manhole increased. For example, over a four month period the average air temperature in MH15105 was measured to be $\approx 194^{\circ} \mathrm{F}$. The internal temperature of samples placed on the floor of the manhole averaged $179^{\circ} \mathrm{F}$. Samples placed approximately four feet above the

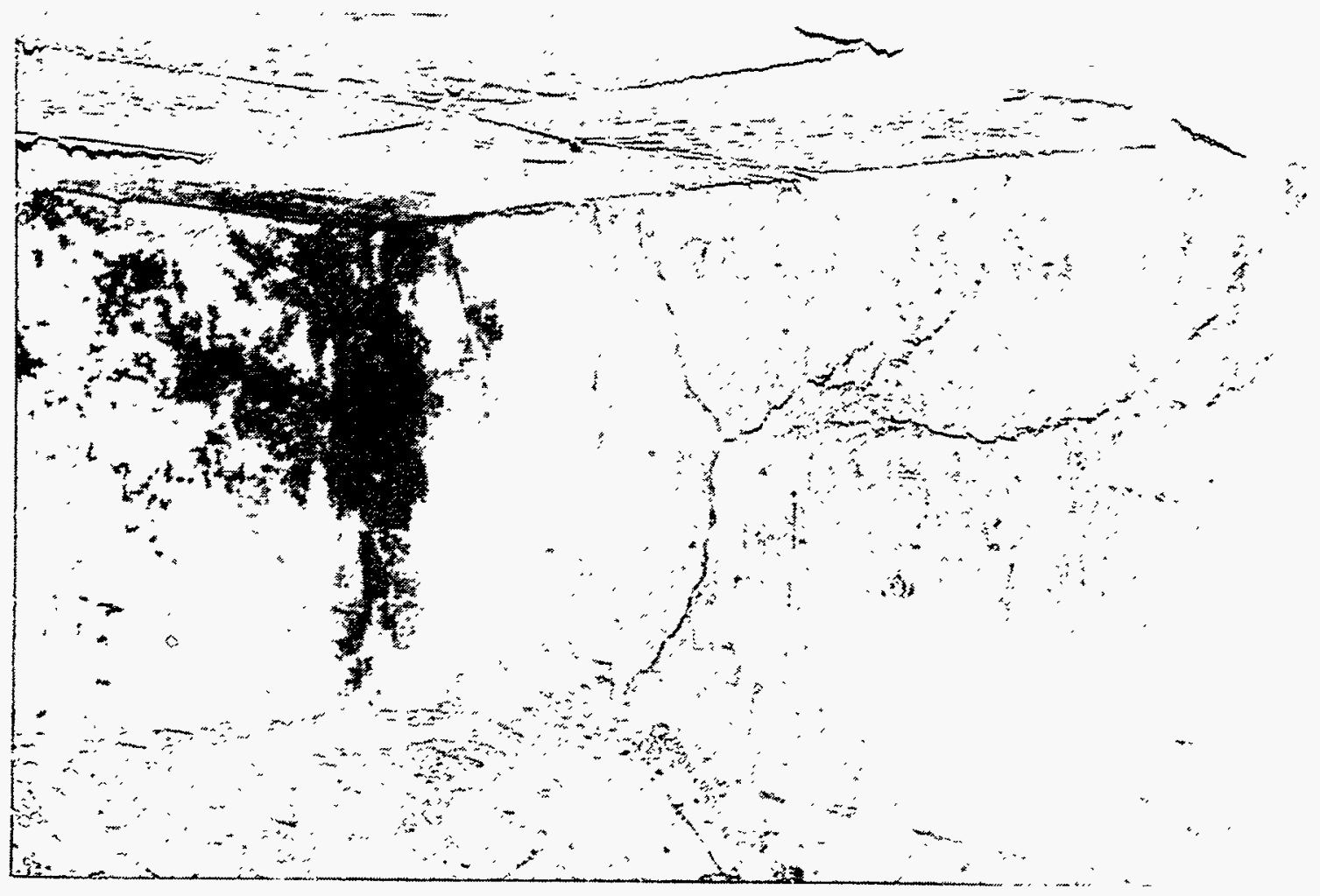

Figure 18. Interior view of MH15105 showing the cracking present in the south wall of the manhole. 


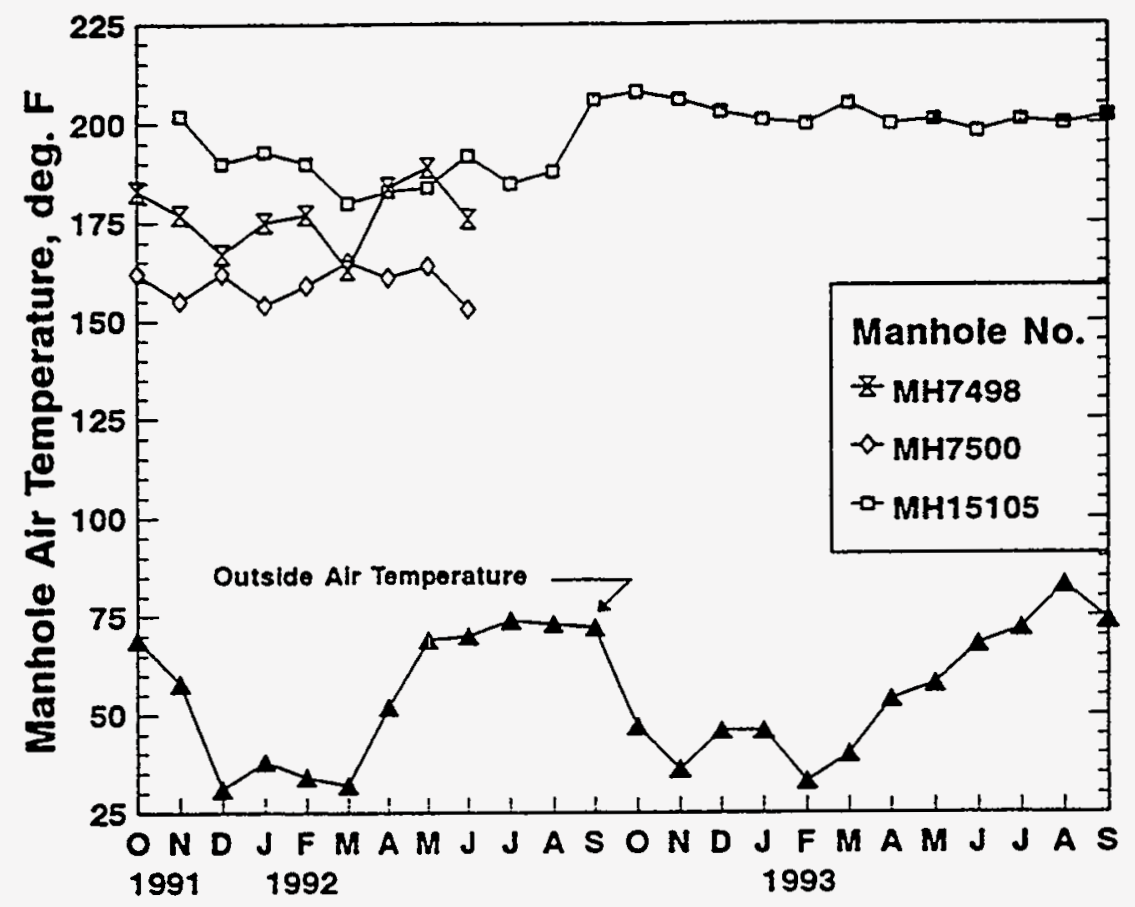

Figure 19. Profiles of the ambient air temperature in each manhole and the outside air temperature.

floor of the manhole had an average internal temperature of $\approx 200^{\circ} \mathrm{F}$, and samples placed at ceiling height ( $7 \mathrm{ft}$ above the floor) had an average internal temperature of $206^{\circ} \mathrm{F}$.

\subsection{Test Program.}

The ST, STP, VET and PF PC systems (refer to section 2.2) and two PCC systems (a non-reinforced portland cement concrete system and a fiber-reinforced portland cement concrete system) were tested in situ. A summary of the systems tested in each manhole is presented below.

\begin{tabular}{|cc|}
\hline Manhole No. & Systems in test in manhole \\
\hline 7498 & ST, VET, and PF PC systems. \\
7500 & ST, VET, and PF PC systems. \\
15105 & ST, STP, VET, and PF PC systems. \\
& Non-reinforced and fiber- \\
& reinforced PCC systems. \\
\hline
\end{tabular}


The in situ tests were started in MH7498 and MH7500 on October 3, 1991 and in MH15105 on October 31, 1991. A selected number of beams and cylinders were removed from each manhole after $1,2,3$, and $6 \mathrm{mo}$. of exposure and brought back to BNL for testing. This testing schedule was later revised to permit the 6 mo. samples to be left in test for longer time if the samples showed no signs of deterioration. Laboratory evaluation of each system was based upon the results of splitting tensile strength, flexure strength, water absorption, and dimensional stability tests.

The testing of samples in MH7498 and MH7500 was stopped on June 11, 1992 due to renovation of the manholes by con Ed. The testing of samples run in MH15105 was stopped on September 14, 1993 with the completion of the program.

\subsection{In Situ Test Results.}

4.4.1 Effects of field exposure on the properties of the PC systems. Table 11 summarizes the results obtained from the laboratory tests done on the in situ test specimen brought back to BNL for evaluation. Flexural yield strength test data for the VET, ST, and PF PC systems is presented graphically in Figures $20-22$.

In general, most of the samples removed within the first 12 months of testing were in good physical condition; i.e. no significant deterioration of the surfaces was noted (Figure 23). The only noticeable change was a discoloration of the PC. The exceptions to this were the ST, VET, and PF samples removed from MH7498. These samples, particularly the cylinders, began to show significant deterioration due to spalling after about 6 months of exposure (Figure 24).

A close visual examination of these samples indicated that the spalling was most likely due to the deterioration of the carbon steel fibers located at the surface of the samples. These fibers began to rust as a result of exposure to the environment within the manhole. The corrosion by-products resulted in an increase in the volume of the fibers, creating tensile stresses in the PC mortar around the fibers. As these stresses increased, cracks developed in the sample which eventually lead to spalling of the surface. $A$ visual examination of the sample cross-sections, after testing, indicated that the fibers in the interior of the samples were not rusted. In fact, the rusted fibers were generally confined to an area within 1/8-in. of the surface of the sample.

It is believed that the high humidity within manhole MH7498 was the primary contributing factor that lead to the advanced deterioration. spalling was also eventually noted in samples which 
Table 11. In situ Test Results

\begin{tabular}{|c|c|c|c|c|c|c|c|c|c|}
\hline PC & MH NO. & $\begin{array}{l}\text { AVERAGE } \\
\text { MANHOLE ARR } \\
\text { TEMP.. (dog.) }\end{array}$ & $\begin{array}{c}\text { EXPOSURE } \\
\text { TIME }\end{array}$ & $\begin{array}{l}\text { TEST } \\
\text { TEMP } \\
\text { (dog.) }\end{array}$ & $\begin{array}{c}\text { FLEXURAL } \\
\text { YELD STRENGTH, } \\
\text { DAl }\end{array}$ & $\begin{array}{l}\text { ULTIMATE } \\
\text { FLEXUAE } \\
\text { STRENGTH. pEI }\end{array}$ & $\begin{array}{l}\text { SPITTING } \\
\text { TENSILE } \\
\text { STRENGTH. PEI }\end{array}$ & $\frac{\text { WATERABS }}{\text { INSTIU }}$ & $\frac{\text { PAPTION, wt\% }}{\text { LAB TEST }}$ \\
\hline \multirow[t]{4}{*}{ VET } & $\mathrm{CUI}$ & -- & -- & $\begin{array}{l}\overline{160 \mathrm{~F}} \\
160 \mathrm{~F} \\
200 \mathrm{~F}\end{array}$ & $\begin{array}{l}2050 \\
2035 \\
1080\end{array}$ & $\begin{array}{l}2620 \\
2400 \\
2100\end{array}$ & $\begin{array}{l}2000 \\
1935 \\
1870\end{array}$ & $\begin{array}{l}=- \\
--\end{array}$ & 0.40 \\
\hline & 7400 & $177 \mathrm{~F}$ & $\begin{array}{l}1 \mathrm{mo} . \\
2 \mathrm{mo} . \\
3 \mathrm{mo} . \\
8 \mathrm{mo} .\end{array}$ & $\begin{array}{c}180 F \\
:\end{array}$ & $\begin{array}{l}1755 \\
1030 \\
1000 \\
1770\end{array}$ & $\begin{array}{l}2000 \\
2380 \\
1000 \\
2005\end{array}$ & $\begin{array}{l}2000 \\
1000 \\
1848 \\
1760\end{array}$ & $\begin{array}{l}0.16 \\
0.16 \\
0.41 \\
0.23\end{array}$ & $\begin{array}{l}0.50 \\
0.21 \\
0.31 \\
0.08\end{array}$ \\
\hline & 7500 & $160 \mathrm{~F}$ & $\begin{array}{l}1 \mathrm{mo} . \\
2 \mathrm{mo} . \\
3 \mathrm{mo} . \\
8 \mathrm{mo} .\end{array}$ & $\begin{array}{c}160 F \\
:\end{array}$ & $\begin{array}{l}1580 \\
1755 \\
1500 \\
1710\end{array}$ & $\begin{array}{l}2435 \\
2730 \\
2245 \\
2405\end{array}$ & $\begin{array}{l}2005 \\
2305 \\
2115 \\
1920\end{array}$ & $\begin{array}{r}0.05 \\
0.05 \\
0.01 \\
-0.06\end{array}$ & $\begin{array}{l}0.50 \\
0.50 \\
0.60 \\
0.60\end{array}$ \\
\hline & 15105 & $100 \mathrm{~F}$ & $\begin{array}{c}1 \mathrm{mo} . \\
2 \mathrm{mo} . \\
3 \mathrm{mo} . \\
8 \mathrm{mo} \text {. } \\
18 \mathrm{mo} .\end{array}$ & $\begin{array}{c}200 \mathrm{~F} \\
\vdots \\
\vdots\end{array}$ & $\begin{array}{l}1420 \\
1550 \\
1460 \\
1670 \\
1725\end{array}$ & $\begin{array}{l}1030 \\
2035 \\
2185 \\
2030 \\
1045\end{array}$ & $\begin{array}{l}1000 \\
1055 \\
1855 \\
1710 \\
1545\end{array}$ & $\begin{array}{l}0.21 \\
0.21 \\
0.18 \\
0.20 \\
0.58\end{array}$ & $\begin{array}{l}0.49 \\
0.50 \\
0.60 \\
0.30 \\
0.75\end{array}$ \\
\hline \multirow[t]{3}{*}{$\begin{array}{c}\text { VETrt } \\
\text { (RT Curo) }\end{array}$} & C्त & - & $\begin{array}{l}-- \\
--\end{array}$ & $\begin{array}{l}200 \mathrm{~F} \\
400 \mathrm{~F}\end{array}$ & $\begin{array}{l}2005 \\
1000\end{array}$ & $\begin{array}{l}2550 \\
1130\end{array}$ & $\begin{array}{r}1785 \\
765\end{array}$ & $=$ & 0.17 \\
\hline & 15105 & $106 \mathrm{~F}$ & $\begin{array}{l}1 \mathrm{mo} . \\
2 \mathrm{mo} . \\
3 \mathrm{mo} . \\
6 \mathrm{mo} . \\
12 \mathrm{mo} .\end{array}$ & $\begin{array}{c}200 F \\
\vdots \\
\vdots\end{array}$ & $\begin{array}{l}2270 \\
1645 \\
2380 \\
2000 \\
1810\end{array}$ & $\begin{array}{l}2505 \\
2800 \\
2850 \\
2500 \\
2860\end{array}$ & $\begin{array}{c}2075 \\
1970 \\
1800 \\
-- \\
--\end{array}$ & $\begin{array}{l}0.05 \\
0.04 \\
0.04 \\
0.70 \\
0.08\end{array}$ & $\begin{array}{l}0.11 \\
0.00 \\
0.11 \\
0.15 \\
0.27\end{array}$ \\
\hline & & & $\begin{array}{l}3 \mathrm{mo} . \\
6 \mathrm{mo} .\end{array}$ & $400 F$ & $\begin{array}{l}905 \\
840\end{array}$ & $\begin{array}{l}1000 \\
1200\end{array}$ & $\begin{array}{l}745 \\
--\end{array}$ & -- & $\begin{array}{l}-- \\
--\end{array}$ \\
\hline \multirow[t]{4}{*}{$\overline{P F}$} & CrI & -- & -- & $\begin{array}{l}160 \mathrm{~F} \\
100 \mathrm{~F} \\
200 \mathrm{~F}\end{array}$ & $\begin{array}{l}1760 \\
1525 \\
1460\end{array}$ & $\begin{array}{l}1055 \\
2325 \\
1715\end{array}$ & $\begin{array}{l}1525 \\
1585 \\
1680\end{array}$ & $\begin{array}{l}-- \\
-- \\
--\end{array}$ & $\begin{array}{c}1.86 \\
.\end{array}$ \\
\hline & 7498 & $177 \mathrm{~F}$ & $\begin{array}{l}1 \mathrm{mo} . \\
2 \mathrm{mo} . \\
3 \mathrm{mo} . \\
7 \mathrm{mo} .\end{array}$ & $\begin{array}{c}180 \mathrm{~F} \\
\vdots\end{array}$ & $\begin{array}{r}1560 \\
1175 \\
1235 \\
800\end{array}$ & $\begin{array}{l}1830 \\
2175 \\
1450 \\
1505\end{array}$ & $\begin{array}{l}1750 \\
1475 \\
1645 \\
1150\end{array}$ & $\begin{array}{l}1.11 \\
1.20 \\
1.30 \\
1.68\end{array}$ & $\begin{array}{l}1.60 \\
2.18 \\
2.03 \\
1.03\end{array}$ \\
\hline & 7500 & $100 \mathrm{~F}$ & $\begin{array}{l}1 \mathrm{mo} . \\
2 \mathrm{mo} . \\
3 \mathrm{mo} . \\
8 \mathrm{mo} .\end{array}$ & $\begin{array}{c}160 \mathrm{~F} \\
\vdots\end{array}$ & $\begin{array}{l}1505 \\
1045 \\
1525 \\
1500\end{array}$ & $\begin{array}{l}1025 \\
2050 \\
1870 \\
2345\end{array}$ & $\begin{array}{c}1025 \\
=- \\
1730 \\
1920\end{array}$ & $\begin{array}{r}0.17 \\
0.36 \\
0.31 \\
-0.37\end{array}$ & $\begin{array}{l}2.18 \\
1.81 \\
2.15 \\
1.24\end{array}$ \\
\hline & 15105 & $190 \mathrm{~F}$ & $\begin{array}{l}1 \mathrm{mo} . \\
2 \mathrm{mo} . \\
3 \mathrm{mo} . \\
9 \mathrm{mo} .\end{array}$ & $\begin{array}{c}200 F \\
:\end{array}$ & $\begin{array}{l}1335 \\
1330 \\
1215 \\
1410\end{array}$ & $\begin{array}{l}1500 \\
1505 \\
1025 \\
1515\end{array}$ & $\begin{array}{l}1335 \\
1515 \\
1590 \\
1165\end{array}$ & $\begin{array}{l}1.40 \\
0.92 \\
0.88 \\
0.63\end{array}$ & $\begin{array}{l}1.51 \\
1.87 \\
1.98 \\
2.10\end{array}$ \\
\hline \multirow[t]{4}{*}{ ST } & ctr & -- & -- & $\begin{array}{l}100 \mathrm{~F} \\
180 \mathrm{~F} \\
200 \mathrm{~F}\end{array}$ & $\begin{array}{l}1310 \\
1440 \\
1045\end{array}$ & $\begin{array}{l}1685 \\
1650 \\
1255\end{array}$ & $\begin{array}{l}1795 \\
1670 \\
1585\end{array}$ & $\begin{array}{l}-- \\
-- \\
--\end{array}$ & 1.34 \\
\hline & 7488 & $17 \mathrm{~F}$ & $\begin{array}{l}1 \mathrm{mo} . \\
2 \mathrm{mo} . \\
3 \mathrm{mo} . \\
6 \mathrm{mo} .\end{array}$ & $\begin{array}{c}180 \mathrm{~F} \\
\vdots\end{array}$ & $\begin{array}{l}1600 \\
1580 \\
1525 \\
1400\end{array}$ & $\begin{array}{l}2420 \\
1000 \\
1755 \\
1825\end{array}$ & $\begin{array}{l}1640 \\
1005 \\
1735 \\
1570\end{array}$ & $\begin{array}{l}0.12 \\
0.25 \\
0.25 \\
0.47\end{array}$ & $\begin{array}{l}1.08 \\
1.07 \\
0.06 \\
0.72\end{array}$ \\
\hline & 7500 & $160 \mathrm{~F}$ & $\begin{array}{l}1 \mathrm{mo} . \\
2 \mathrm{mo} . \\
3 \mathrm{mo} . \\
8 \mathrm{mo} .\end{array}$ & $\begin{array}{c}160 \mathrm{~F} \\
\vdots\end{array}$ & $\begin{array}{l}1415 \\
1635 \\
1500 \\
1600\end{array}$ & $\begin{array}{l}1605 \\
2300 \\
2005 \\
2300\end{array}$ & $\begin{array}{l}1675 \\
1750 \\
1605 \\
1730\end{array}$ & $\begin{array}{c}0.05 \\
0.05 \\
0 \\
-0.10\end{array}$ & $\begin{array}{l}1.10 \\
1.02 \\
1.00 \\
0.00\end{array}$ \\
\hline & 15105 & $106 \mathrm{~F}$ & $\begin{array}{c}1 \mathrm{mo} . \\
2 \mathrm{mo} . \\
3 \mathrm{mo} . \\
18 \mathrm{mo} .\end{array}$ & $\begin{array}{c}200 F \\
\vdots\end{array}$ & $\begin{array}{l}1335 \\
1670 \\
1455 \\
1525\end{array}$ & $\begin{array}{l}1505 \\
2315 \\
2070 \\
1870\end{array}$ & $\begin{array}{l}1585 \\
1885 \\
1775 \\
1405\end{array}$ & $\begin{array}{l}0.13 \\
0.10 \\
0.14 \\
0.61\end{array}$ & $\begin{array}{l}0.44 \\
0.47 \\
0.44 \\
0.85\end{array}$ \\
\hline \multirow[t]{2}{*}{ STP } & CtrI & -- & $=$ & $200 \mathrm{~F}$ & 1005 & 2175 & 1214 & -- & 1.05 \\
\hline & 15105 & $106 \mathrm{~F}$ & $\begin{array}{l}1 \mathrm{mo} . \\
2 \mathrm{mo} . \\
3 \mathrm{mo} .\end{array}$ & $200 \mathrm{~F}$ & $\begin{array}{l}1680 \\
1980 \\
1570\end{array}$ & $\begin{array}{l}2100 \\
2560 \\
2150\end{array}$ & $\overline{1180}$ & $\begin{array}{l}0.10 \\
0.17 \\
0.23\end{array}$ & $\begin{array}{l}1.05 \\
0.81 \\
0.03\end{array}$ \\
\hline
\end{tabular}

All values are an average of a minimum of 3 test spocimens.

The floxural modulus of rupture is defined as that stress corresponding to the end of the linoar portion of the load vs. defiection curvo. 


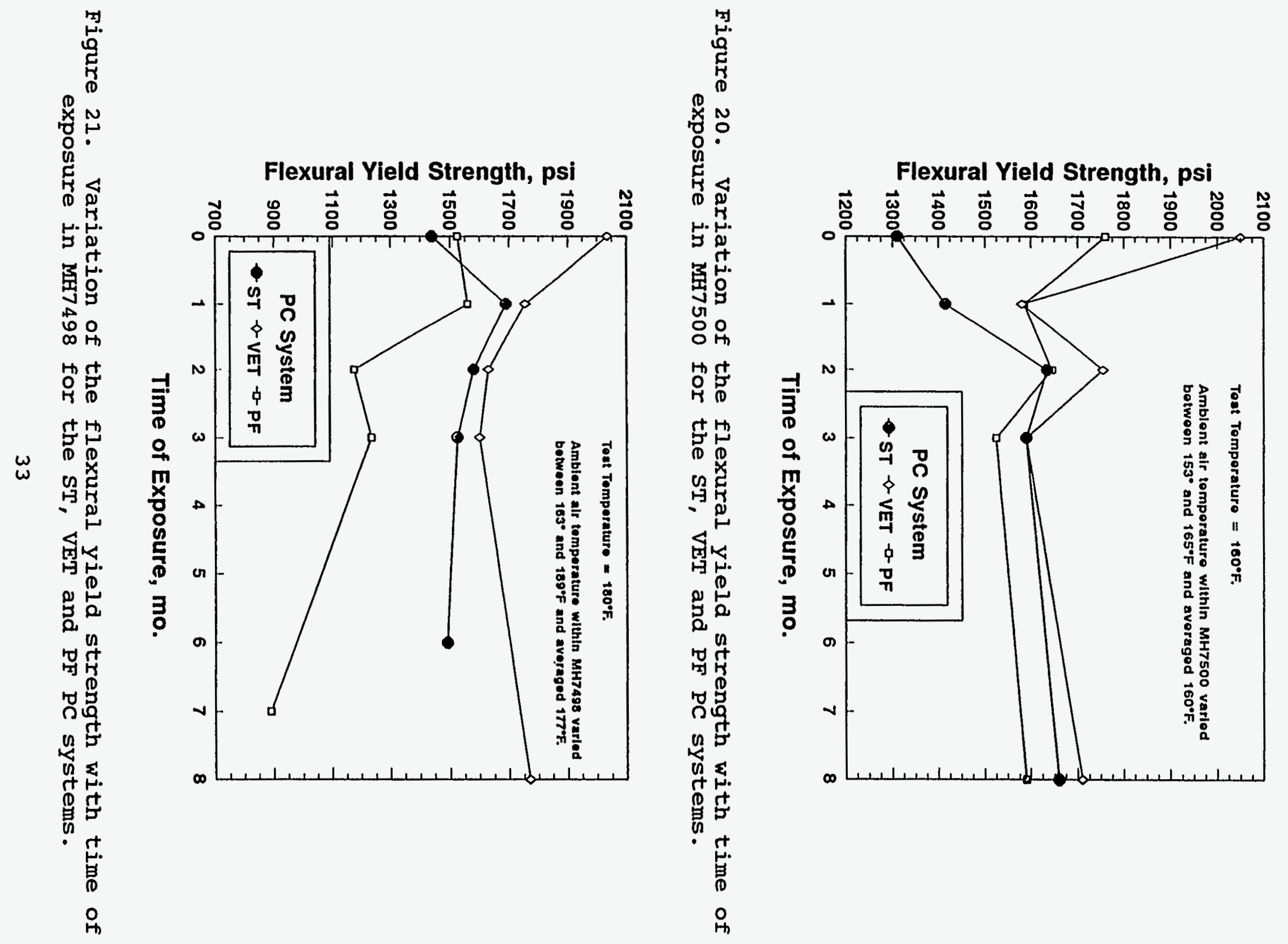




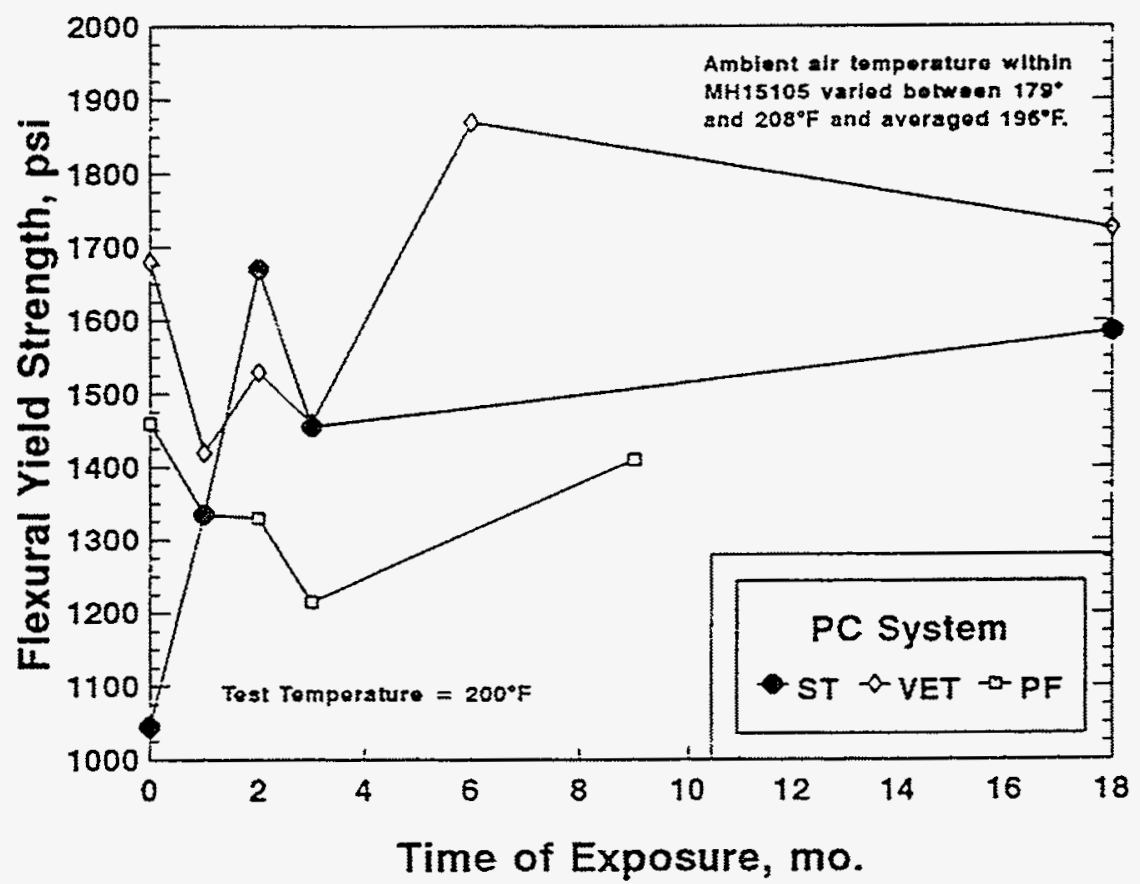

Figure 22. Variation of the flexural yield strength with time of exposure in MH15105 for the ST, VET and PF PC systems.

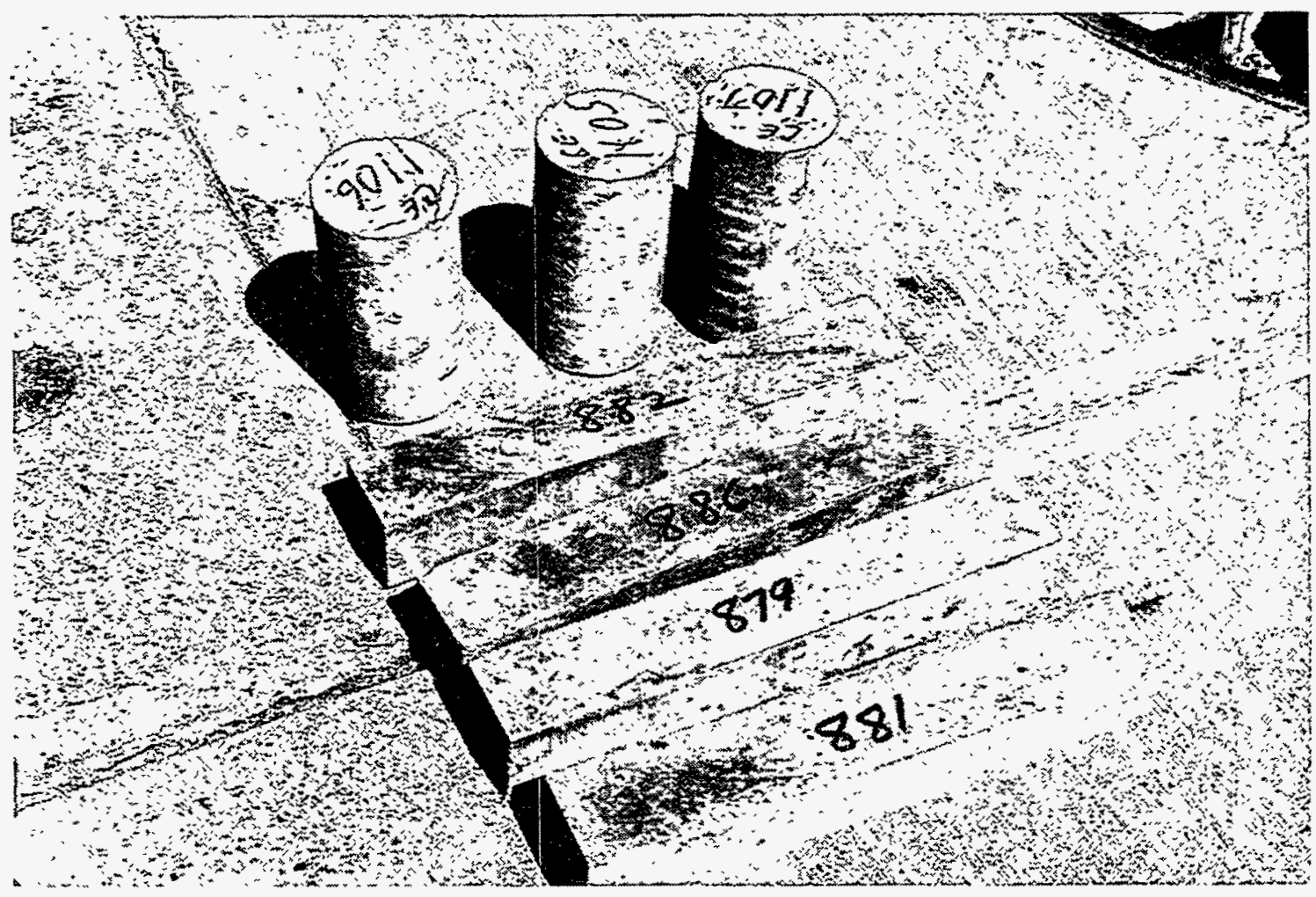

Figure 23. VET PC samples after 8 mo. of exposure in MH7500. 


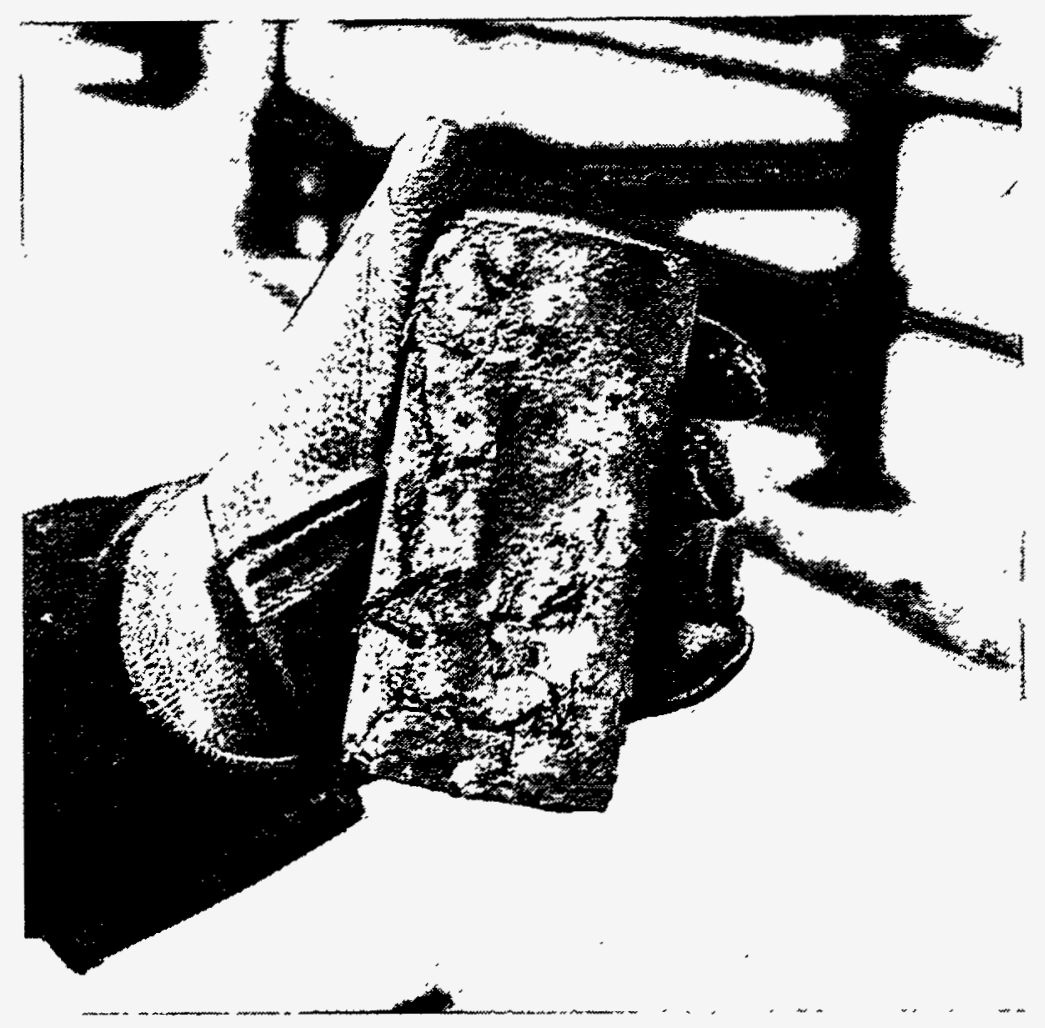

Figure 24. A ST PC sample after $6 \mathrm{mo}$. exposure in MH7498. Rusting of fibers located near the surface has resulted in deterioration due to spalling.

had been in test for 18 months in MH15105. The humidity in MH15105, however, was not as high as that in MH7498 and as a result the fibers did not rust as quickly.

A comparison of TGA data for polymer samples taken from laboratory controls and from beams and cylinders which had exhibited significant deterioration due to spalling indicated that there was no degradation of the polymer binders.

The test data shows that, in general, each of the ST, VET, and PF PC systems exhibited reductions in strength as a result of exposure to the environment within the manholes. After 6 to 9 mo. of exposure in the manholes, the FYS values for the VET, ST, and PF PC systems, measured at $160^{\circ}$ to $200^{\circ} \mathrm{F}$, may be summarized as follows:

\begin{tabular}{|cr|}
\hline PC System & Flexural Yield Strength \\
\hline VET & 1710 to 1870 psi \\
ST & 1490 to 1660 psi \\
PF & 890 to 1590 psi \\
\hline
\end{tabular}


These ranges represent a decrease in the FYS for the VET and PF systems and an increase in the FYS the ST system, when compared to their respective control values. The data also indicates that the VET system exhibits the highest range of FYs values of the three systems. Results of the tests done to evaluate the physical properties of the VET and ST systems after 18 mo. of exposure in MH15105 indicate that the FYS for the VET system, measured at $200^{\circ} \mathrm{F}$, decreased about 1.4 percent when compared to the control values for the system. The FYS for the ST system, measured at $200^{\circ} \mathrm{F}$, decreased about 24 percent.

The tendency of the systems to absorb moisture also increased as a result of the exposure. This is indicated by a comparison of the water absorption values measured in situ and in the laboratory. The increase in the tendency of the PC systems to absorb moisture may have also contributed to the rusting of the carbon steel fibers and the resultant spalling.

The overall changes in the flexural characteristics of the PC systems can be seen by examining the load versus deflection versus time of exposure curves for the ST, VET and PF PC systems. These curves are presented in Appendix A.

In situ tests to evaluate the STP PC system were done in MH15105. This system was tested to evaluate if the addition of PMMA to the system would improve the field performance of the styrene-based system. The test results are summarized in Table 11. Figures 25 and 26 show the comparison of the results from splitting tensile and flexure strength tests for ST and STP systems.

Figure 25 shows that the STP system has higher FYS values and lower splitting tensile strength values than the ST system when measured at $200^{\circ} \mathrm{F}$. Figure 26 shows the load versus deflection curves for both systems after $3 \mathrm{mo}$. of exposure in MH15105. Both systems show similar behavior in flexure; however, the STP system has a slightly higher $E$ value and a higher ultimate flexure strength. The load versus deflection versus time of exposure curves for the STP system are presented in Appendix A.

4.4.2 In situ post-curing of a PC system. BNI had assumed that any PC system used to cast a manhole would be completely postcured before the manhole was placed into service. Consequently, all samples used in the laboratory-scaled and in situ field tests were post-cured when fabricated. Subsequent discussions with con Ed engineers indicated that there was no assurance that a manhole, which had been cast-in-place using PC, would be fully post-cured before being put into service. Therefore, tests were done to determine if the heat generated within a manhole could be used to post-cure the ST and VET PC systems.

The tests were done using 1-in. diameter PC mortar cylinders. The cylinders were cast in the $l a b$ and cured only at room 


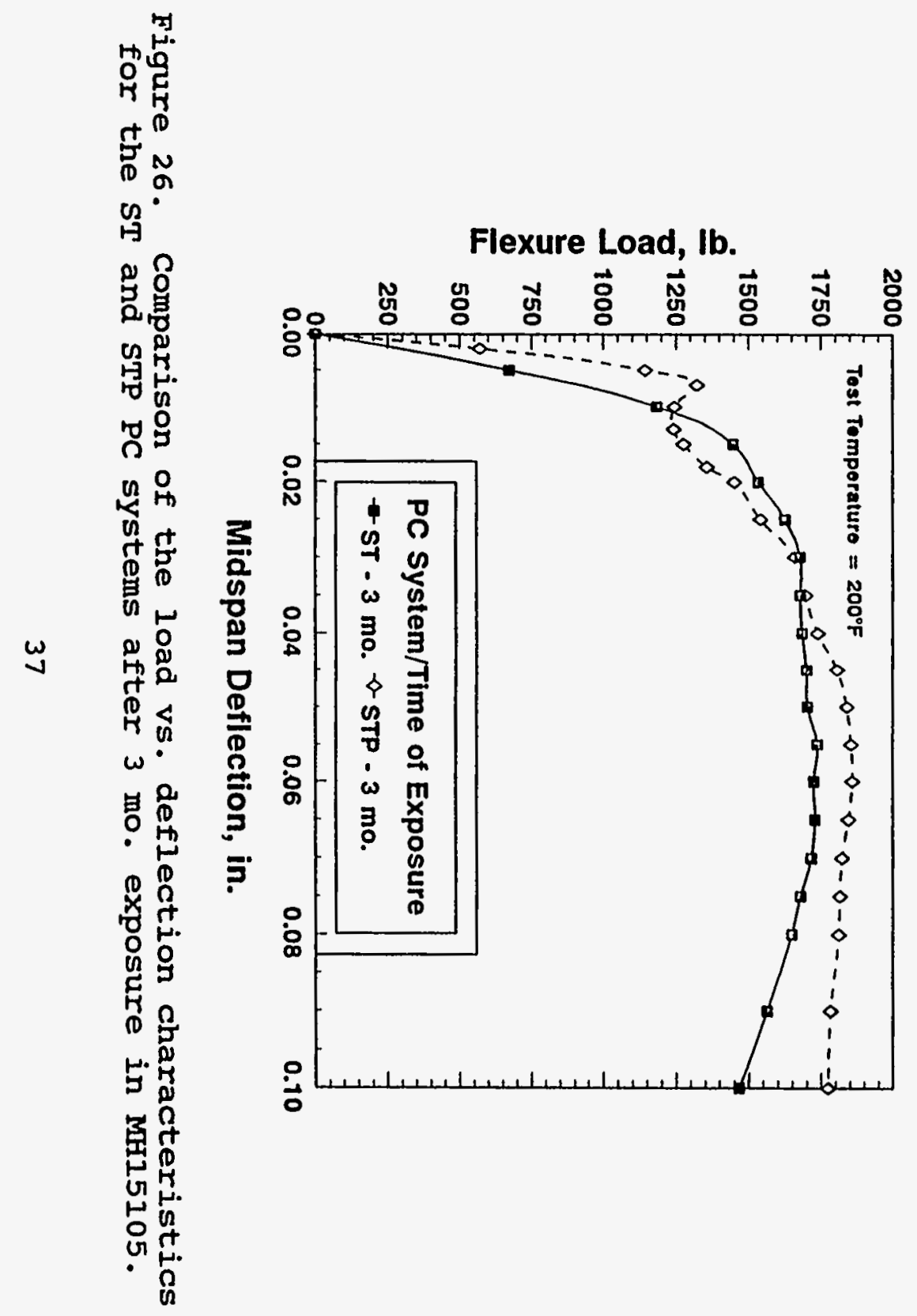

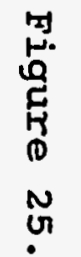

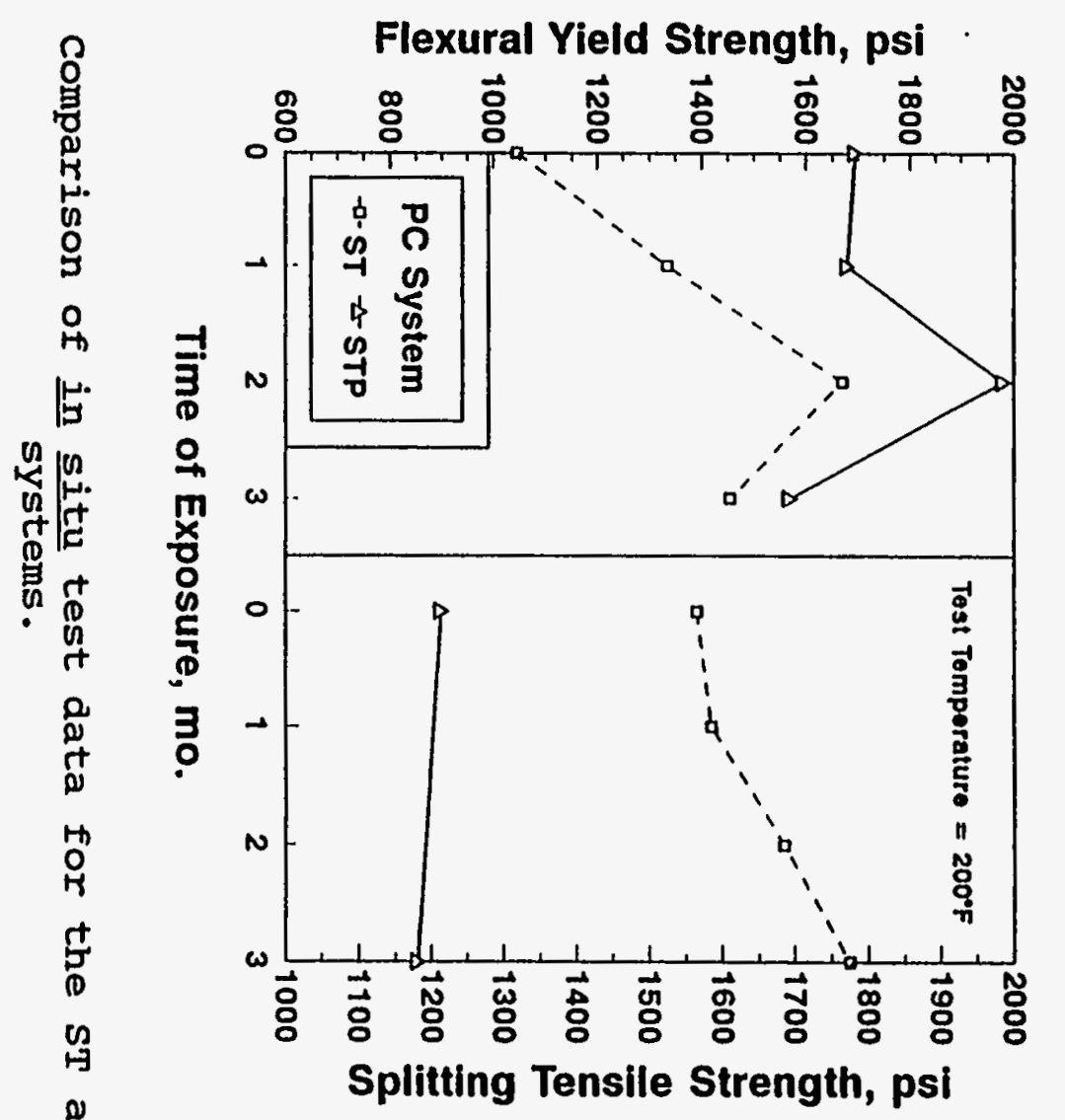


temperature. The VET cylinders were tested in MH7500 (ambient temp. $=160^{\circ} \mathrm{F}$ ) and MH15105 (ambient temp. $=189^{\circ} \mathrm{F}$ ), and the ST cylinders were tested in MH15105. Samples were removed after 1, 2, 3 , and 6 months of exposure and brought back to BNL for compressive strength tests. The results, summarized in Figures 27 and 28, show that the compressive strengths of both systems increased after exposure to the elevated temperatures of the manholes, demonstrating that the heat within the manholes can be used to post-cure the PC systems as presently formulated.

Based upon these results, a series of tests were done to further evaluate the strength properties of the VET PC system, which had been post-cured, using the heat within MH15105. The tests were done using 3-in. diameter by 6-in. Iong cylinders and 2 by 2 by 12 -in. long beams. The test specimens were exposed to the heat within MH15105 for 3 months. Samples were removed after 1, 2, and 3 months of exposure and then brought back to BNL for testing.

Figure 29 shows an overall increase in the flexure and splitting tensile strengths of the VET system with time as a result of the post-curing of the system. Improvements in the flexural strength properties are shown in Figure 30. The load carrying capability of the system increases with the time of exposure and is most likely due to the post-curing of the system by the heat generated within the manhole.

4.4.3 In situ testing of samples made with stainless steel fibers. As a result of the problems associated with the rusting of the carbon steel fibers, a series of tests were done to evaluate the use of 1.5-in. long, corrugated, 430 stainless steel fibers as a replacement for carbon steel fibers. The stainless steel fibers, known as Xorex steel fibers, are manufactured by Novocon International, Inc. This is the same company which manufactures the carbon steel fibers. The cost of the 430 stainless steel fibers is approximately 4 times greater than that of the carbon steel fibers.

Preliminary tests were done in the laboratory to compare the flexural characteristics of PC beams made with the stainless steel fibers to PC beams made with the carbon steel fibers. The tests were done at $72^{\circ}$ and $200^{\circ} \mathrm{F}$ using beams made with the VETrt PC system. The test results are illustrated in Figures 31 and 32 . In general, the results indicate that at $72^{\circ} \mathrm{F}:$ (a) the FYs of the beams made with the stainless steel fibers is approximately 30 percent higher than the FYS of the beams made with the carbon steel fibers, (b) the ultimate flexure strength of the beams made with the stainless steel fibers is approximately 6 percent higher than that measured for the beams made with the carbon steel fibers, and (c) the deflection, at ultimate strength, of the beams made with the stainless steel fibers is approximately 37 percent lower than that measured for the beams made with the carbon steel fibers. When tested at $200^{\circ} \mathrm{F}$ the beams made with the stainless steel fibers 


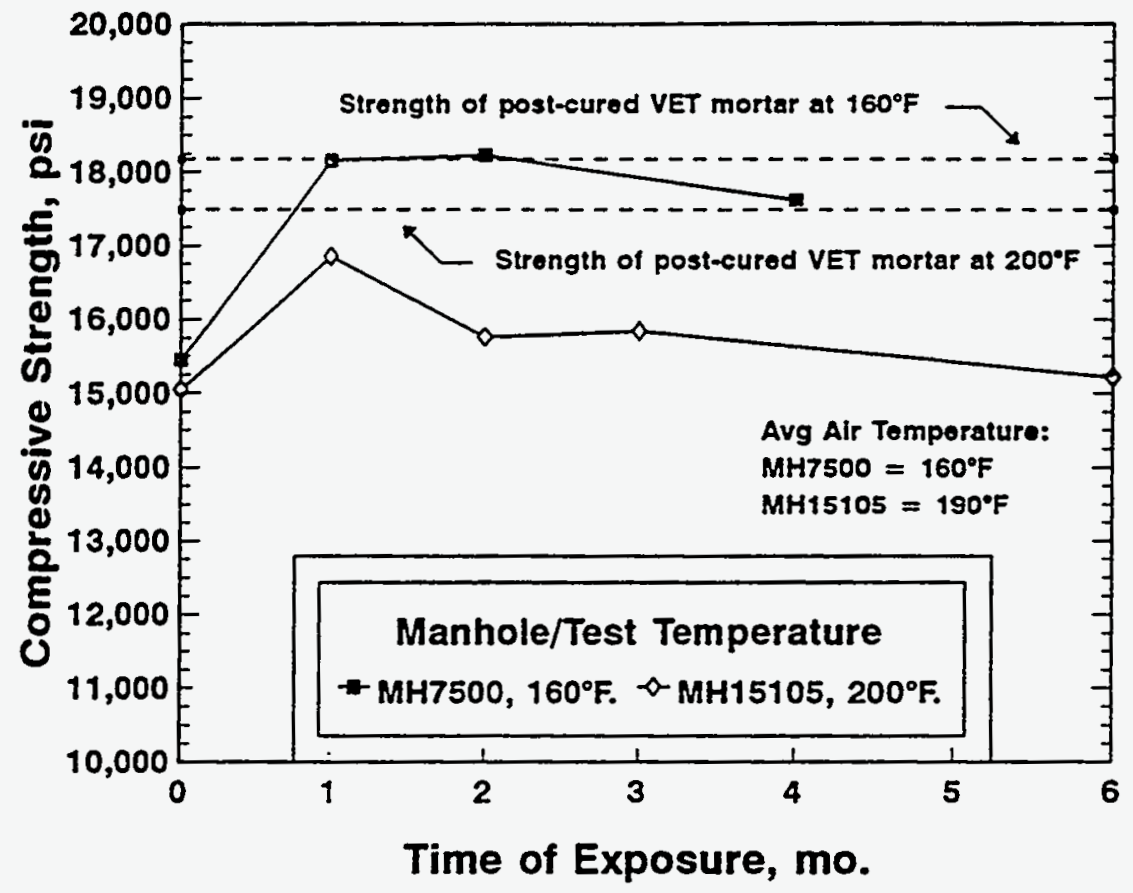

Figure 27. Compressive strength of VET mortars post-cured in situ.

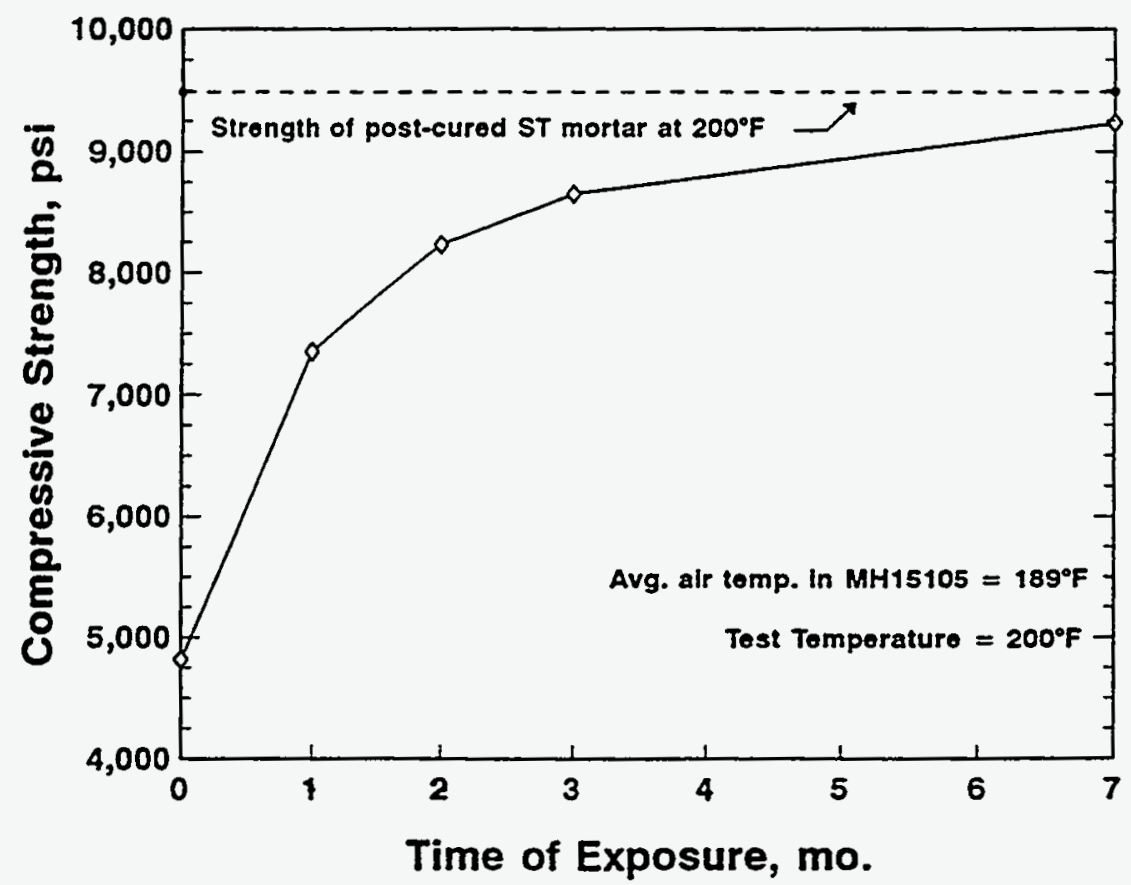

Figure 28. Compressive strength of ST mortars post-cured in situ. 


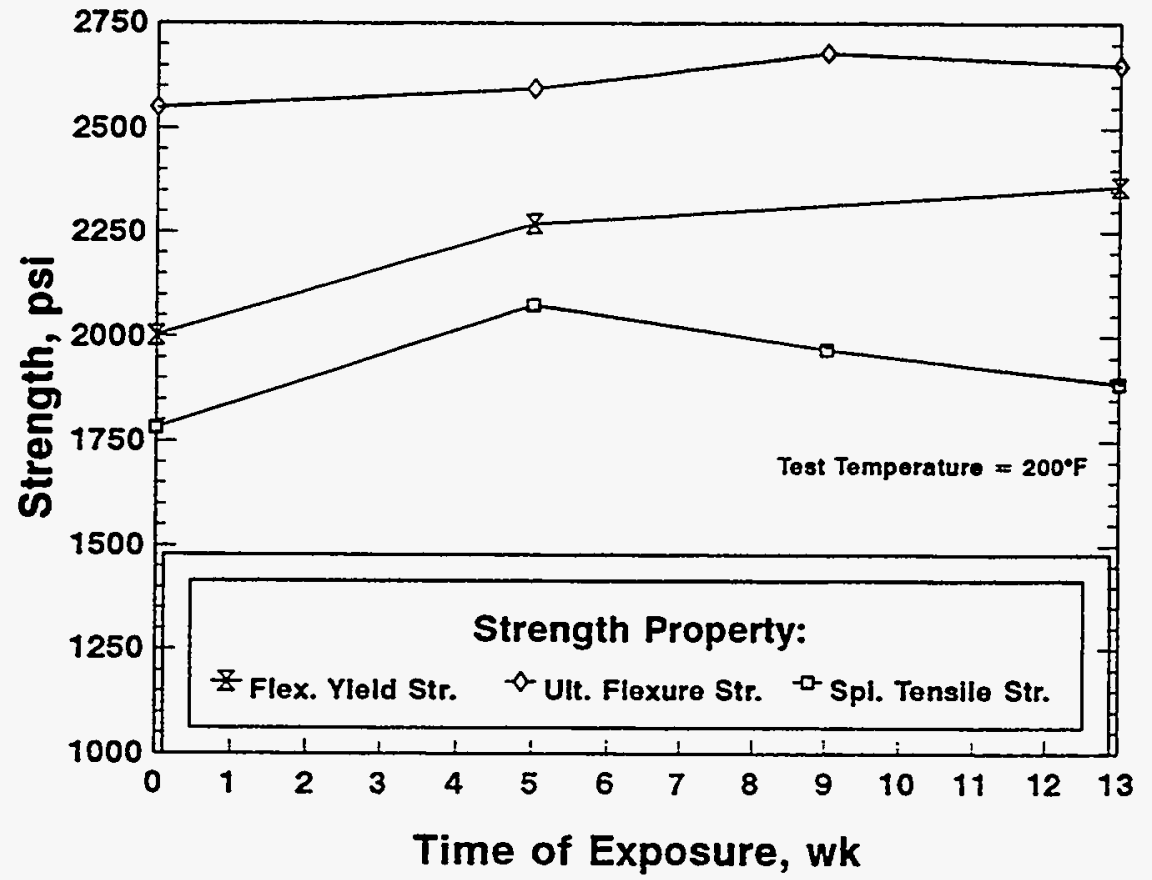

Figure 29. Variation of strength properties with in situ time of exposure for the ambient temperature-cured VET PC system.

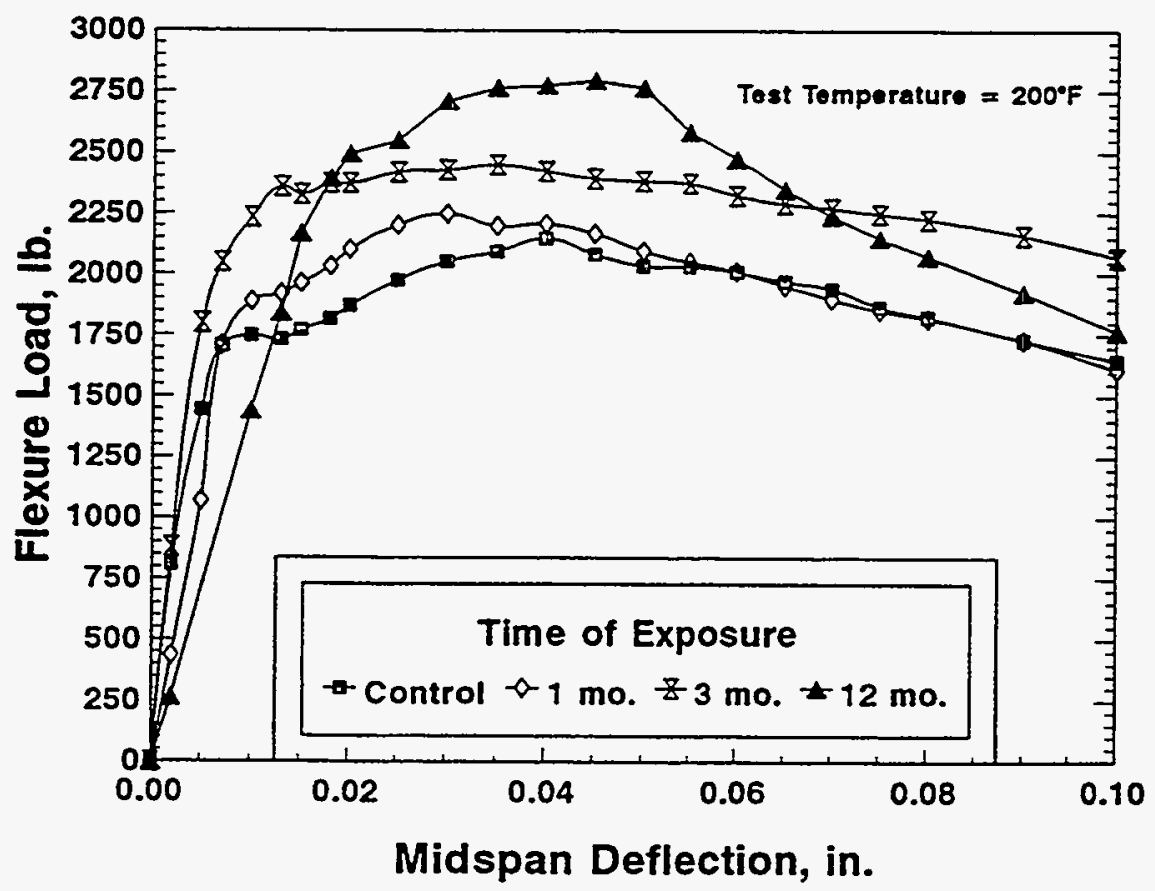

Figure 30. Variation of load vs. deflection characteristics with in situ time of exposure in MH15105 for the ambient temperaturecured VET PC system. 


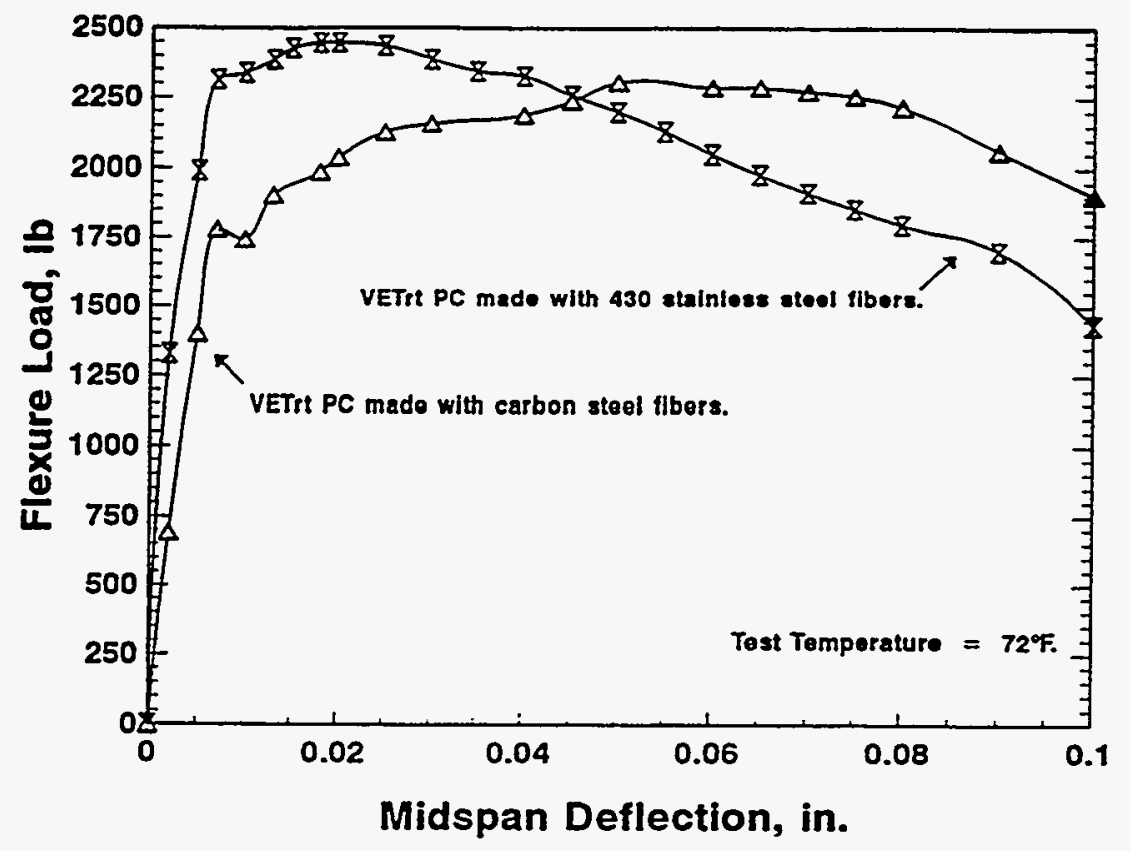

Figure 31. Load-deflection characteristics, at $72^{\circ} \mathrm{F}$, of VETrt PC beams made with carbon steel and 430 stainless steel fibers.

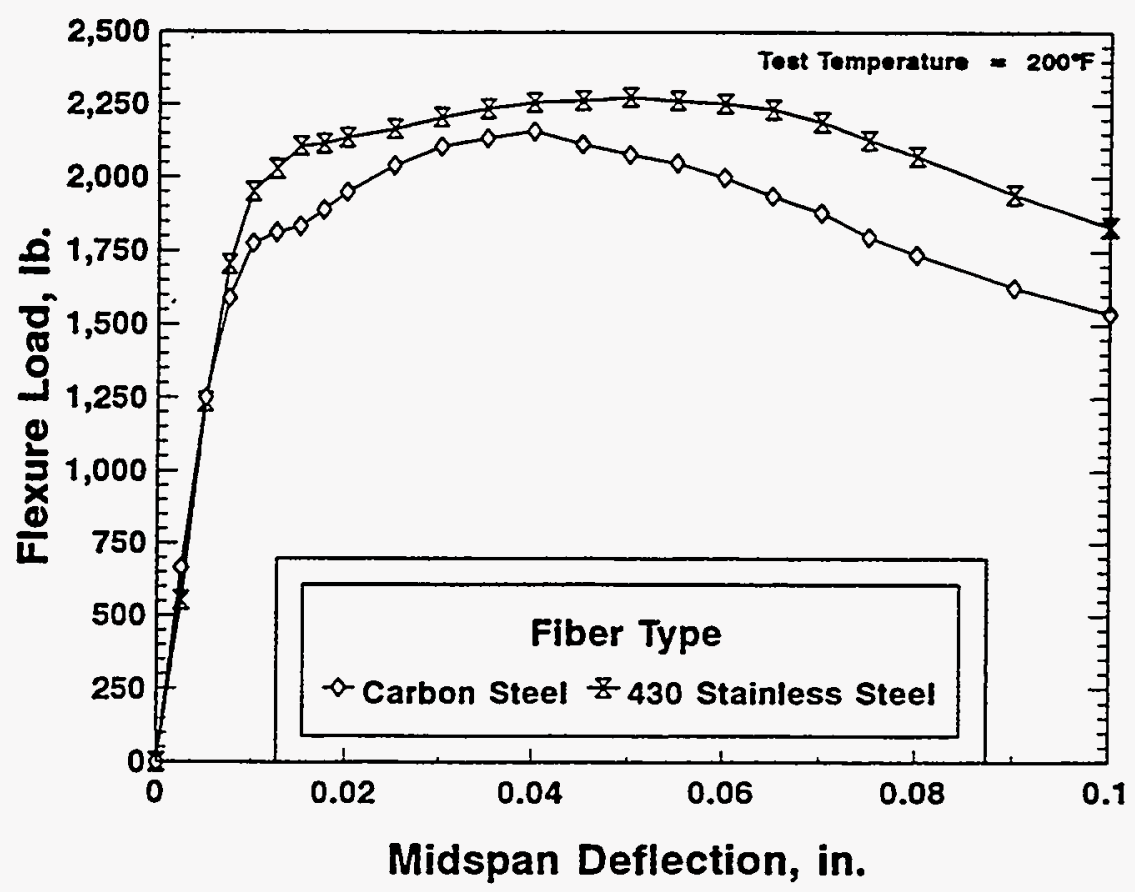

Figure 32. Load-deflection characteristics, at $200^{\circ} \mathrm{F}$, of VETrt PC beams made with carbon steel and 430 stainless steel fibers. 
continue to exhibit higher FYS and ultimate strength values. However, the ductility of the beams made with the stainless steel fibers increases and is similar to that for the beams made with the carbon steel fibers.

Upon completion of the laboratory tests, VETrt PC beams and cylinders made with the stainless steel fibers were placed into test in MH15105. Test results for samples removed after 1, 3, and 12 mo. of exposure are summarized in Table 12. Test results for samples made with carbon steel fibers are included for comparison. Flexural characteristics for samples removed 3 and 12 mo. of exposure are illustrated in Figure 33.

The results indicate that at $200^{\circ} \mathrm{F}$ the strength properties of the samples made with the stainless steel fibers are very similar to those measured for the samples made with the carbon steel fibers. Figure 33 illustrates that after 3 mo. of exposure the load-deflection characteristics of both systems are almost identical. After $12 \mathrm{mo}$. of exposure the FYs of the beams made with stainless steel fibers has decreased slightly and the system has become more ductile. It should be noted that after $12 \mathrm{mo}$. of exposure there was no evidence of any rust or spalling on those samples made with the stainless steel fibers. After $3 \mathrm{mo}$. of exposure, some rust stains were noted on those samples made with carbon steel fibers. However, no spalling was evident.

To further evaluate the corrosion resistance of the 430 stainless steel fibers, open-topped jars containing an equal number of carbon steel and stainless steel fibers were placed in MH15105 for a period of 11 months. The fibers are visually examined on a monthly basis to determine the extent of corrosion of each type of fiber. The carbon steel fibers began to rust within 1 mo. of being placed in test while the stainless steel fibers exhibited no evidence of rusting after 11 months of exposure (Figure 34).

Table 12. Properties of the VETrt PC system made with carbon steel and 430 stainless steel fibers.

\begin{tabular}{|c|c|c|c|c|c|c|c|c|c|}
\hline $\begin{array}{c}\text { PC } \\
\text { SYSTEM }\end{array}$ & MHNO. & $\begin{array}{c}\text { AVERAGE } \\
\text { MANHOLEAIR } \\
\text { TEMP., (dog.) }\end{array}$ & $\begin{array}{l}\text { EXPOSURE } \\
\text { TIME }\end{array}$ & $\begin{array}{l}\text { TEST } \\
\text { TEMP } \\
\text { (dog.) }\end{array}$ & $\begin{array}{c}\text { FLEXURAL } \\
\text { YELD STRENGTH. } \\
\text { p\&l }\end{array}$ & $\begin{array}{l}\text { ULTIMATE } \\
\text { FLEXURE } \\
\text { STRENGTH, psI }\end{array}$ & $\begin{array}{l}\text { SPLITING } \\
\text { TENSILE } \\
\text { STRENGTH. psi }\end{array}$ & $\frac{\text { WATERA }}{\text { IN SITU }}$ & $\frac{\text { RPTION, wT\% }}{\text { LAB TEST }}$ \\
\hline \multirow{2}{*}{$\begin{array}{c}\text { VETrt } \\
\text { w/CS Fors }\end{array}$} & Contol & -- & -- & $200 \mathrm{~F}$ & 2005 & 2580 & 1785 & -- & 0.17 \\
\hline & 15105 & $108 \mathrm{~F}$ & $\begin{array}{l}1 \mathrm{mo} . \\
3 \mathrm{mo} . \\
12 \mathrm{mo} .\end{array}$ & $\stackrel{200 F}{\bullet}$ & $\begin{array}{l}2200 \\
2300 \\
1810\end{array}$ & $\begin{array}{l}2570 \\
2650 \\
2660\end{array}$ & $\begin{array}{l}2075 \\
1800 \\
--\end{array}$ & $\begin{array}{l}0.05 \\
0.04 \\
0.08\end{array}$ & $\begin{array}{l}0.11 \\
0.11 \\
.027\end{array}$ \\
\hline \multirow{2}{*}{$\begin{array}{c}\text { VETrt } \\
\text { w/SS Fbrs }\end{array}$} & Contol & -- & -- & $200 \mathrm{~F}$ & 2180 & 2600 & -- & -- & 0.20 \\
\hline & 15105 & $106 \mathrm{~F}$ & $\begin{array}{l}1 \mathrm{mo} . \\
3 \mathrm{mo} . \\
12 \mathrm{mo} .\end{array}$ & $200 \mathrm{~F}$ & $\begin{array}{l}2210 \\
2140 \\
2330\end{array}$ & $\begin{array}{l}2750 \\
2605 \\
2770\end{array}$ & $\begin{array}{l}2070 \\
2110\end{array}$ & $\begin{array}{l}0.02 \\
0.08 \\
0.12\end{array}$ & $\begin{array}{l}0.12 \\
0.24 \\
0.11\end{array}$ \\
\hline
\end{tabular}

NOTES: All values are an average of a minimum of 3 test specimens. VETrt = vinyl oster-TMPTMA systom, cured at room tomperature conditions. w/CS fbrs = the PC system is made with carbon stool fibors. w/SS fbrs = the PC system is made with 430 stainiess stoel tibars. 


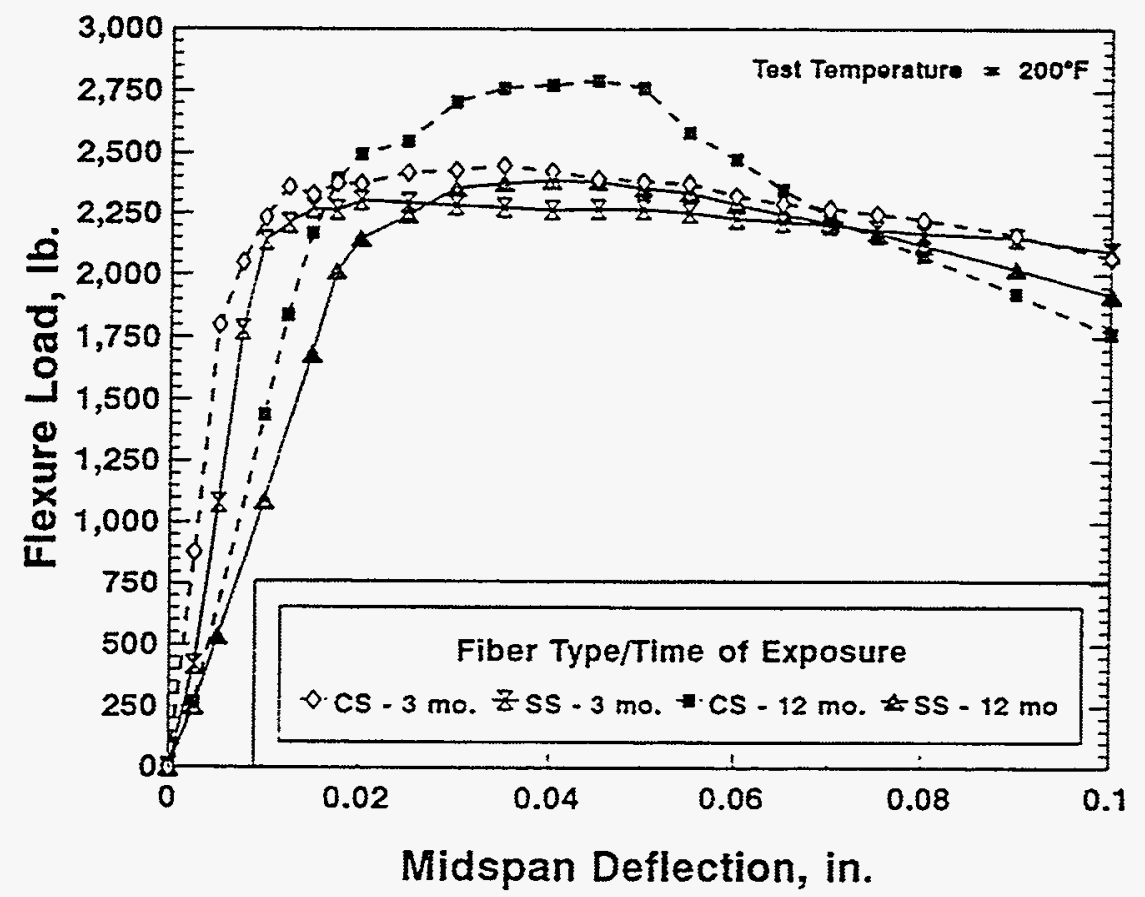

Figure 33. Load-deflection characteristics, at $200^{\circ} \mathrm{F}$, of VETrt PC beams made with carbon steel and 430 stainless steel fibers after 3 and 12 mo. exposure in MH15105.

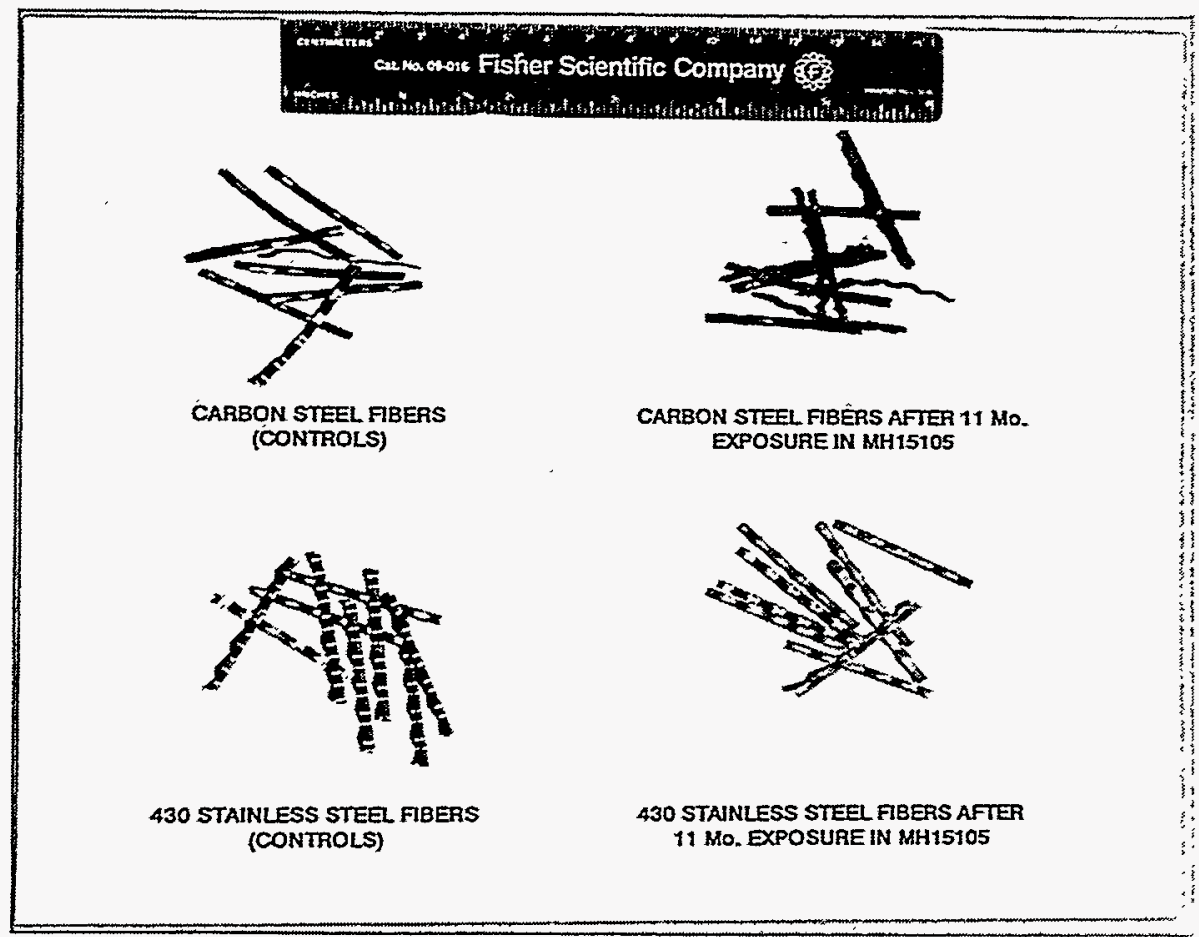

Figure 34. 430 stainless steel and carbon steel fibers after 11 mo. exposure in MH15105. 
4.4.4 In situ load testing of VETrt PC beams. In situ loaddeflection tests were done in MH15105 to evaluate the creep characteristics of the fiber-reinforced VETrt PC system. The tests were done using 2 -in. by 8 -in. by 6.25 -ft long beams (Figure 35 ) which were cast in the laboratory at room temperature conditions. The beams were not post-cured.

The beams were set up as a simply supported beams loaded with a concentrated load of $250 \mathrm{lb}$ at the midpoint of the span. This loading produced a computed maximum bending stress of 844 psi. Assuming that the maximum permitted design stress is 50 percent of the flexural yield strength (FYS $=2005 \mathrm{psi}$ at $200^{\circ} \mathrm{F}$, see Table 11), the loading produces a computed maximum bending stress which is 84 percent of the allowable design stress.

The deflection characteristics of the beams were monitored by measuring the deflection at the quarterpoints with dial gauges (Figure 36). Initial deflection data was collected when the beams were placed into test and at subsequent intervals of approximately 3 to 5 weeks.

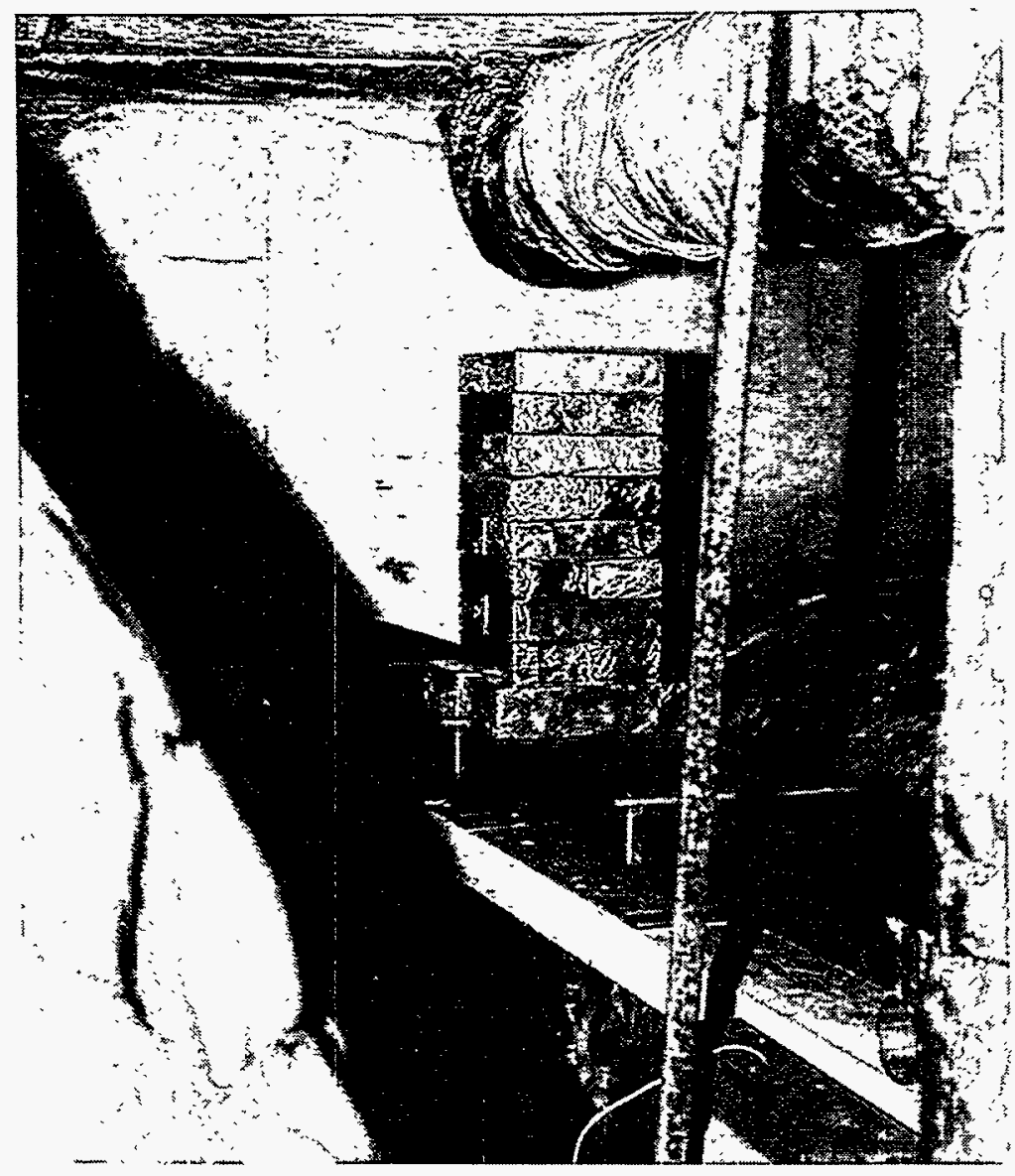

Figure 35. In situ creep test beam in place in MH15105. 


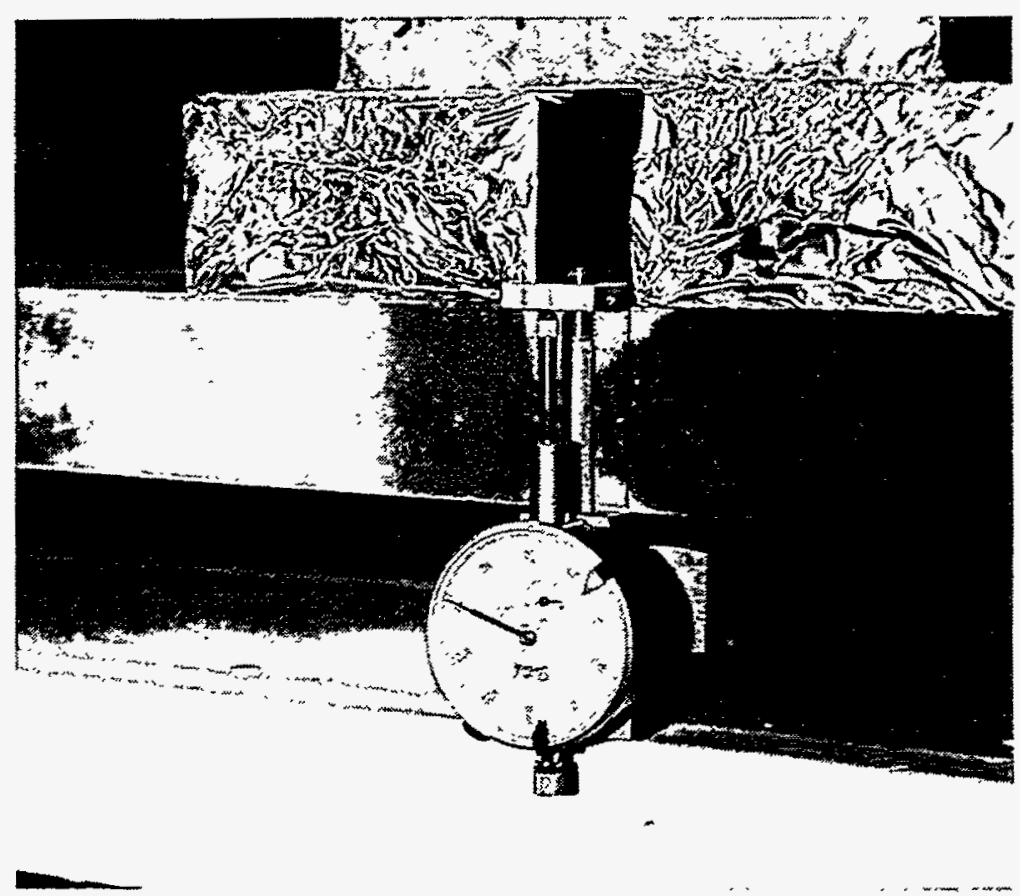

Figure 36. Dial gauge used to measure deflections.

The in situ testing of the fiber-reinforced VETrt PC beam was stopped after 54 weeks. A visual inspection of the beam, after removal from the manhole, indicated no significant deterioration of the PC. The beam had been slightly discolored while in test and some of the carbon steel fibers exposed at the surface of the beam had begun to rust. However, with the exception of one small area of approximately $1 \mathrm{sq}$ in., there was no scaling of the surface of the beam due to the rusting of the fibers.

The deflection data, which is presented in Figure 37, indicates that after 54 weeks the midspan deflection was measured to be approximately $0.748 \mathrm{in}$. The data also illustrates that the beam continued to creep throughout the duration of the test. In addition, there was a noticeable ( 7 percent) increase in deflections measured after the 24 th and 28 th weeks of the test. This large increase in deflection may, in part, have been due to the increase in the air temperature in the manhole. Over the first 17 weeks of the test the air temperature varied between $179^{\circ}$ and $192^{\circ} \mathrm{F}$ and averaged $186^{\circ} \mathrm{F}$. over the last 30 weeks the air temperature varied between $200^{\circ}$ and $208^{\circ} \mathrm{F}$ and averaged $204^{\circ} \mathrm{F}$. This represents an increase in the average air temperature of the manhole of 10 percent. It should also be noted that the rate of creep, before and after the increase in the manhole air temperature, remained relatively constant at approximately 0.010 in./wk. 


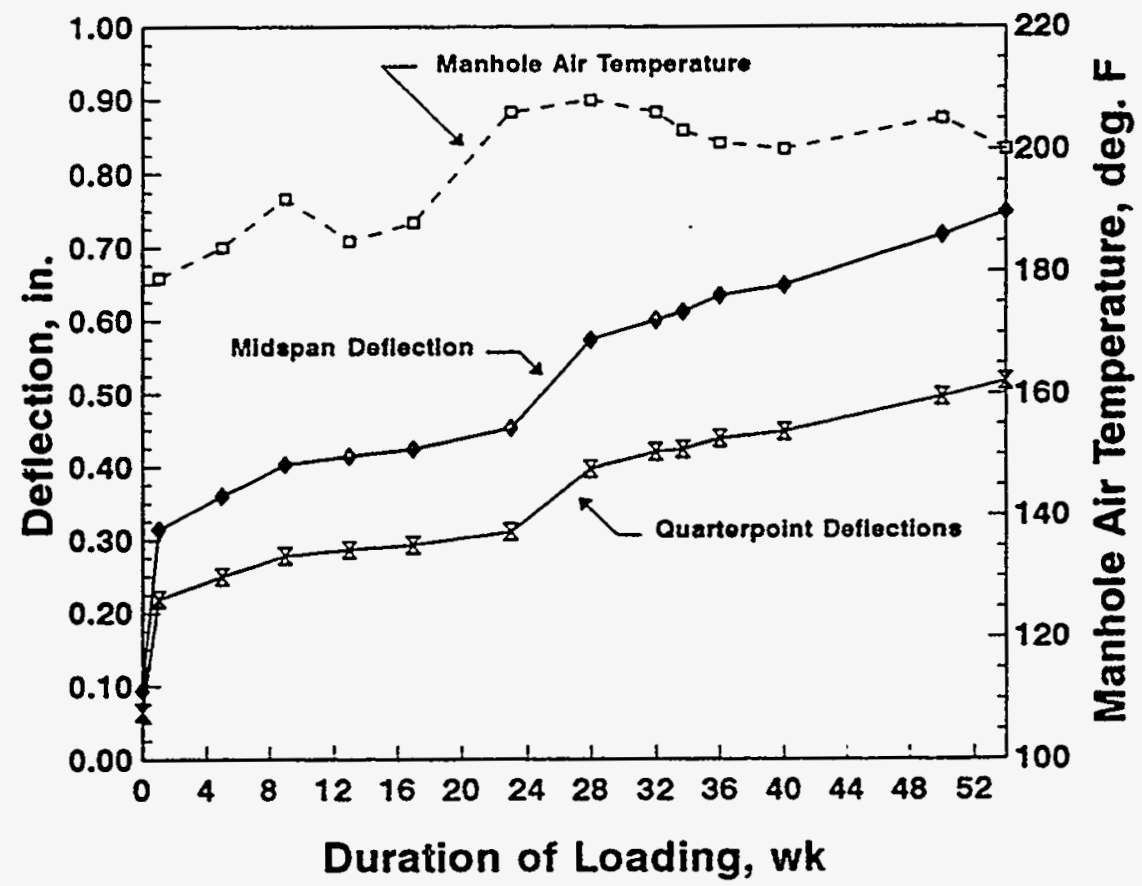

Figure 37. In situ creep test results for the fiber-reinforced VETrt PC beam tested in MH15105.

Based upon these results, it was hypothesized that conventional steel reinforcing bars (rebars) could be used to help control the creep being exhibited by the VETrt PC system. To verify this hypothesis, a fiber-reinforced VETrt PC beam containing steel rebars was placed in test in MH15105 for a period of approximately 21 weeks.

The dimensions of the new beam placed into test were identical to those of the beam which had been removed from the manhole, i.e. 2 in. thick by 8 in. wide by $6.25 \mathrm{ft}$ long. The beam was analyzed using a working stress analysis to determine the amount of reinforcing required to support a concentrated load of 250 lb located at the midpoint of the span. Based on this analysis three No. 3 reinforcing bars were placed on 2 in. centers at a distance of $1.25 \mathrm{in}$. from the top of the beam.

The test results, which are illustrated in Figure 38 , indicate that the rebar did not reduce the deflections exhibited by the VETrt PC system nor did it reduce the rate of creep. In fact the deflections measured for the beam containing the rebar (Beam No. 2046) were greater than those measured for the beam which had no rebar (Beam No. 1573) and the rate of creep measured for Beam No. 2046 was almost identical to that measured for Beam No. 1573 . 


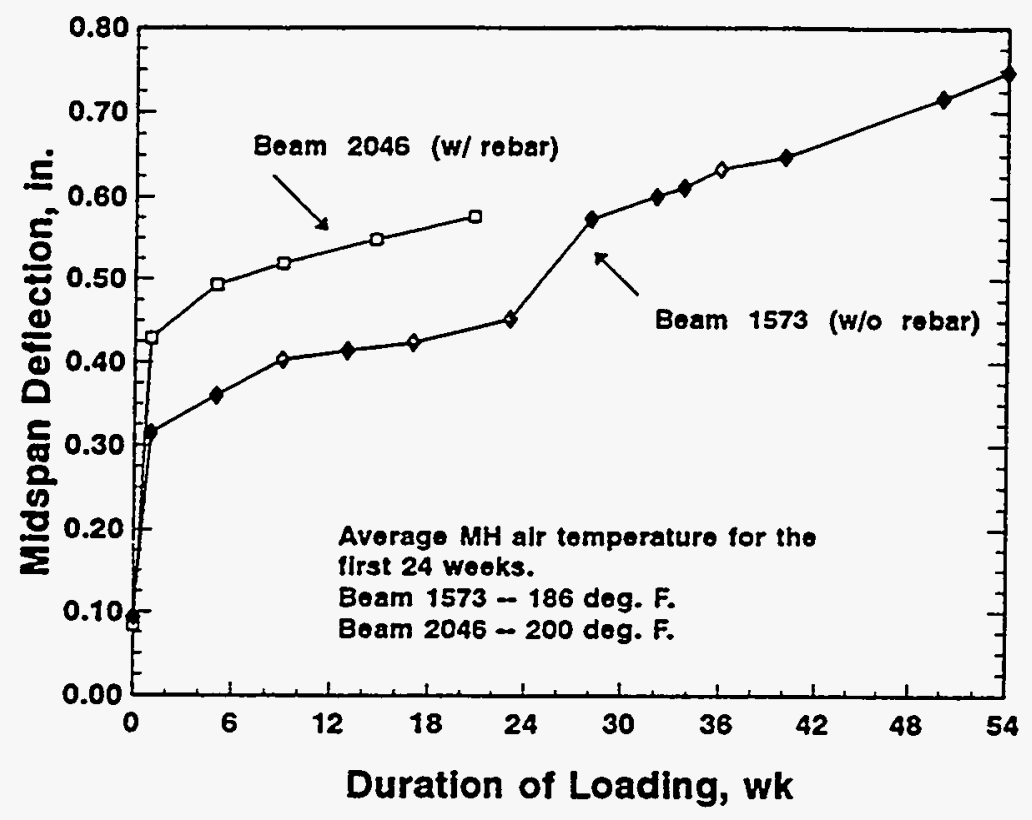

Figure 38. In situ creep test results for VETrt PC beams made with and without conventional reinforcing steel.

An explanation for the increased deflections exhibited by Beam No. 2046 was not readily apparent. With one exception, the conditions under which the two beams were tested were identical. The only difference between the two tests being that the ambient air temperature in MH15105 was on average 14 degrees higher during the time that Beam No. 2046 was in test. While this may have accounted for some of the increase noted in the deflections it is unlikely that it was the sole cause for the increase. It was therefore decided that tests would be done under controlled, laboratory conditions to evaluate the creep characteristics of fiber-reinforced VETrt PC beams made with and without steel rebar.

The laboratory creep tests were done in a walk-in oven using two 2 -in. thick by 8 -in. wide by $6.25-\mathrm{ft}$. long beams made with the fiber-reinforced VETrt PC system. One of the beams contained three No. 3 bars placed $2-$ in. on center at a distance of $1.25-$ in. from the top surface of the beam. These beams were identical to those tested in situ in MH15105.

As in the field, the beams were set up as simply supported beams with a concentrated load of 250 lb located at the midpoint of the span, Figure 39. This loading produced a computed maximum bending stress of approximately $844 \mathrm{psi}$. The deflection 


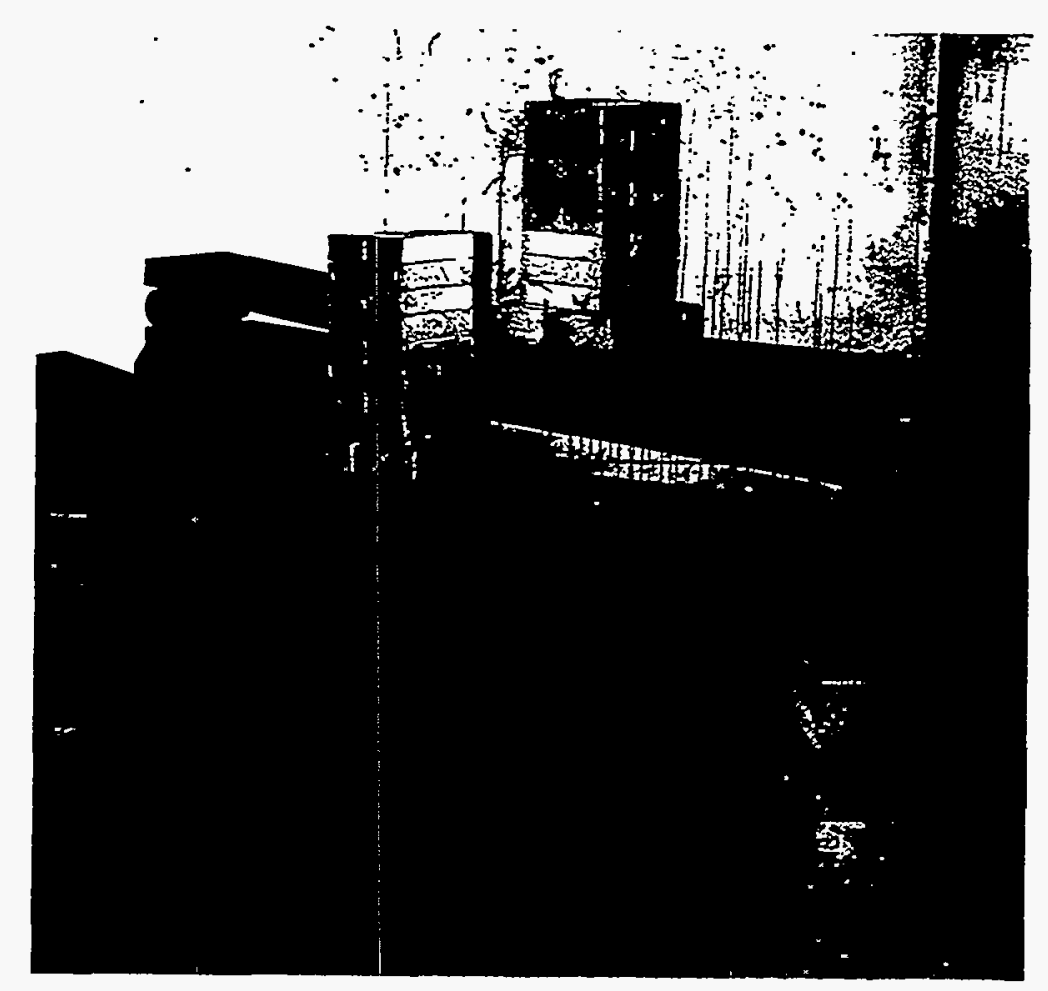

Figure 39. Set-up for the laboratory-scale creep tests, with Beam No. 2036 in the foreground and Beam No. 2037 in the back right.

characteristics of the beams were monitored by measuring the deflections at the quarterpoints and midpoint of the span.

Prior to loading, the beams were subjected to a range of temperatures intended to simulate the conditions which are likely to exist in the field during placement of a typical PC manhole. The beams, which were cast at room temperature conditions (i.e. $75^{\circ} \mathrm{F}$ ), were first heated for 4 days at $145^{\circ} \mathrm{F}$ to simulate the temperature within the manhole during placement of the PC. This segment of the preheating cycle was to have been run at $120^{\circ} \mathrm{F}$ but problems with the oven's control panel resulted in the beams being heated to $145^{\circ} \mathrm{F}$. The beams were then heated for 2 days at $208^{\circ} \mathrm{F}$ to simulate the temperature conditions within an enclosed manhole which has been placed in service but has not yet been loaded, i.e. soil and pavement loads have not been applied to the roof of the manhole. The beams were then loaded.

The beams were load tested for a period of $8 \mathrm{wk}$. With the exception of a 3 day period during the third week, the beams were tested for $7 \mathrm{wk}$ at an average temperature of approximately $218^{\circ} \mathrm{F}$. (It was necessary to shut down the oven for 3 days during the test. 
The loads were left in place during the shutdown and the temperature averaged $78^{\circ} \mathrm{F}$.) After $7 \mathrm{wk}$, the test temperature was raised to $400^{\circ} \mathrm{F}$, to simulate the temperature conditions within a manhole during a large steam leak. The temperature was maintained at $400^{\circ} \mathrm{F}$ for $48 \mathrm{hr}$, afterwhich it was returned to $218^{\circ} \mathrm{F}$ and the tests were stopped. The deflection measurements obtained for each beam are graphically summarized in Figures 40 and 41 .

Figure 40 illustrates that, as in the field tests, the deflections exhibited by the beam containing the rebar (Beam No. 2037) are greater than those exhibited by the beam without the rebar (Beam No. 2036). After 7 wk the midpoint deflection for Beam No. 2037 was measured to be 0.294 in. This is approximately 25 percent greater than that measured for Beam No. 2036.

A comparison of the deflections measured for the in situ and laboratory test beams, after 1 wk in test, indicate that if the PC is allowed to post-cure in situ prior to being loaded, the deflection of the system can be reduced. After 1 wk, the deflections measured for the beams being tested in the laboratory were significantly less than those measured for the beams tested in situ. The midspan deflection of Beam No. 2037 is 45 percent less than that measured for Beam No. 2046. The beams tested in situ were cast at room temperature conditions but were not "heat treated" prior to being loaded.

Figure 41 illustrates the affects of increasing the ambient temperature, from $200^{\circ}$ to $400^{\circ} \mathrm{F}$, on the load-deflection behavior of the beams. In general, both beams failed, refer to Figure 39 . Beam No. 2036 failed catastrophically, i.e. it collapsed, while Beam No. 2037 was able to continue to support the applied load. However, the midspan deflection of Beam No. 2037 increased from 0.294 in., when measured at $200^{\circ} \mathrm{F}$, to 1.254 in., when measured at $400^{\circ} \mathrm{F}$. In addition, an examination of Beam No. 2037 indicated that there were numerous cracks in the tension face of the beam and that these cracks extended atleast halfway into the thickness of the beam. Deflection measurements made after the beam had been unloaded and allowed to cool to room temperature indicated the beam rebounded about 10 percent.

Results of tests done to determine the flexural properties of VETrt PC beams which had been placed in test in MH15105 indicated that the creep test beams might possibly fail under the imposed loading when the temperature was increased to $400^{\circ} \mathrm{F}$, see Figure 42 . The figure illustrates that the ultimate flexure strength of the VETrt.PC system increased from 850 to 940 psi after 3 mo. of exposure in MH15105. However, these strength values were very close to the calculated stress of $844 \mathrm{psi}$ imposed by the test load. Obviously there was not enough reserve strength in the PC system to prevent it from failing when the ambient temperature was raised to $400^{\circ} \mathrm{F}$. 


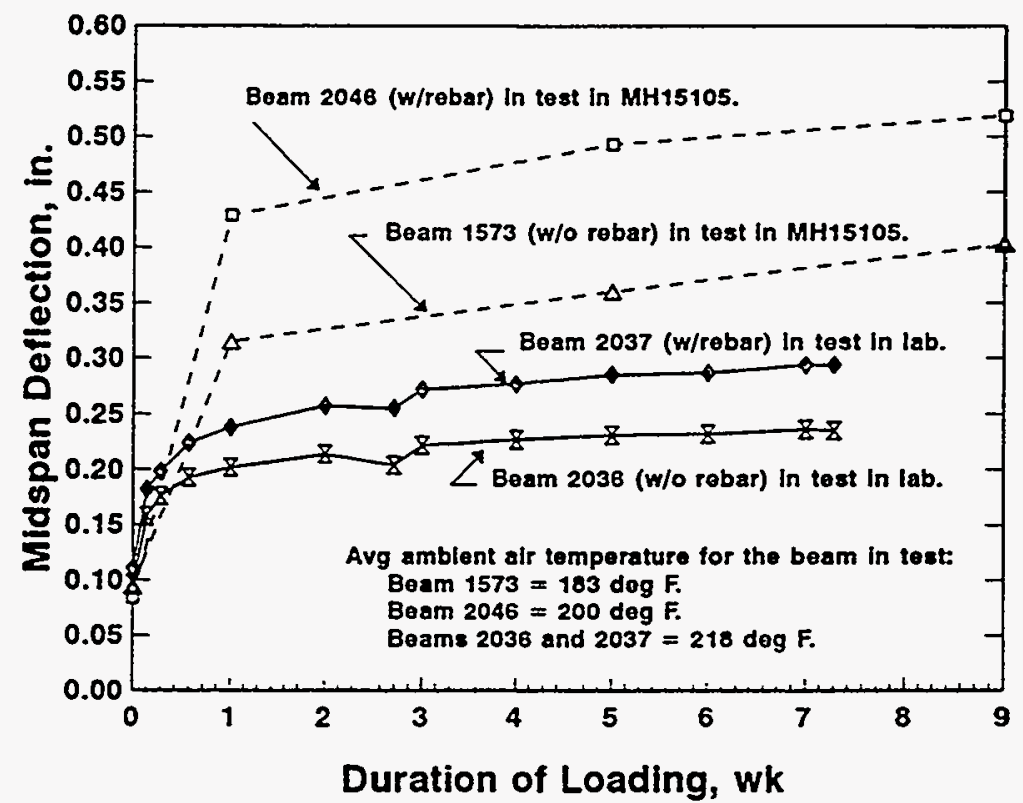

Figure 40. Laboratory and in situ creep test results for VETrt PC beams made with and without conventional steel reinforcing bars.

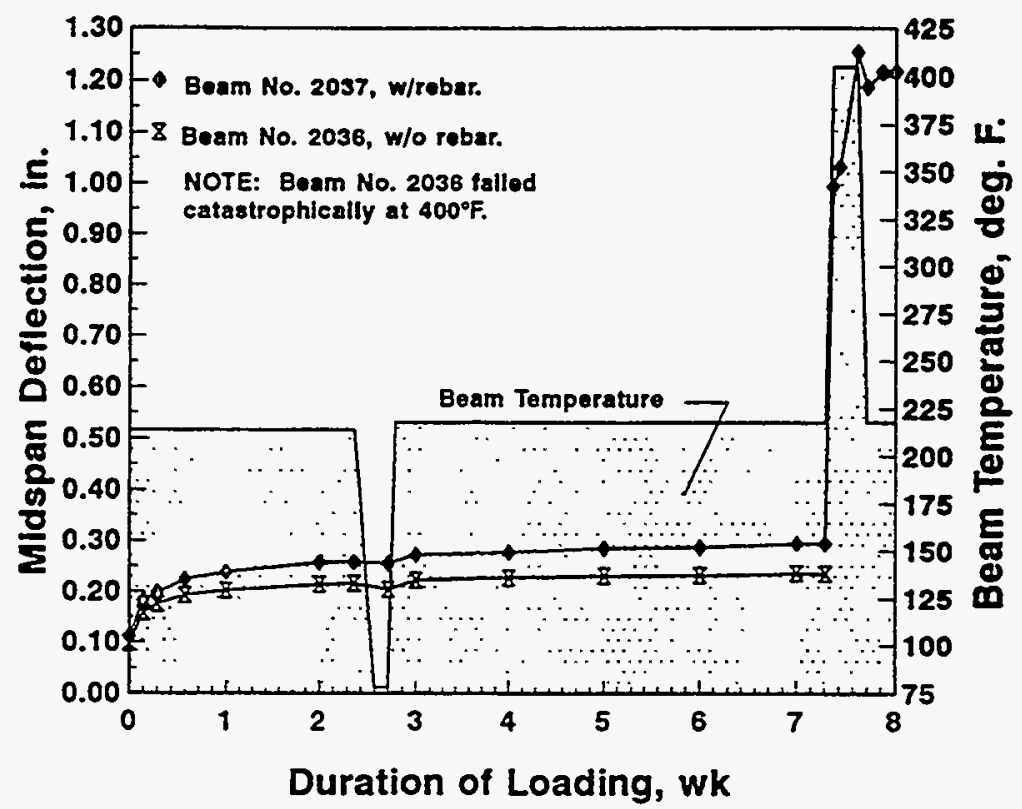

Figure 41. Load vs. deflection characteristics, measured at $200^{\circ}$ and $400^{\circ} \mathrm{F}$, for VETrt PC beams made with and without conventional steel reinforcing bars. 


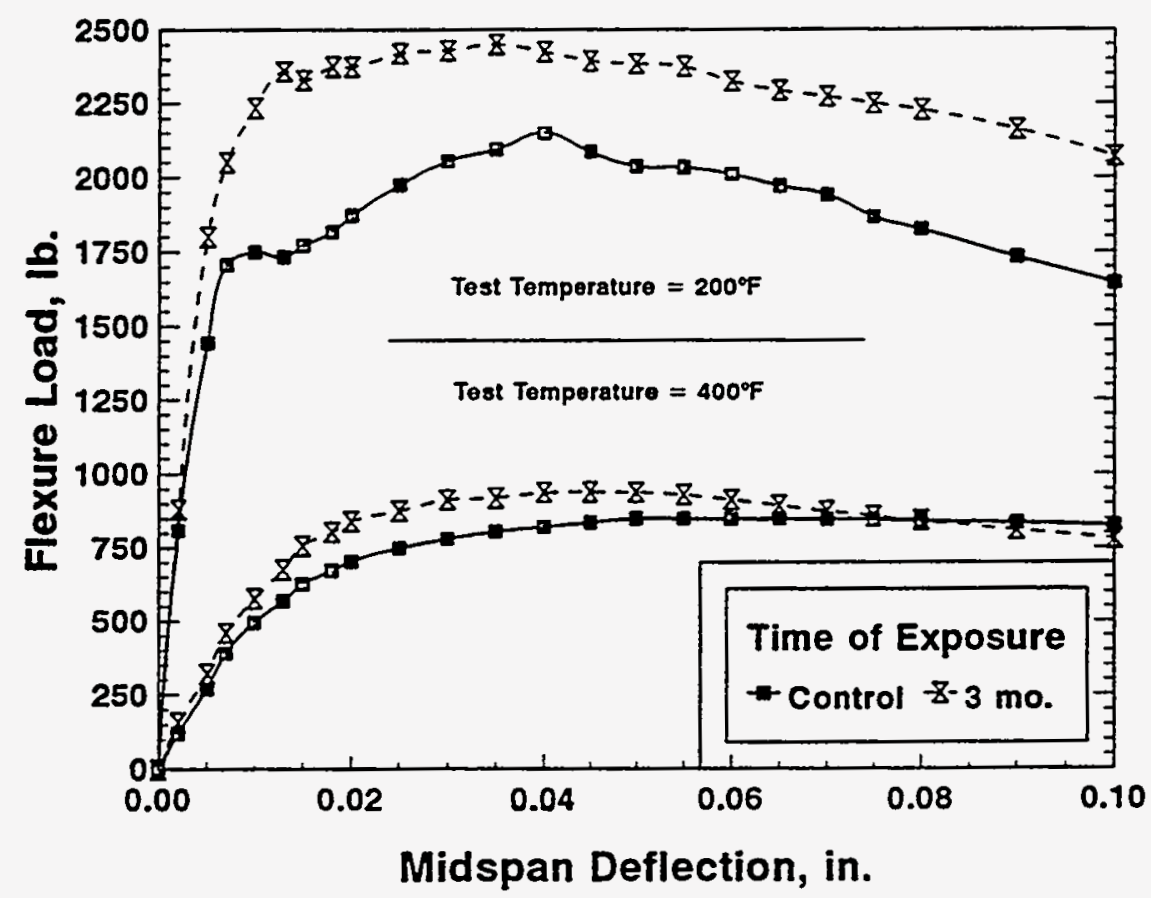

Figure 42. Variation of flexure load vs deflection characteristics, at $200^{\circ}$ and $400^{\circ} \mathrm{F}$, for the VETrt PC system after 3 mo. in MH15105.

4.4.5 Effects of field exposure on the properties of portland cement concrete systems. In situ testing of conventional portland cement concrete (PCC) was done using non-reinforced and fiberreinforced PCC. The tests were done using 3-in. diameter by $6-i n$. long cylinders and 2- by 2- by 12-in. long beams. All samples were cast and stored at room temperature until they were placed into test seven to ten days after being cast. Table 12 summarizes the mix designs.

The tests were done in MH15105 and the results are presented in Table 13. The effect of elevated temperatures on the compressive strength is illustrated by comparing the 28-day compressive strength values measured for each mix at $72^{\circ}$ and $200^{\circ} \mathrm{F}$. Both mixes show a significant decrease in compressive strength as a result of being tested at an elevated temperature. The compressive strength of the non-reinforced PCC decreased from 4,045 to 2,030 psi and the compressive strength of the fiber-reinforced PCC decreased from 4,670 to 2,830 psi.

In general, all samples removed from test appeared to be in good condition with no visible deterioration. Compressive and flexure strength values for both PCC systems, measured at $200^{\circ} \mathrm{F}$, 
Table 12. Portland cement concrete (PCC) mix designs.

A. Non-reinforced PCC.

Mix Component
Type I portland cement
$3 / 8-$ in. crushed gravel
Blended silica sand
Mix water
Air entraining agent

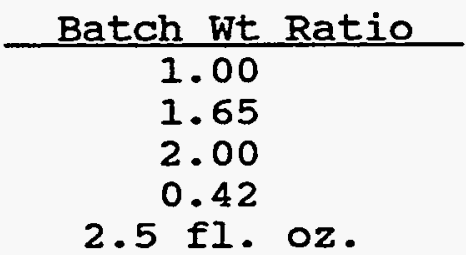

Slump $\approx 2.5 \mathrm{in.}$ Entrained air content $\approx 6$ percent.

B. Fiber-reinforced PCC.

Mix Component

Type I portland cement

3/8-in. crushed gravel

Blended silica sand

Mix water

1.5-in. steel fibers

Air entraining agent

\begin{tabular}{c} 
Batch Wt Ratio \\
\hline 1.00 \\
2.50 \\
1.50 \\
0.43 \\
0.092
\end{tabular}

2.5 fl. Oz

increased after 3 mo. of exposure. Changes in the sample weight and water absorption characteristics of both mixes also were noted. of particular interest is the data regarding weight change. Both PCC systems exhibited reductions in weight. The weight loss is most likely due to a loss of moisture from the samples, not from any physical deterioration. The continued loss of moisture from the samples may, at some point, adversely affect the strength development of the systems by reducing the rate at which the cement in the matrix hydrates.

Con Ed indicated to BNL, after the start of the tests, that it would have been more representative of actual field placement conditions if the PCC samples had been cast and cured at an ambient temperature of $100^{\circ}$ to $125^{\circ} \mathrm{F}$. In general, this is the temperature range at which the concrete for a steam-valve manhole is normally placed. Subsequently, a second group of fiber-reinforced PCC cylinders and beams were cast and put into test in MH15105.

The samples were cast under three different sets of conditions to determine the effect of placement conditions on the strength properties of PCC. One series of beams and cylinders were cast at room temperature and moist cured in the molds for seven days. They were then demolded and stored at room temperature until tested. The second series of samples were cast at an ambient temperature of $110^{\circ} \mathrm{F}$ and cured in the molds at this temperature for 24 hours. The 
Table 13. In Situ test results for non-reinforced and fiber-reinforced portland cement concrete.

\begin{tabular}{|c|c|c|}
\hline Property & $\begin{array}{c}\text { Non-Reinforced } \\
\text { Concrete }\end{array}$ & $\begin{array}{c}\text { Fiber-Reinforced } \\
\text { Concrete }\end{array}$ \\
\hline $\begin{array}{l}\text { Compressive strength, psi } \\
\text { Initial } 28-\text { Day strength } \\
\text { at } 72^{\circ} \mathrm{F} \\
\text { at } 200^{\circ} \mathrm{F} \\
\text { After } 1 \text { mo. Exposure } \\
\text { at } 200^{\circ} \mathrm{F} \\
\text { After } 3 \text { mo. Exposure } \\
\text { at } 200^{\circ} \mathrm{F}\end{array}$ & $\begin{array}{l}4,045 \\
2,030 \\
3,385 \\
3,510\end{array}$ & $\begin{array}{l}4,670 \\
2,830 \\
3,850 \\
4,155\end{array}$ \\
\hline $\begin{array}{l}\text { Flexure strength, psi } \\
\text { Initial } 28-\text { Day Strength } \\
\text { at } 200^{\circ} \mathrm{F} \\
\text { After } 1 \text { mo. Exposure } \\
\text { at } 200^{\circ} \mathrm{F} \\
\text { After } 2 \text { mo. Exposure } \\
\text { at } 200^{\circ} \mathrm{F} \\
\text { After } 3 \text { mo. Exposure } \\
\text { at } 200^{\circ} \mathrm{F}\end{array}$ & $\begin{array}{l}715 \\
670 \\
828 \\
765\end{array}$ & $\begin{array}{l}730 \\
730 \\
--- \\
815\end{array}$ \\
\hline $\begin{array}{l}\text { Water Absorption, wto } \\
\text { Initial } 28 \text {-Day Samples } \\
\text { After } 1 \text { mo. Exposure } \\
\text { After } 2 \text { mo. Exposure } \\
\text { After } 3 \text { mo. Exposure }\end{array}$ & $\begin{array}{l}6.13 \\
6.10 \\
6.27 \\
6.55\end{array}$ & $\begin{array}{l}7.17 \\
7.61 \\
-- \\
6.75\end{array}$ \\
\hline $\begin{array}{l}\text { Weight Change, wto } \\
\text { After } 1 \text { mo. Exposure } \\
\text { After } 2 \text { mo. Exposure } \\
\text { After } 3 \text { mo. Exposure }\end{array}$ & $\begin{array}{l}-3.95 \\
-3.10 \\
-3.60\end{array}$ & $\begin{array}{c}-3.91 \\
- \\
-2.94\end{array}$ \\
\hline
\end{tabular}

samples were then demolded and stored in a laboratory oven at $190^{\circ} \mathrm{F}$ until tested. The third series of samples also were cast at an ambient temperature of $110^{\circ} \mathrm{F}$ and cured in the molds at this temperature for 24 hours. The samples were then demolded and placed into test in MH15105, the average ambient temperature of which was approximately $190^{\circ} \mathrm{F}$. The results of the tests done to evaluate the properties of this group of samples is summarized in Table 14.

This data shows that the strength properties of the concrete cast and cured at elevated temperatures are significantly less than that of the concrete cast and moist cured at room temperature. When tested at $200^{\circ} \mathrm{F}$, there was an average reduction in compressive 
strength of 36 percent for the samples cast and cured at the elevated temperatures as compared to the samples cured at room temperature. Reductions in flexure strength values were also noted.

Table 14. Strength properties of fiber-reinforced PCC cast and cured at elevated temperatures.

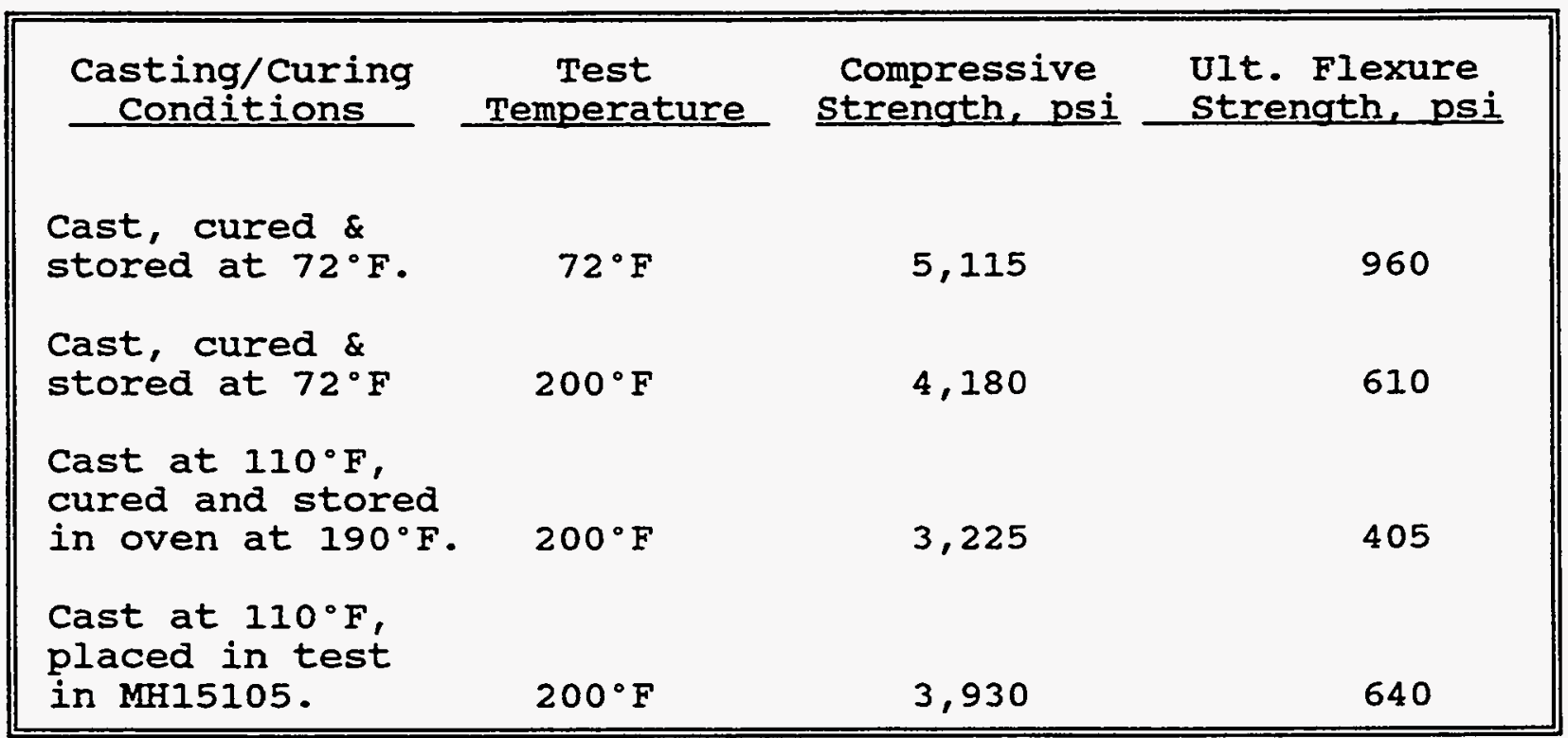

Note: All strength data are 32 -day strengths. 


\subsection{PREIIMINARY DESIGN OF A MANEOLE MADE FITH FIBER-REINFORCED POLYMER CONCRETE}

\subsection{Introduction.}

A design study was made to replace a typical reinforced portland cement concrete manhole with a cast-in-place, fiberreinforced polymer concrete (FPC) manhole.

The procedure used for the design was to consider the manhole as a series of plates: roof, sidewall, and foundation slab. Each plate was subjected to loads resulting from soil pressure, highway loading, and dead weight and was analyzed using classical plate theory. A similar design approach was used by BNI in the design and development of precast FPC natural gas vaults ${ }^{[6]}$.

This chapter discusses the loadings, material properties, and stress evaluations used in the design of manholes for the Con Ed steam distribution system.

\subsection{Loading conditions.} components:

The loading acting on the manhole shall contain three

(1) The dead weight of the manhole.

(2) The effect of soil pressure on the manhole (unless a specified value is available use $110 \mathrm{lb} / \mathrm{cu} \mathrm{ft}$ ).

(3) A live load component that shall be taken as one of the following (Note: the design criteria for a particular application should specify which of these is to be considered) :

(a) A uniform vertical load of $600 \mathrm{psf}$ (such as required by the NYC building code).

(b) The HS-20 AASHTO loading, which consists of the more severe of a uniform lane load of $640 \mathrm{lb} / \mathrm{ft}$

distributed over a $10 \mathrm{ft}$ lane width, or two concentrated wheel loads of $20,800 \mathrm{lb}$ each a 30 percent impact factor) spaced at

(c) A 15 cubic yard concrete truck; the rear wheels of this truck produce four loads of 20,250 lb spaced at direction.

$5 \mathrm{ft}$ in one direction and $6 \mathrm{ft}$ in the other

The forces acting on each element of the box by these loadings are discussed below. 
5.2.1 Forces on the roof. The roof will be loaded with the dead weight of the roof slab plus any soil overburden placed as a uniform load on the cover plate. Because the roof will generally be close to the surface (the roof is usually about one foot below the ground surface), the highway loading is placed directly on the roof. The roof should be designed for either a uniform live load of 600 psf or a single wheel load of 20,800 lb placed at the center of the roof. For manholes that have plan dimensions greater than $10 \mathrm{ft}$, consideration should be given to placing the two or four wheel loads (depending on whether the box is designed for HS-20 or the $15 \mathrm{cu}$ yd concrete truck) on the roof in a position leading to the highest bending moments.

5.2.2 Forces on the sidewal1s. The loading on the sidewalls, which are in contact with the soil, is taken as the soil pressure (resulting from soil weight and highway loading) component that is normal to the surface of the plate (i.e., the loading on the vertical plates is equal to the horizontal soil pressure at the depth of interest). In all cases, the horizontal soil pressure is taken as one-half of the vertical pressure. While the actual loading on the wall will vary over the depth of the wall, it is recommended that the wall be designed for a uniform pressure equal to the average loading applied to the wall.

The loading component of the soil pressure due to its own weight $\left(p_{s}\right)$ is:

$$
P_{s}=\gamma z / 2
$$

where, $\gamma=$ soil density, $1 \mathrm{~b} / \mathrm{cu} \mathrm{ft}$

$z=$ depth below the surface, ft

$\mathrm{P}_{\mathrm{s}}=$ pressure, psf

The loading component for the $15 \mathrm{cu} \mathrm{yd}$ concrete truck is computed by converting the four wheel loads to a uniform loading over an area of $5 \mathrm{ft}$ by $6 \mathrm{ft}$, and spreading the load by 45 degrees as depth from the surface increases. The pressure acting on the sidewall is one-half of the vertical component of the soil pressure. Therefore, the pressure acting on the sidewall is:

$$
p_{c t}=81,000 /[(2)(5+2 z)(6+2 z)]
$$

(Eq. 2)

The loading component for the HS-20 loading will be critical for the two wheel loads. The loading is taken to act on an area of $6 \mathrm{ft}$ by $1 \mathrm{ft}$ on the surface and to spread out at a 45 degree angle with depth. Therefore, the pressure acting on the sidewall is:

$$
\mathrm{p}_{\mathrm{HS}}=20,800 /[(2)(6+2 z)(1+2 z)] \quad \text { (Eq. 3) }
$$

The uniform pressure of 600 psf is not attenuated with depth so that the resulting load on the sidewall is: 


$$
p_{\text {HYC }}=600 / 2=300 \text { psf }
$$

This pressure must be less than the allowable soil bearing pressure. If it is not, the plan dimensions of the manhole must be increased.

The actual loading on the sidewall will vary linearly over the depth of the wall. An average uniform loading will be used so that the design process may be expedited. Any errors which may result are well within the reliability within which the loads are known.

5.2.3 Forces on the foundation slab. The forces on the foundation slab shall be taken as a uniform pressure equal to the weight of the manhole plus the weight of the soil over the roof plus the total highway load acting on the roof divided by the area of the slab. Therefore,

$$
\mathrm{p}_{\mathrm{FS}}=\gamma \mathrm{h}+\left(\mathrm{W}_{\mathrm{B}}+\mathrm{W}_{\mathrm{H}}\right) / \mathrm{A} \text { (Eq. 5) }
$$

where, $h=$ depth of the soil over the roof, ft

$W_{B}=$ weight of the manhole, $1 \mathrm{~b}$

$\mathrm{W}_{\mathrm{H}}=81,000 \mathrm{lb}$ for the concrete truck

$=41,60016$ for the HS-20 loading

$=600$ psf $\times A$ for the NYC building code

$A=$ plan area of the foundation slab, sq ft

$\gamma=$ soil density of $110 \mathrm{lb} / \mathrm{cu} \mathrm{ft}$

\subsection{Material Properties.}

The properties of FPC can be adjusted by the proper selection of resin type, resin content, and fiber characteristics. The most significant properties of the FPC that are used for design are the flexure strength of the $\mathrm{mix}$ and the ductility of the material when subjected to flexural loads. The flexure strength should be determined by a modulus of rupture test. The test should be continued to failure and the flexural yield strength $\left(f_{R}\right)$ should be determined as the stress corresponding to the load at the end of the linear portion of the load vs. deflection curve. The design is based on an allowable flexural stress of $f_{R} / 2$. The material used to construct the manholes should have sufficient ductility such that the area under the load vs. deflection curve between the end of the linear portion of the curve (the point defining $f_{R}$ ) and the failure load be at least ten times the area under the linear portion of the curve.

other strength properties of interest include the shear strength of the material $\left(v_{F}\right)$ and the modulus of elasticity (E). The modulus of elasticity can be found from the modulus of rupture test used to determine $f_{R}$. 
A punching shear test should be run to evaluate the shear strength. The allowable shear stress in the manhole should be limited to $v_{F} / 3$.

FPC composite materials have a density of $\approx 150 \mathrm{lb} / \mathrm{cu} \mathrm{ft}$.

\subsection{Stress Evaluations.}

The manhole consists of six plate elements. Classical plate theory was used to evaluate the bending stresses. The loading on the sidewalls and foundation slab will be uniform as discussed in Sections 5.2.2 and 5.2.3. The loading on the roof may be either uniform or a point load at the center of the plate as discussed in Section 5.2 .1 .

Because the manholes are cast monolithically (or in some cases sections of the manholes are connected with joints having strengths equivalent to a monolithic pour), it is recommended that the boundary conditions of adjoining plates be taken as fixed. Therefore, all foundation slabs can be designed as having fixed boundary conditions. Sidewalls will have three sides fixed and the edge adjoining the roof will be fixed, if a FPC roof is adequately joined to the sidewall, and free, if not. The roof will be fixed if the sidewall-cover joint is adequate. If not, the edges of the cover will be simply supported. szilard [7].

Solutions for these load cases are given in tabular form by

\subsection{Preliminary Design Calculations.}

5.5.1 Design assumptions. The following assumptions have been used for the design:

(1) The design includes the effect of temperature on material properties but does not include thermal expansion loads acting on the manhole. The thickness of the sidewalls are likely to increase by as much as 50 percent if the expansion loads are to be resisted by these walls.

(2) The primary load on the manhole is that arising from a 15 cu yd concrete truck placed near the manhole.

(3) The top of the manhole is placed with $1 \mathrm{ft}$ of soil on the roof.

(4) The ductility of the material is assumed to satisfy the requirements discussed in section 5.3, i.e. the total area under the load vs. deflection curve be at least ten times the area under the curve up to the point used to define the flexural yield strength (end of the Iinear portion of the load-deflection curve). 
5.5.2 Preliminary design. Preliminary designs were developed for a manhole to be constructed using each of the three PC systems under evaluation, i.e. the VET system, the ST system, and the PF system.

Two design temperatures were considered, $285^{\circ}$ and $400^{\circ} \mathrm{F}$. As stated in Section 5.3, the design of the manhole will be governed by the flexural properties of each system. Table 15 summarizes the typical properties of each PC system at $285^{\circ}$ and $400^{\circ} \mathrm{F}$.

The flexural yield strength of each system at $285^{\circ}$ and $400^{\circ} \mathrm{F}$ is as follows:

\begin{tabular}{|ccc|}
\hline & & \multicolumn{2}{c|}{ Flexural Yield } & Strength, psi \\
\cline { 3 - 4 } FPC System & $285^{\circ} \mathrm{F}$ & $400^{\circ} \mathrm{F}$ \\
\cline { 3 - 4 } VET & 2070 & 1440 \\
ST & 1625 & 930 \\
PF & 1620 & 1390 \\
\hline
\end{tabular}

One half of each of these values was used for design purposes.

The dimensions of the manhole are assumed to be 10 by $12 \mathrm{ft}$ in plan and $8 \mathrm{ft}$ high (Figure 43). The design follows the procedures outlined in Section 5.2 .

Table 15. Typical properties of the candidate PC systems at $285^{\circ}$ and $400^{\circ} \mathrm{F}$.

\begin{tabular}{|c|c|c|c|c|c|}
\hline PC SYSTEM & $\begin{array}{c}\text { FLEXURAL } \\
\text { YIELD } \\
\text { STRENGTH, psi }\end{array}$ & $\begin{array}{l}\text { FLEXURAL } \\
\text { MODULUS of } \\
\text { ELASTICITY, psi }\end{array}$ & $\begin{array}{l}\text { SPLITING } \\
\text { TENSILE } \\
\text { STRENGTH, psi }\end{array}$ & $\begin{array}{l}\text { COEFFICIENT } \\
\text { of THERMAL } \\
\text { EXPANSION, } \\
\text { in./in./deg F }\end{array}$ & $\begin{array}{l}\text { COEFFICIENT } \\
\text { of THERMAL } \\
\text { CONDUCTIVITY, } \\
\text { BTU/hr/ft/deg F }\end{array}$ \\
\hline $\begin{array}{l}\text { VET } \\
@ 285 \text { deg F } \\
@ 400 \text { deg F }\end{array}$ & $\begin{array}{l}2070 \\
1440\end{array}$ & $\begin{array}{l}2.09 \times E+6 \\
0.88 \times E+6\end{array}$ & $\begin{array}{l}1900 \\
1385\end{array}$ & $\begin{array}{r}9.3 \times E-6 \\
10.2 \times E-6\end{array}$ & $\begin{array}{l}1.79 \\
1.70\end{array}$ \\
\hline $\begin{array}{l}\text { ST } \\
@ 285 \mathrm{deg} F \\
@ 400 \mathrm{deg} F\end{array}$ & $\begin{array}{r}1625 \\
930\end{array}$ & $\begin{array}{l}1.54 \times E+6 \\
0.64 \times E+6\end{array}$ & $\begin{array}{l}1495 \\
965\end{array}$ & $\begin{array}{l}9.7 \times E-6 \\
9.3 \times E-6\end{array}$ & $\begin{array}{l}1.75 \\
1.55\end{array}$ \\
\hline $\begin{array}{l}\text { PF } \\
@ 285 \mathrm{deg} F \\
@ 400 \mathrm{deg} F\end{array}$ & $\begin{array}{l}1620 \\
1390\end{array}$ & $\begin{array}{l}1.45 \times E+6 \\
1.19 \times E+6\end{array}$ & $\begin{array}{l}1630 \\
1505\end{array}$ & $\begin{array}{l}8.2 \times E-6 \\
7.2 \times E-6\end{array}$ & $\begin{array}{l}1.42 \\
1.42\end{array}$ \\
\hline
\end{tabular}



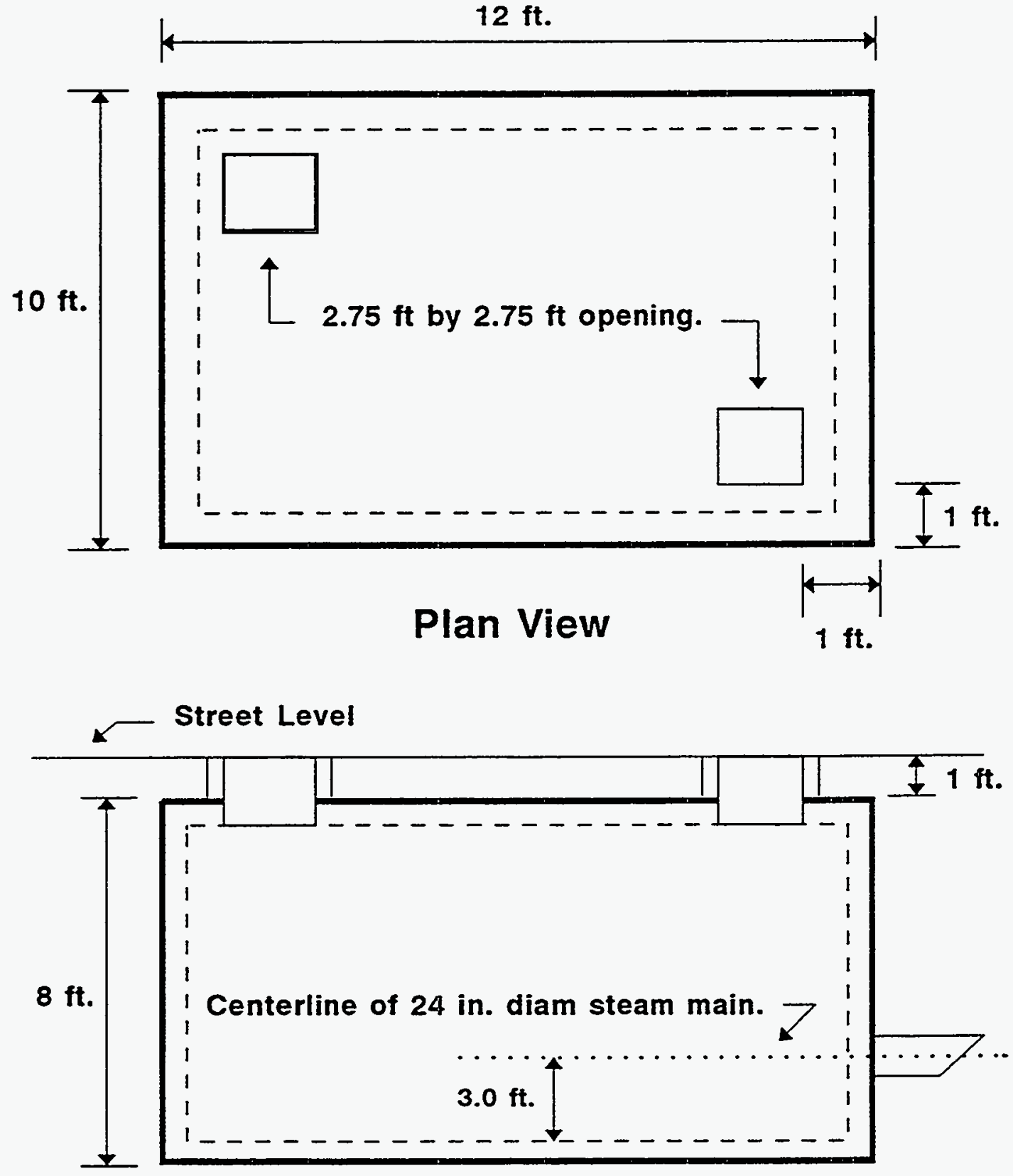

\section{Elevation}

NOTE: Drawing not to scale.

Figure 43. Layout of a typical Con Ed steam-valve manhole. 


\subsubsection{Sidewall design.}

The load on the 8 by $12 \mathrm{ft}$ sidewall consists of the soil pressure (Eq. 1) and the concrete truck (Eq. 2). The resulting pressures to the top of the wall $(z=1 \mathrm{ft})$, the bottom of the wall $(z=9 \mathrm{ft})$, and the average are as given below.

Load on the sidewall.

\begin{tabular}{|crcc||}
\hline & \multicolumn{3}{c|}{ Pressure, psf } \\
\cline { 2 - 4 } Load & Top & Bottom & Average \\
\hline & & 495 & \\
Soil & 55 & 495 & \\
Concrete Truck & 723 & 73 & 678 \\
TOTAL & 778 & 578 & 678 \\
\hline
\end{tabular}

The maximum bending moment is calculated assuming that the plate is fixed at the four boundaries (Szilard, Case 80). The moment is:

$$
M_{\max }=0.075 \mathrm{p}_{0} \mathrm{~L}^{2}=0.075 \times 678 \times 8^{2}=3254 \mathrm{ft} \mathrm{lb} / \mathrm{ft}
$$

The required thickness $(t)$ is:

$$
t=\left[6 \mathrm{M}_{\max } / f_{\mathrm{allow}}\right]^{1 / 2}
$$

The required thicknesses ( $t_{y}$ of Fig. 32 ) of the sidewalls for each of the PC systems are as follows:

\begin{tabular}{|ccc|}
\hline & \multicolumn{2}{c|}{ Required sidewall thickness $\left(t_{N}\right)$, in. } \\
\cline { 2 - 3 } FPC System & \multicolumn{2}{c|}{ Design Temperature, ${ }^{\circ} \mathrm{F}$} \\
\hline VET & $285^{\circ}$ & $400^{\circ}$ \\
ST & 4.35 & 5.20 \\
PF & 4.90 & 6.50 \\
& 4.90 & 5.30 \\
\hline
\end{tabular}

\subsubsection{Foundation slab design.}

The foundation slab is designed to carry the combined weight of the box (estimated to be $61,800 \mathrm{lb}$ ), overburden soil (estimated to be $13,200 \mathrm{lb})$, and the concrete truck $(81,000 \mathrm{lb})$. Using Eq. 5 this results in a plate bearing pressure of $1300 \mathrm{psf}$. The maximum bending moment is calculated assuming that the slab is fixed at the four boundaries (Szilard, Case 80). The moment is:

$$
M_{\max }=0.064 \mathrm{p}_{\mathrm{o}} \mathrm{L}^{2}=0.064 \times 1300 \times 10^{2}=8320 \mathrm{ft} \mathrm{lb} / \mathrm{ft}
$$


This moment requires the following slab thicknesses $\left(t_{f}\right)$ :

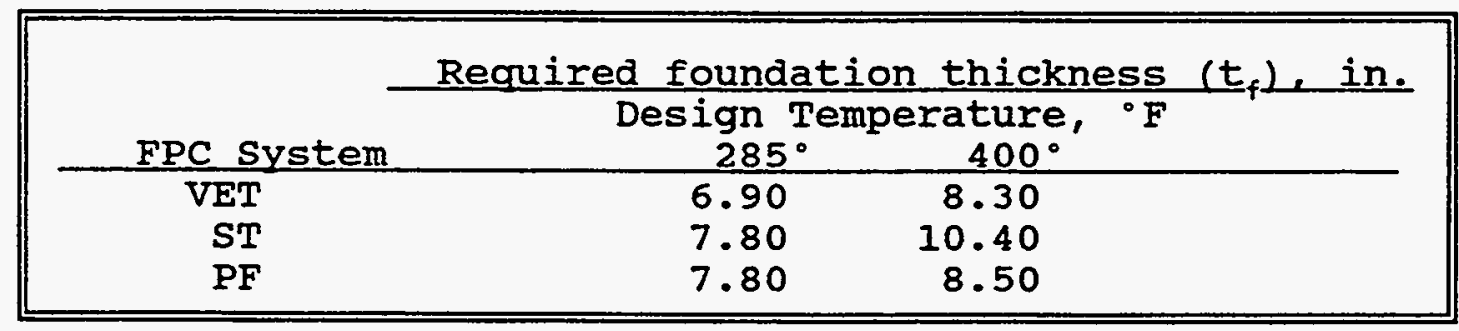

\section{5 .2 .3 Roof slab.}

The roof slab was designed to carry the weight of the slab itself (conservatively estimated at 150 psf), one foot of overburden soil ( $110 \mathrm{psf}$ ), and the total weight of the concrete truck distributed uniformly over the roof $(81000 / 120=675$ psf). The moments are computed from case 80 of Szilard. The maximum moment is:

$$
M_{\max }=0.064 \mathrm{p}_{0} \mathrm{~L}^{2}=0.064 \times(150+11+675) \times 10^{2}=5984 \mathrm{ft} \mathrm{lb} / \mathrm{ft}
$$

The required thickness is increased to account for the manhole cutouts. If area replacement is used to account for the cutouts the thickness should be increased by a factor of $[11 /(11-2.75)=$ 1.33]. The required thicknesses are determined from the following equation:

$$
t=1.33\left[6 \mathrm{M}_{\max } / f_{\mathrm{allow}}\right]^{1 / 2}
$$

The following slab thicknesses $\left(t_{r}\right)$ are required:

\begin{tabular}{|ccc|}
\hline & \multicolumn{2}{c|}{ Required roof thickness $\left(t_{N}\right)$, in. } \\
\cline { 2 - 3 } FPC System & \multicolumn{2}{c|}{ Design Temperature, ${ }^{\circ} \mathrm{F}$} \\
\hline VET & $285^{\circ}$ & $400^{\circ}$ \\
ST & 7.80 & 9.40 \\
PF & 8.80 & 11.70 \\
T & 8.90 & 9.60 \\
\hline
\end{tabular}

\subsubsection{Design Summary.}

A summary of the required design thicknesses for each of the components of the manhole is presented below. 


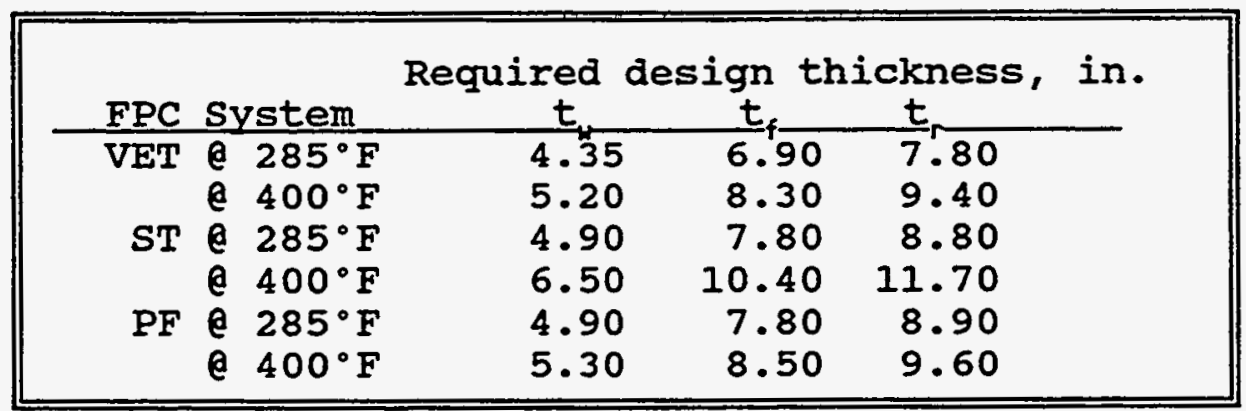

Note: $t_{H}=$ thickness of the walls, $t_{f}=$ thickness of the floor, and $t_{r}=$ thickness of the roof.

by con Ed.

5.6 Preliminary Design of a Full-Scale, Steam-Valve Manhole

A preliminary design of a VET PC steam-valve manhole was also performed by the Con Ed Civil Design Division. In general, the Con Ed design utilized a working stress design approach to analyze and design the manhole. The roof support system was designed as a series of beams; B1, B2, and B3 (see Figure 44). B1 and B2 are the support beams around the openings in the roof and B3 is the "slab" which spans the center of the roof between the openings. To help control deflections and creep conventional reinforcing steel was added to the beams (BI and B2) around the openings in the roof. The walls were considered to be one large beam.

The design assumed the manhole was located $3 \mathrm{ft}$ below street level and that it had the following interior dimensions:

Length $=9 \mathrm{ft}$ (clear).

Width $=6 \mathrm{ft} 4 \mathrm{in.}$ (clear).

Floor to ceiling height $=6 \mathrm{ft} 8.5 \mathrm{in.}$ (clear).

The design also assumed that the PCC floor system was intact and in good condition and would not need to be replaced. Dowels would be used to anchor the walls to the PCC floor slab.

The manhole was designed for a service temperature of $240^{\circ} \mathrm{F}$. At this temperature the VET PC system has the following properties:

Flexural yield strength

Flexural modulus of elasticity

Compressive strength

$$
\begin{array}{r}
1,805 \text { psi } \\
1.67 \times \text { E+6 psi } \\
10,395 \text { psi }
\end{array}
$$

In summary, the design required that the sidewalis have a minimum thickness of $4.5 \mathrm{in}$. and that the roof beams have a minimum thickness of 8.0 in. The design calculations are presented in Appendix $B$. 
$9.0 \mathrm{ft}$ CL.
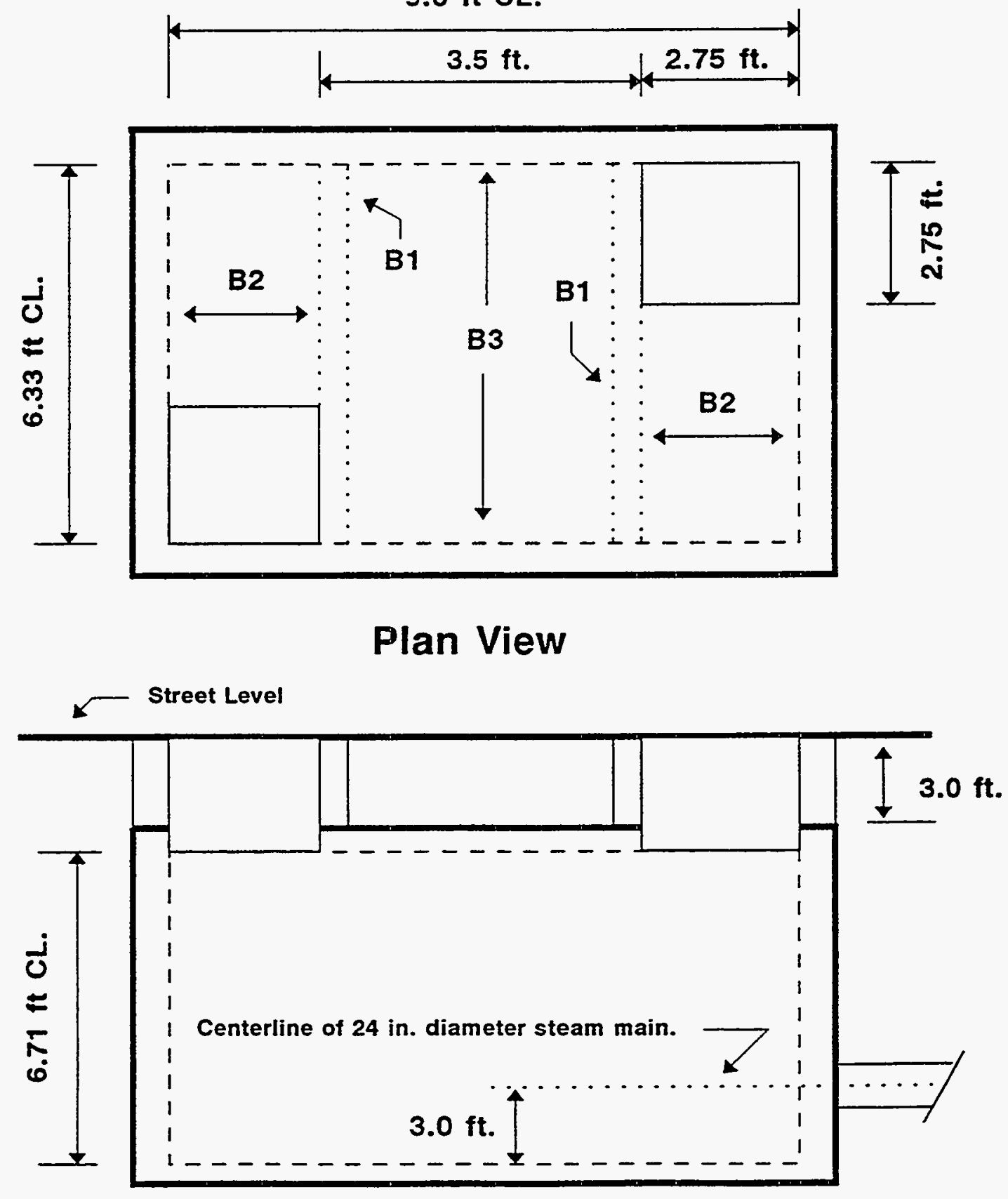

\section{Elevation}

NOTE: Drawing not to scale.

Figure 44. Plan of the VET PC steam-valve manhole designed by the Con Ed Design Civil Division. 


\subsection{PRELIMINARY COST ANALYSIS}

The following analysis provides a preliminary estimate of the costs associated with the field placement of a steam-valve manhole consisting of a PCC floor slab and PC walls and roof. The estimate was provided by Polymer construction specialties (PCS), Inc. of Patchogue, NY. PCS Inc. is a construction company located on Long Island that specializes in projects involving polymer concrete materials.

The estimate includes the cost for fabricating and placing all necessary formwork, mixing and placement of the PCC floor, and mixing and placement of the PC wall and roof systems. The estimate does not include the cost of excavating and removing the existing manhole structure nor does it include the cost for backfilling the new manhole and replacing the pavement.

The cost estimate was based on the following assumptions.

Manhole size $=8 \mathrm{ft}$ long by $5 \mathrm{ft}$ wide by $7 \mathrm{ft}$ high. Floor thickness $=12$ in., cast using conventional PCC. wall thickness $=5$ in.

Roof thickness $=6.5$ in., with two $2.75 \mathrm{ft}$ by $2.75 \mathrm{ft}$ openings for the manhole rings to be located diagonally opposite each other.

The walls and roof will be cast using the fiber-reinforced VET PC system. The materials cost of this system was estimated to be approximately $\$ 80 / \mathrm{cu} \mathrm{ft}$.

PCS Inc. also provided a comparative estimate for a manhole cast completely of conventional PCC. The walls of the manhole were assumed to have a minimum thickness of 10 in. and the roof a minimum thickness of 12 in. Table 16 summarizes the cost estimates made by PCS.

The estimates indicate that the cost of the cast-in-place PC manhole is approximately $\$ 32,316$ compared to a cost of $\$ 20,800$ for the PCC manhole. It should be noted that while the cost of a PC manhole is approximately 50 percent higher than that of a conventional PCC manhole the increased service life of a PC manhole will offset the initial increase in investment. 
Table 16. Comparative cost estimates for the field placement of cast-in-place PC and PCC manholes."

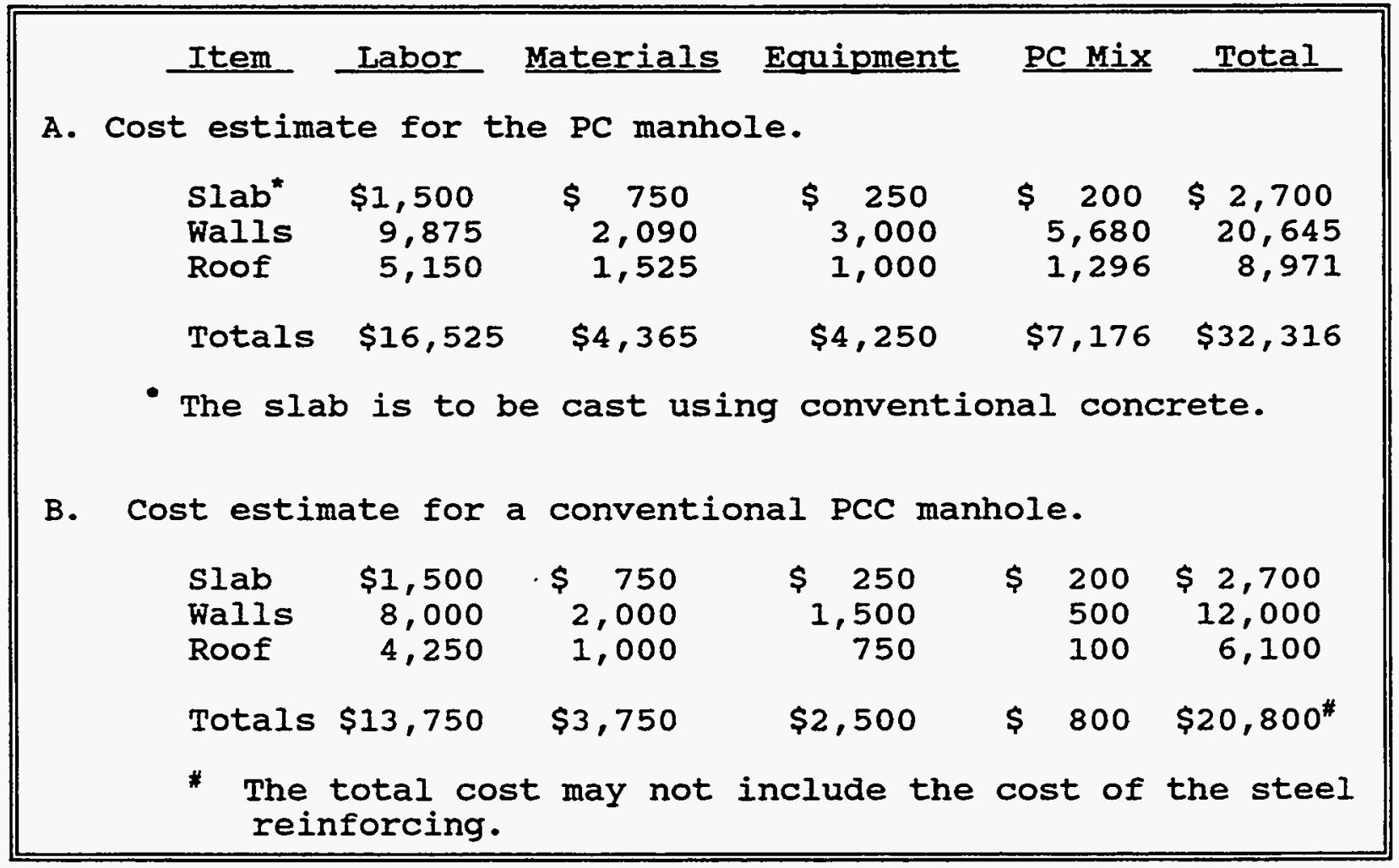

${ }^{\star *}$ Cost estimate by PCS Inc. 


\subsection{BUMMARY AND RECOMLENDATIONS}

\subsection{Summary.}

Deteriorated steam manholes in the steam distribution system of the Consolidated Edison Company of New York, Inc. (Con Ed) are being rebuilt using conventional portland cement concrete (PCC). Because the manholes are located beneath the streets and sidewalks of New York City, there is a great emphasis to minimize the time involved in rebuilding the manhole. Therefore, the manholes are often cast and placed into service very quickly. Consequently, the concrete is often only a few days old when it is subjected to the harsh environment of the manholes. In addition, by placing the manhole into service so quickly the concrete is not allowed to fully develop the strength and physical characteristics that it would normally attain under ideal curing conditions. This can sometimes result in the development of a substandard quality of concrete. The combination of quickly pouring and placing the newly cast PCC manhole into service and the severe operating conditions to which the manholes are exposed invariably result in a shorter than desired service life.

With the development in recent years of more advanced materials of construction, such as polymer concrete (PC), it may be possible to cast manholes that have a longer maintenance-free service life resulting from the improved physical and mechanical properties of these materials.

The Process Materials Group of the Energy Efficiency and Conservation Division, Department of Applied Science at Brookhaven National Laboratory (BNL) conducted a research program for Con Ed regarding the development of high temperature, corrosion resistant polymer concretes for use as construction materials in its underground steam distribution system. The results of this program are described in this report.

The primary objective of the program was to develop and experimentally evaluate PC materials that could be used as an alternative construction material to steel-reinforced PCC. The exposure conditions within a typical steam-valve manhole required that any PC system being considered for use exhibit the following characteristics: (a) it should be thermally stable at temperatures up to $400^{\circ} \mathrm{F}$, (b) it should have good strength and stiffness at temperatures up to $400^{\circ} \mathrm{F}$, (c) it should be impermeable to moisture penetration, and (d) it should have good resistance to possible chemical attack. The PC system should also lend itself to cast-inplace and/or precast applications. 
Three PC systems were developed and evaluated. Each system consisted of four components: a polymer binder system, a blended fine aggregate system, a graded coarse aggregate system, and a fiber reinforcement. The primary difference between each system was the monomer/resin system used as the binder. The three binder systems evaluated were a styrene-trimethylolpropane trimethacrylate (TMPTMA) based [ST] monomer system, a vinyl ester-TMPTMA based [VET] monomer system, and a phenol formaldehyde [PF] resin system. Each binder system is thermally stable at $400^{\circ} \mathrm{F}$.

One and one-half inch long corrugated, carbon steel fibers were selected for use as the reinforcing system. Synthetic fibers, such as graphite and Kevlar aramid fibers, also were evaluated, but the carbon steel fibers were found to provide the greatest improvements in load carrying capacity and ductility. stainless steel fibers were later evaluated when results of the in situ field tests indicated that corrosion of some of the carbon steel fibers exposed at the surface of the samples was causing some of the PC systems to deteriorate.

Preliminary evaluation of each candidate system was based upon the results of a series of laboratory-scale tests designed to (a) determine the physical and mechanical properties of the systems over a temperature range of $72^{\circ}$ to $400^{\circ} \mathrm{F}$ and (b) to determine if exposure to simulated field conditions deteriorated these properties.

The results of the laboratory tests indicated that the strength properties of each system decrease with increasing temperature. Compressive strengths for the three systems generally range between 12,220 and $14,270 \mathrm{psi}$ at $72^{\circ} \mathrm{F}$ and between 4,730 and $9,415 \mathrm{psi}$ at $400^{\circ} \mathrm{F}$. The flexural yield strengths vary between 2,145 and $2,865 \mathrm{psi}$ at $72^{\circ} \mathrm{F}$ and 930 and $1,440 \mathrm{psi}$ at $400^{\circ} \mathrm{F}$. The highest strength values are generally exhibited by the VET PC system. The strength reductions were due to a softening of the polymer binder systems, and not to any physical deterioration of the PC systems.

Results of small-scale, short-term load-deflection tests showed that the VET PC system is the most rigid of the systems, while the ST PC system is the most flexible. Each of the three systems will creep under a sustained load.

The coefficients of thermal expansion for the PC systems are higher than those for conventional PCC, which has an average coefficient of thermal expansion of $5.5 \times 10^{-6}$ in./in. $/{ }^{\circ} \mathrm{F}$. The coefficients for each system vary slightly depending upon the binder, and also tend to vary with temperature, generally increasing slightly with increases in temperature. The coefficients of thermal conductivity for the PC systems are within the range of values associated with conventional PCC, i.e. they varied between 0.8 and $2.1 \mathrm{BTU} / \mathrm{hr} / \mathrm{ft} /{ }^{\circ} \mathrm{F}$. Thermal conductivity 
values were found to vary slightly with the type of binder and also were found to vary slightly with temperature.

Water absorption values for the PC systems were found to be well below those of conventional PCC, which normally vary between 5 and 7 wt: The PC systems had average water absorption values varying between 0.41 and 1.86 wt .

Tests were done under simulated field conditions in an autoclave to evaluate how each system might perform in the field. The tests showed that exposure to simulated field conditions resulted in a slight decrease in compressive strength for the PF system, while the strengths of the VET and ST systems remained relatively constant. Visual examinations of the samples throughout the tests indicated no significant deterioration due to autoclaving. The results suggested that each of the PC systems should perform well in the field.

When the laboratory-scale tests were completed, in situ field tests were started. The objectives of the field tests were: (a) to evaluate the effects of exposure to actual field conditions on the physical and mechanical properties of PC and PCC systems, (b) to determine if the heat generated within a typical manhole could be used to post-cure a PC system, and (c) to evaluate the long-term creep characteristics of a PC beam under load.

Samples were tested in situ in three operational steam-valve manholes. The manholes (MH) used in the tests were MH7498, MH7500, and MH15105. The average air temperature within each manhole was as follows: MH7498 - $177^{\circ} \mathrm{F}, \mathrm{MH} 7500-160^{\circ} \mathrm{F}$, and MH15105 - $194^{\circ} \mathrm{F}$. Four PC systems and two PCC systems were tested in situ. The PC systems were the ST, STP, VET, and PF systems. The PCC systems were a non-reinforced portland cement concrete system and a fiberreinforced portland cement system. The specimen placed in test included 2- by 2- by 12-in. long beams and 3-in. diameter by 6-in. long cylinders.

In general, most of the samples removed within the first 12 months of testing were in good physical condition; i.e. no significant deterioration of the surfaces was noted. The exceptions were the ST, PF, and VET samples removed from MH7498 after 6 to 8 months of exposure. These samples were beginning to show signs of scaling caused by the rusting of some of the steel fibers located near the surfaces of the samples. An examination of these samples after testing indicated that the rusted fibers were present only in that region located near the surface of the samples and that the rusting had not progressed to the fibers located in the interior of the samples.

Results of the splitting tensile strength and flexure strength tests showed that each of the PC systems exhibits some reduction in strength as a result of exposure to the environment within the 
manholes. However, these reductions in strength had been predicted by the results of the laboratory-scale autoclave tests. After 6 to 9 months of exposure in the manholes, the flexural yield strength of the PC systems, measured at $160^{\circ}$ to $200^{\circ} \mathrm{F}$, varied between 890 and 1870 psi, with the VET PC system exhibiting the highest strengths.

Results of in situ exposure tests done on ST and VET PC beams and cylinders cast and cured at room temperature indicated that the heat generated within the steam-valve manholes can be used to postcure the PC systems. The flexural yield strength of the VET PC system was found to increase 12 percent after $3 \mathrm{mo}$. of exposure in MH15105.

The results of tests done to evaluate the use of 430 stainless steel fibers as a replacement for carbon steel fibers indicated that at $200^{\circ} \mathrm{F}$ the strength properties of the samples made with the stainless steel fibers are very similar to those for samples made with the carbon steel fibers. In addition, the stainless steel fibers do not deteriorate. In situ testing of exposed fibers in MH15105 indicated that carbon steel fibers began to rust within 1 mo. of being placed in test while the 430 stainless steel fibers exhibited no evidence of rusting after 11 mo. of exposure.

In situ load testing in MH15105 (at an ambient temperature of $\left.\approx 196^{\circ} \mathrm{F}\right)$ of a 2 -in. by 8 -in. by $6.25 \mathrm{ft}$. long fiber-reinforced VETrt PC beam cast at room temperature indicated that this system will creep under a sustained load. When tested for 54 weeks at 84 percent of its design capacity the beam was found to deflect approximately 0.748 in. at midspan. The rate of creep was calculated to be approximately $0.010 \mathrm{in./wk}$.

The results of laboratory and in situ load tests of fiberreinforced VETrt PC beams containing conventional reinforcing bars indicated that at $200^{\circ} \mathrm{F}$ the system continues to creep under a sustained load, i.e. the addition of conventional reinforcing bar does not appear to help control the creep exhibited by this system.

Results of tests done on fiber-reinforced PCC samples cast for use in the in situ exposure tests showed that the strength properties of concrete cast and cured at elevated temperatures are significantly less than those for concrete cast and cured at room temperature. When tested at $200^{\circ} \mathrm{F}$, there was an average reduction in compressive strength of 36 percent for the samples cast and cured at elevated temperatures $\left(f_{c}=3225 \mathrm{psi}\right)$ as compared to the samples cast and cured at room temperature ( $f_{c}=4890$ psi). Reductions in flexure strength values also were noted.

In situ test results for non-reinforced and fiber-reinforced PCC samples after 3 months of exposure in MH15105 showed that the samples were in good condition and that the strength properties had increased slightly. The most significant change noted in either of 
the PCC systems was that both systems showed a weight loss. This was most likely due to a loss of moisture from the samples and not to any physical deterioration. The continued loss of moisture from the samples may at some point adversely affect the strength development of the system by reducing the rate at which the cement in the matrix hydrates.

A preliminary design study was made to determine the necessary floor slab, wall, and roof thicknesses required to replace a typical reinforced PCC manhole with a cast-in-place, fiberreinforced PC manhole. The design approach used classical plate theory by considering the manhole to be a series of plates subjected to loads resulting from soil pressures, highway loading, and dead weight. Designs were performed for each PC system under evaluation. The preliminary design analysis indicated that the required wall thicknesses will vary between 4.35 and 6.50 in. depending upon the PC system used and the required design temperature. The roof slab will vary between 7.80 and 11.70 in. A preliminary design by the Con Ed Civil Design Division produced similar results.

Polymer Construction Specialties, Inc. did a preliminary cost analysis for BNL to provide an estimate of the costs associated with the placement of a $8 \mathrm{ft}$ by $5 \mathrm{ft}$ by $7 \mathrm{ft}$ high cast-in-place PC manhole made with the VET PC system. A comparative estimate also was done for a manhole cast with conventional PCC. The estimates showed that the cost of the cast-in-place PC manhole is approximately $\$ 32,316$, compared to $\$ 20,800$ for the PCC manhole. It should be noted that while the cost of a PC manhole is approximately 50 percent higher than that of a conventional PCC manhole the increased service life of a PC manhole will offset the initial increase in investment.

In general, the results of the laboratory and in situ field tests indicate that the physical and mechanical properties and the corrosion resistance characteristics of the vinyl ester-TMPTMA (VET) PC system are superior to those of the other PC systems evaluated. However, the suitability of using the VET PC system as a structural material in the construction of underground, steamvalve manholes would, at present, appear to be limited by several factors which influence the performance of the system at elevated temperatures. As a result, the program was not carried beyond the design stage and full-scale testing of a PC manhole was not performed. The factors influencing this decision included the following:

(a) The VET PC system exhibits outstanding strength properties at $72^{\circ} \mathrm{F}$, e.g. the system has a compressive strength of 14,270 psi and a flexural yield strength of 2,865 psi. However, test results have shown that the strength properties decrease significantly with increases in temperature. When compared to values measured at $72^{\circ} \mathrm{F}$, the VET PC system 
exhibits a 20 to 25 percent decrease in strength at $240^{\circ} \mathrm{F}$ and a 50 percent decrease in strength at $400^{\circ} \mathrm{F}$.

(b) Long-term field tests performed on beams made with and without conventional reinforcing bars have indicated that the system exhibits an excessive amount of creep when loaded at 84 percent of its theoretical design capacity. Efforts to solve this problem have, to date, been unsuccessful.

(c) The lack of established design methods makes it difficult to accurately predict how the system will perform in the field, particularly at elevated temperatures. Conventional reinforced concrete design theory was used in the design studies performed in this program. It was also used to design the in situ creep tests. The results of the creep indicate that the assumptions made during the design of the experiments did not adequately predict the results which were obtained.

\subsection{Recommendations.}

Based upon the results presented in this report it is concluded that the PC systems evaluated in this program are not, at this time, ready for use as a construction material for steam-valve manholes. Additional work will need to be done to address the limitations of the materials at elevated temperatures before they are ready for use in the field. Suggested areas of research include the following:

(a) Because the use of $P C$ as a structural material is still relatively new there are, at present, no established design standards which will accurately predict actual field performance, particularly at elevated temperatures. As a result, additional laboratory and field tests need to be done to completely define the behavior of PC at ambient and elevated temperature conditions. One area in particular which needs to be addressed is creep. Tests results have shown that under the presently selected design loads the creep exhibited by the system is excessive. A more extensive series of load tests needs to be done to fully define the creep characteristics and to identify acceptable design limitations.

(b) Before a full-scale steam-valve manhole is built and put into service, at least one small-scale (one-quarter or one-half scale) model should be load tested to verify the analysis used in the design of the manhole.

(c) Long-term in situ testing of PC samples should be done to gather as much information as possible about the performance and durability of the PC systems under actual field conditions. 
(d) The VET PC system may be best suited for use in applications in which the maximum ambient temperature is less than $150^{\circ} \mathrm{F}$. When compared to values measured at $72^{\circ} \mathrm{F}$, the VET PC system exhibits only a 5 to 9 percent reduction in strength at $150^{\circ} \mathrm{F}$ as compared to a 20 to 25 percent decrease in strength at $240^{\circ} \mathrm{F}$ and a 50 percent decrease in strength at $400^{\circ} \mathrm{F}$. Work should be done to more fully define the physical and mechanical properties of the VET PC system at temperatures of $150^{\circ} \mathrm{F}$, of less. 


\section{REFERENCES}

1. "Guide for the Use of Polymers in Concrete," ACI 548.IR-86, American Concrete Institute, Detroit, MI, 1986.

2. Fontana, J. and Zeldin, A. Concrete Polymer Materials as Alternate Materials of Construction for Geothermal Applications-Field Test Evaluations, ASTM 717, American Society for Testing and Materials, Philadelphia, PA, 1981.

3. Kukacka, L. E. and Fontana, J. Polymer Concrete Patching Materials, Final Report, FHWA 77-11 Vol. II, Federal Highway Administration, Washington, DC, 1977.

4. Fontana, J. Insulating ING Storage Tank Containment Dikes with a Lightweight Polymer Concrete, BNL 40564, Brookhaven National Laboratory, Upton, NY, 1987.

5. Gjorv, O. E., et al. Effect of Condensed Silica Fume on the steel-Concrete Bond. American Concrete Institute Materials Journal, 87-M61, Nov.-Dec. 1990, 573-80.

6. Fontana, J., et. al. Development of Polymer Concrete Vaults for Natural Gas Regulator stations. BNL 45270, Brookhaven National Laboratory, Upton, NY, 1990.

7. Szilard, R. Theory and Analysis of Plates, Classical and Numerical Methods, Prentice-Hall Inc., Englewood Cliffs, NJ, 1974. 
APPENDIX A.

In Situ Flexure Load vs. Deflection vs. Time of Exposure Test Data 


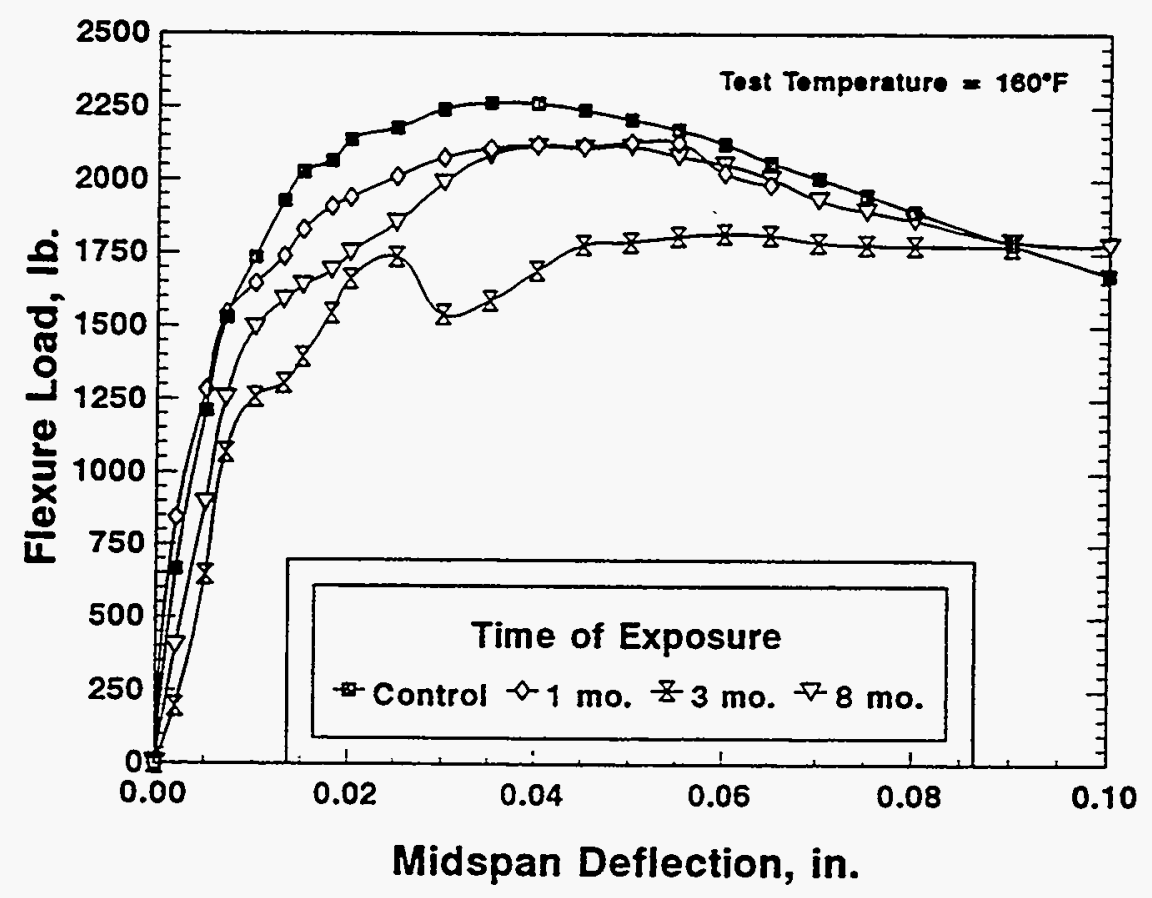

Figure Al. Variation of flexure load vs. deflection characteristics vs. time of exposure in MH7500 for the VET PC system.

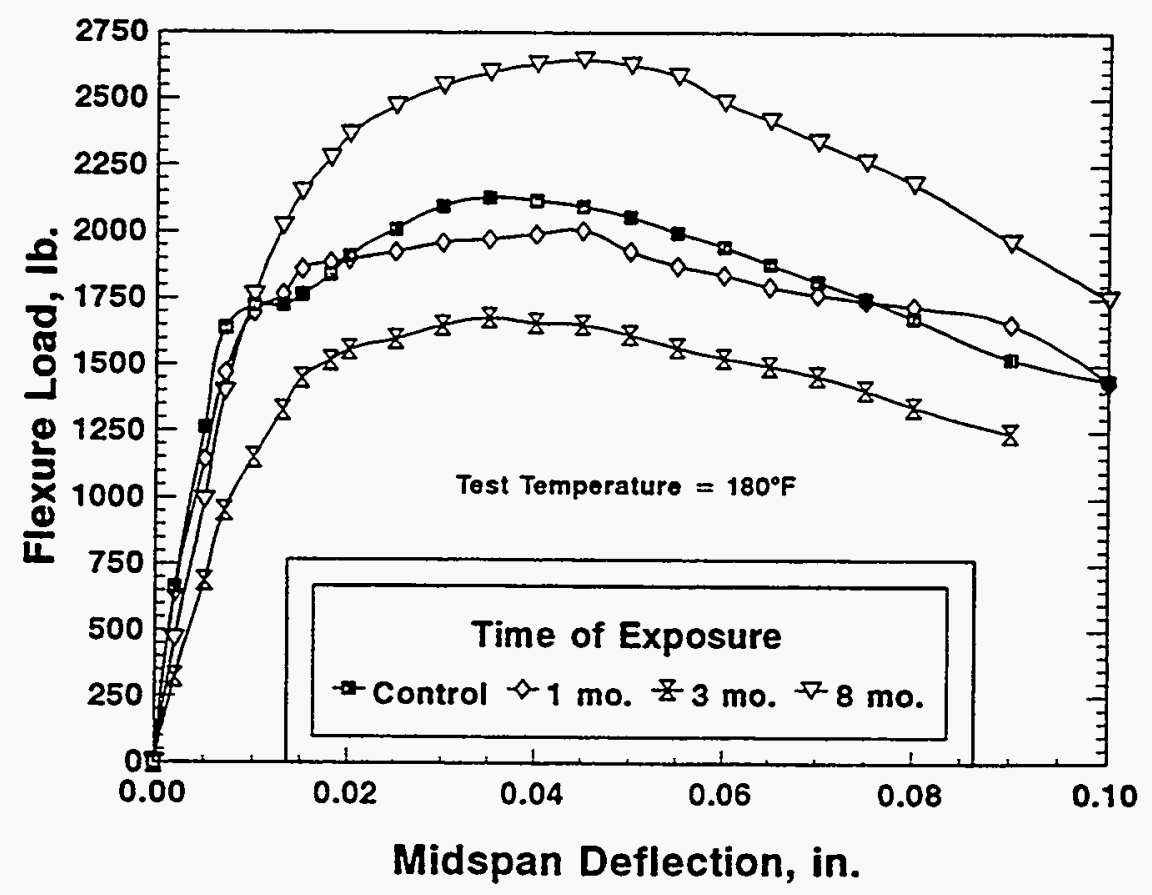

Figure A2. Variation of flexure load vs. deflection characteristics vs. time of exposure in MH7498 for the VET PC system. 


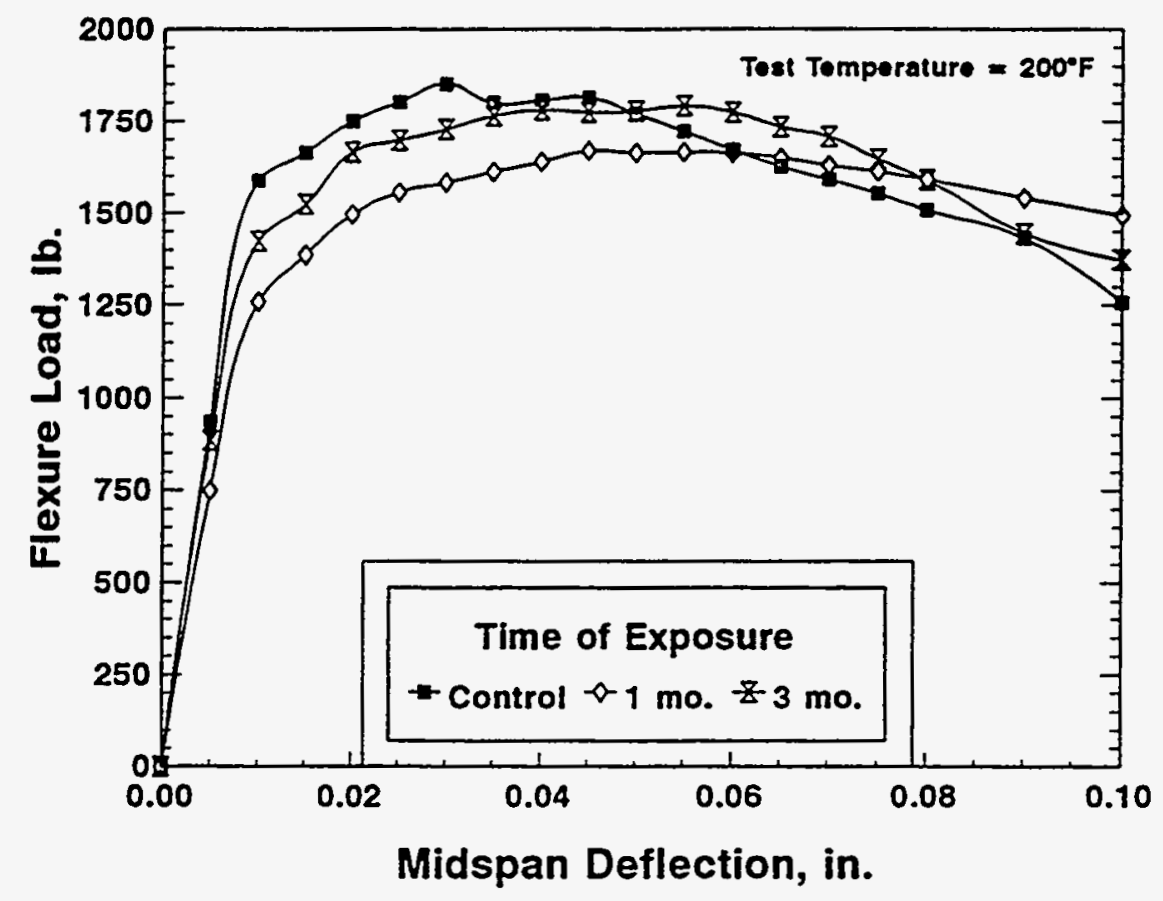

Figure A3. Variation of flexure load vs. deflection characteristics vs. time of exposure in MH15105 for the VET PC system.

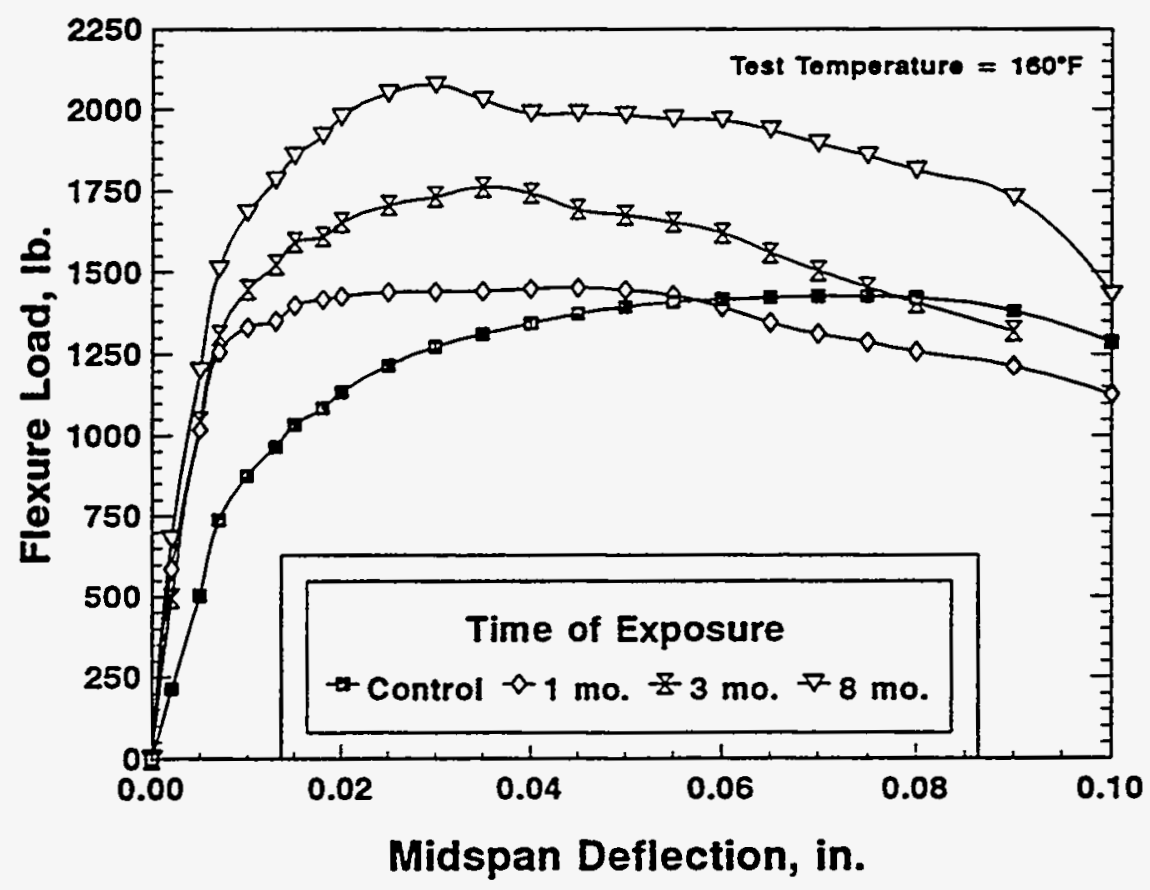

Figure A4. Variation of flexure load vs. deflection characteristics vs. time of exposure in MH7500 for the ST PC system. 


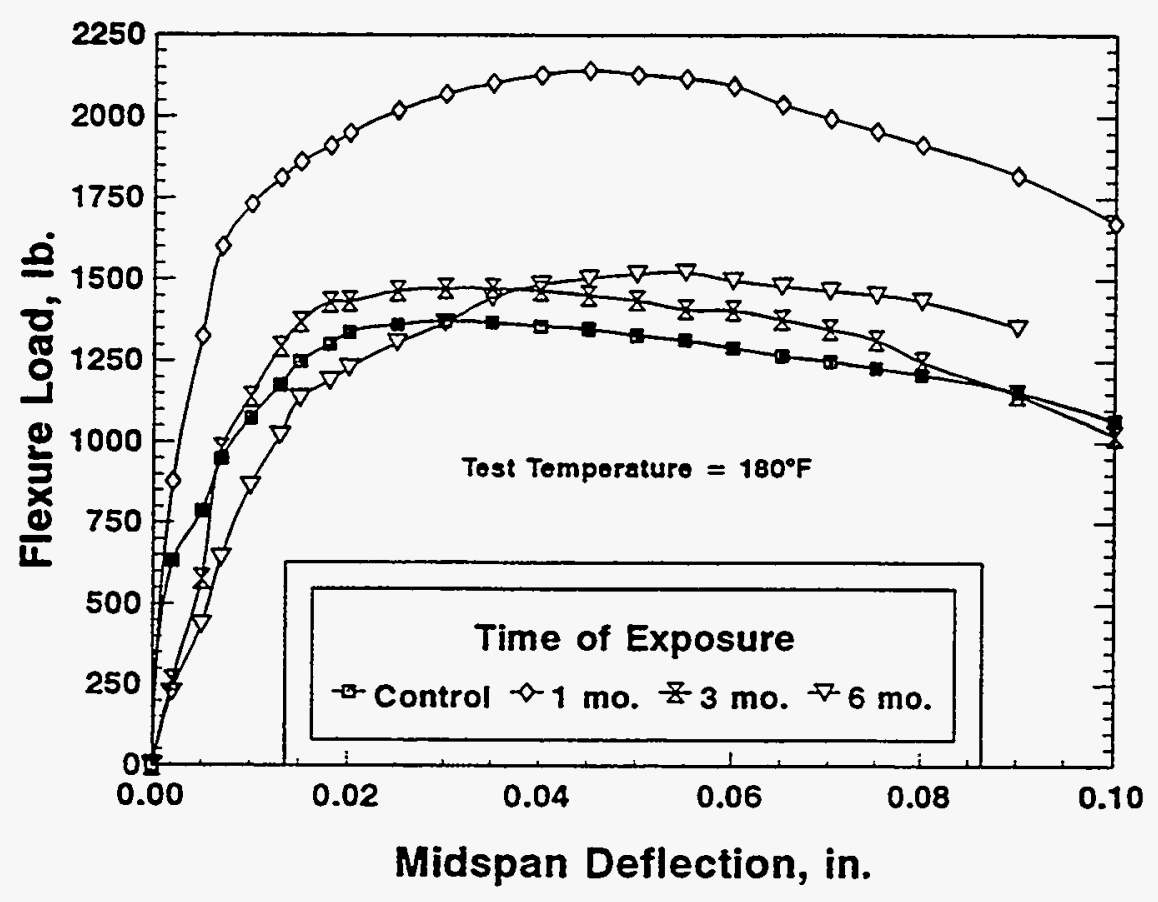

Figure A5. Variation of flexure load vs. deflection characteristics vs. time of exposure in MH7498 for the ST PC system.

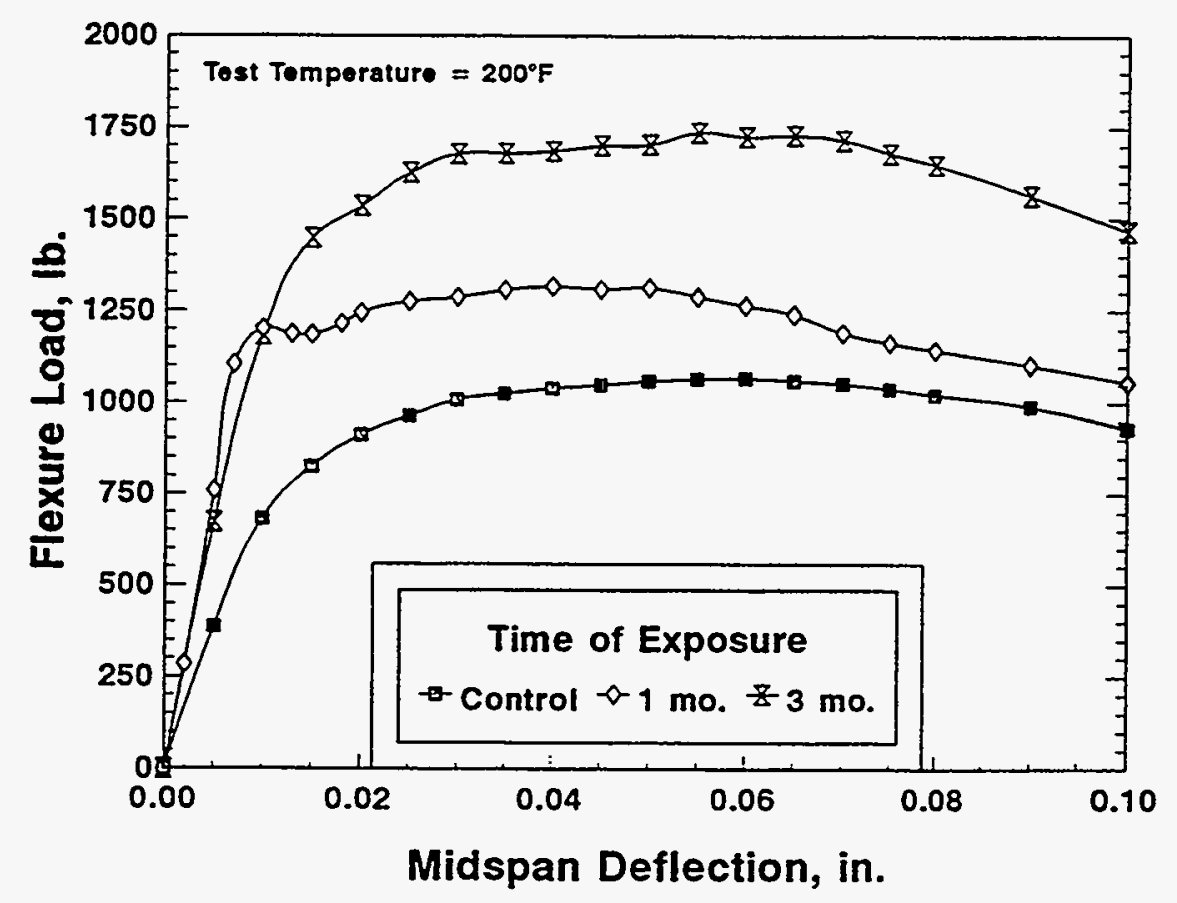

Figure A6. Variation of flexure load vs. deflection characteristics vs. time of exposure in MH15105 for the ST PC system. 


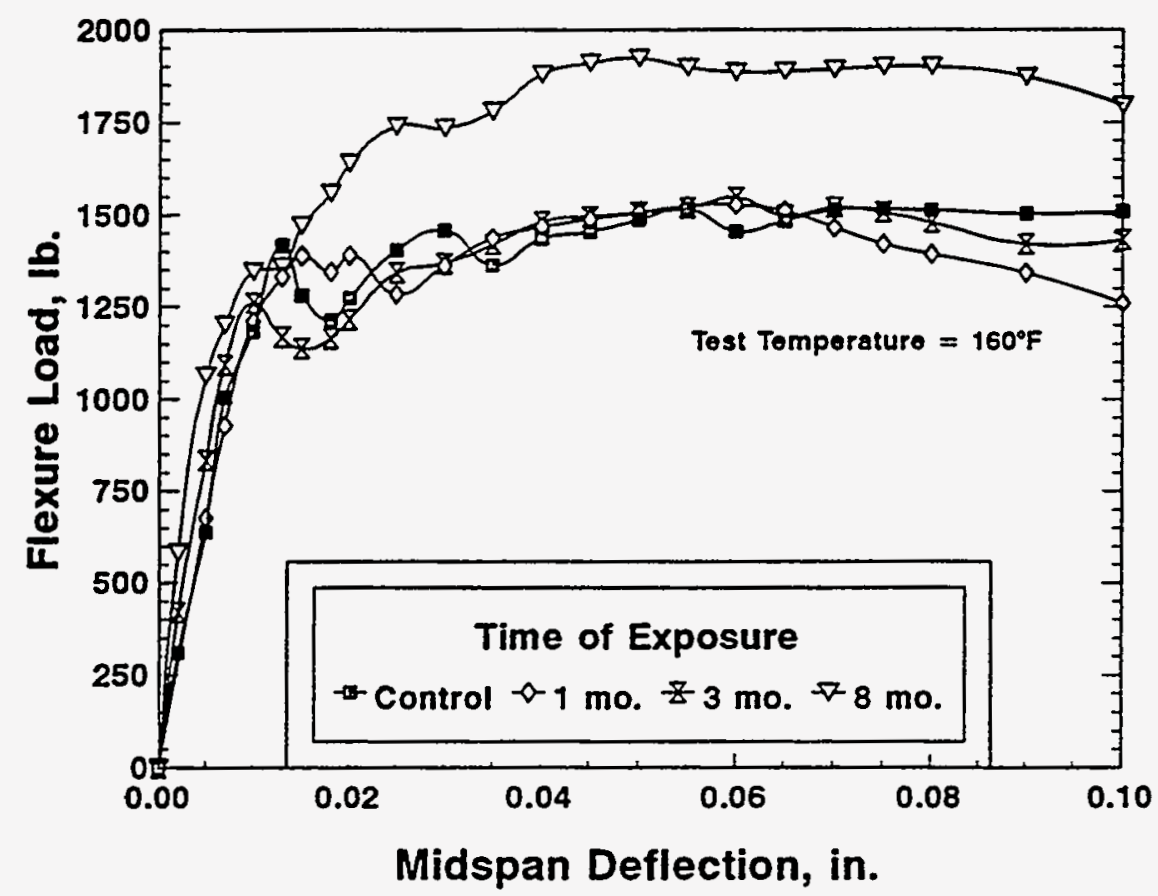

Figure A7. Variation of flexure load vs. deflection characteristics vs. time of exposure in MH7500 for the PF PC system.

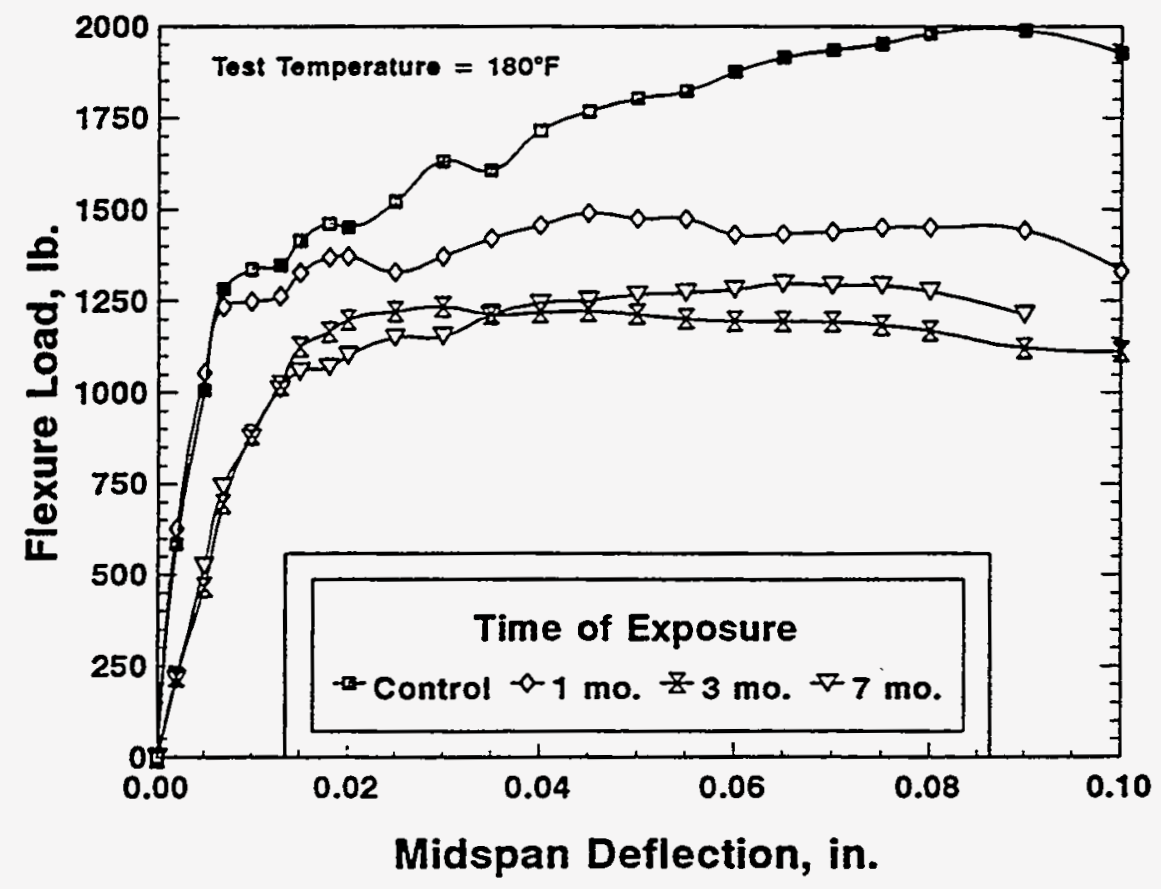

Figure A8. Variation of flexure load vs. deflection characteristics vs. time of exposure in MH7498 for the PF PC system. 


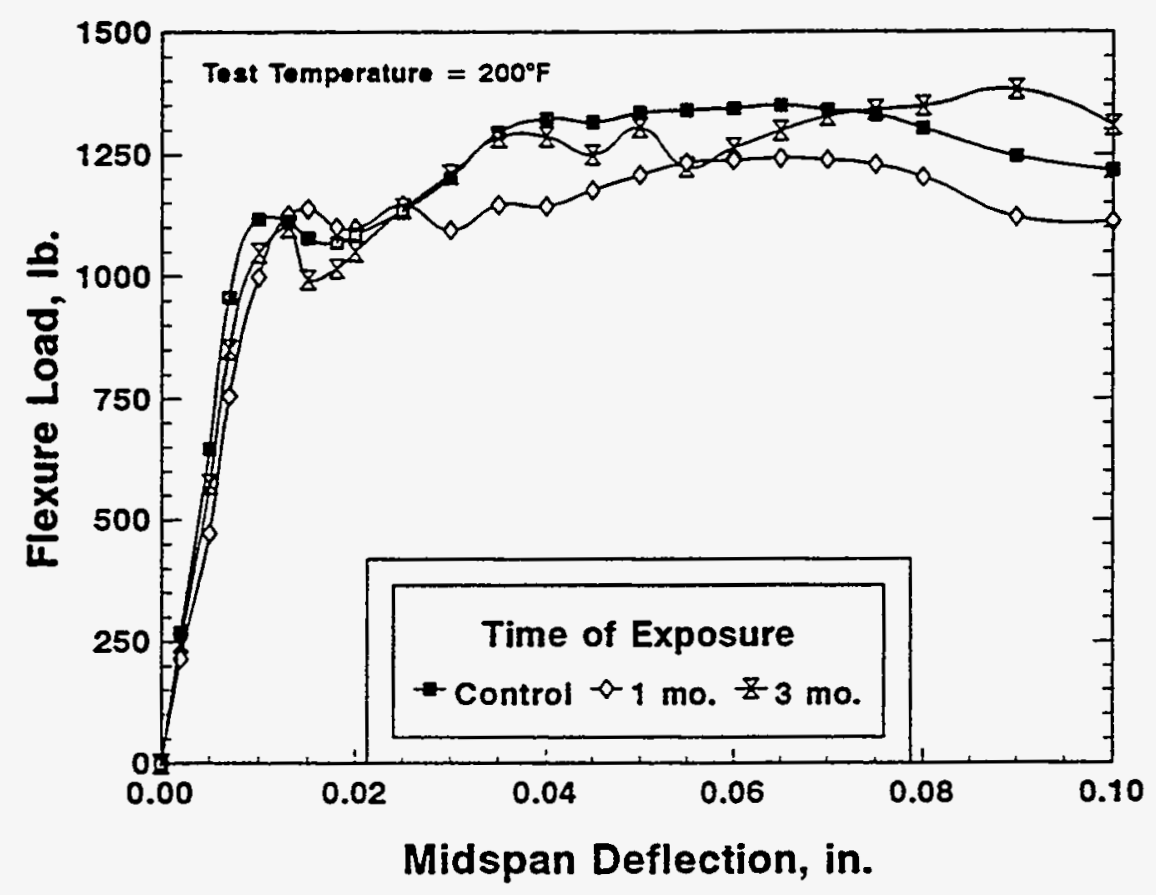

Figure A9. Variation of flexure load vs. deflection characteristics vs. time of exposure in MH15105 for the PF PC system.

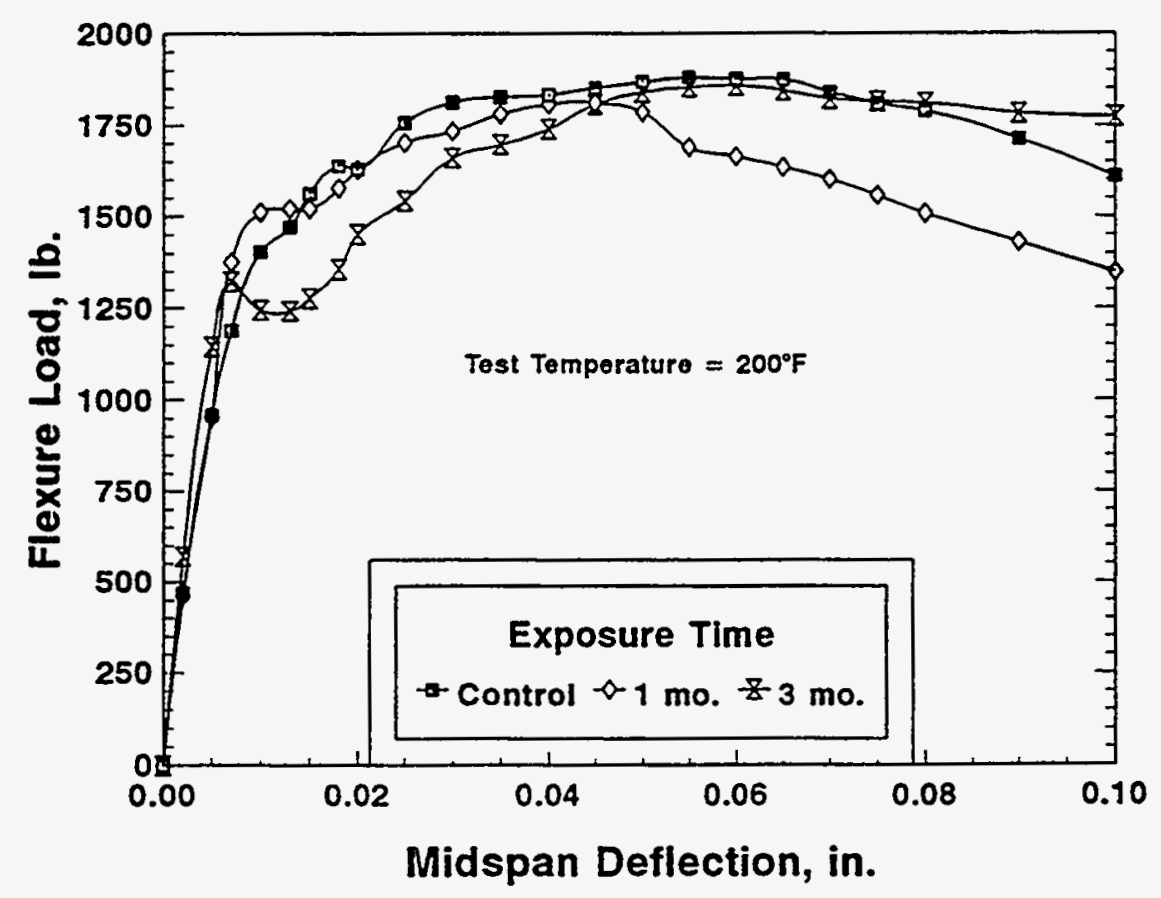

Figure Al0. Variation of flexure load v. deflection characteristics vs. time of exposure in MH15105 for the STP PC system. 


\section{APPENDIX B}

\section{Calculations for the Preliminary Design of a VET PC steam-Valve Manhole by the Con Ed Design Division}

\section{B.1 Design Assumptions.}

(a) The interior dimensions of the manhole are as follows (refer to Figure 44 ):

$$
\begin{aligned}
& \text { Length }=9 \mathrm{ft} \text { (clear) } \\
& \text { Width }=6 \mathrm{ft} 4 \text { in. (clear). } \\
& \text { Height }=6 \mathrm{ft} 8.5 \mathrm{in.} \text { (clear). }
\end{aligned}
$$

(b) Assume the manhole is approximately $3 \mathrm{ft}$ below street level and that it is located in the middle of a two lane commercial/residential street.

(c) There is a 24-in. diameter insulated, steam main which runs through the midale of the manhole and the centerline of the steam main is located $2 \mathrm{ft} 11.5 \mathrm{in.} \mathrm{above} \mathrm{the} \mathrm{floor} \mathrm{of} \mathrm{the} \mathrm{manhole.}$

(d) The concrete floor will remain in place and only the walls and roof will be cast of PC. Dowels will be used to anchor the walls to the concrete floor slab.

(e) To control deflections and creep in the roof, reinforcing steel will be used in the roof slab. The minimum amount of tension reinforcement to be used should be equal to that specified for use in concrete roof slabs, i.e. one No. 6 bar at a spacing of 12 in.

(f) The manhole should be designed for a service temperature of $240^{\circ} \mathrm{F}$. The properties of the VET PC system at this temperature are:

Flexural yield strength (FYS)

Flexural modulus of elasticity $\left(E_{p c}\right)$

Compressive strength $\left(f{ }^{\prime}\right)$

$$
\begin{array}{r}
1,805 \text { psi } \\
1.67 \times \mathrm{E}+6 \\
10,395 \mathrm{psi}
\end{array}
$$

B.2 Design Analysis Using the Working Stress Method.

B.2.I Design Values.

Use a factor of safety (FS) of 2 for all calculations.

The allowable flexural strength $\left(f_{T}\right)$ is:

$$
\mathrm{f}_{\mathrm{T}}=\mathrm{FYS} / 2=1805 / 2=902.5 \quad \text { Use } 900 \mathrm{psi} \text {. }
$$


The allowable compressive strength $\left(f_{\mathrm{pc}}\right)$ is:

$$
f_{p C}=f^{\prime}{ }^{\prime} / 2=10395 / 2=5197.5 \text { Use } 5200 \text { psi. }
$$

The allowable tensile strength of the reinforcing steel $\left(f_{s}\right)$ is equal to $24,000 \mathrm{psi}$ and the modulus of elasticity $\left(E_{\mathrm{s}}\right)$ is equal to $29,000,000$ psi.

$$
\begin{aligned}
& \eta=E_{S} / E_{P C}=29,000,000 / 1,670,000=17.37 \text { Use } 17.5 \\
& k=\left[1+\left(f_{s} / 0.45 n f_{p c}\right)\right]^{-1}=0.631 \\
& J=I-(\mathrm{k} / 3)=0.789 \\
& p=k f_{p C} / 2 f_{s}=0.038 \\
& \mathrm{~K}=\mathrm{kJ} \mathrm{f}_{\mathrm{PC}} / 2=582.5 \text { Use } \mathrm{K}=583
\end{aligned}
$$

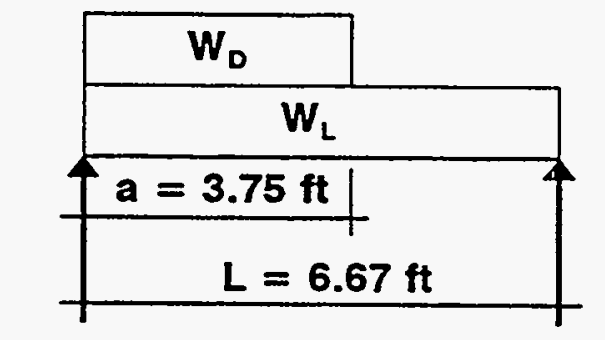

$R_{1}$
Use a uniform dead load (dead load of the PC + soil + asphalt and concrete subbase) of $410 \mathrm{lb} / \mathrm{ft}$ over the entire span and a partially uniform live load of $5,547 \mathrm{lb} / \mathrm{ft}$ (the concentrated highway loading which is transferred through the manhole chimney to the roof slab has been converted to a partially $\mathbf{R}_{2}$ uniform load).

$$
\begin{aligned}
R_{1} & =w_{D} I / 2+w_{L} a(2 I-a) / 21 \\
& =410(6.67) / 2+5,547(3.75)(2[6.67]-3.75) /(2[6.67]) \\
& =16,3211 \mathrm{~b}
\end{aligned}
$$$$
V_{0}=R_{1}-\left(w_{D}+w_{L}\right) x \text { when } x<3.75 \mathrm{ft} \text {, Solving for } x \text { : }
$$$$
0=16,321-(410+5,547) x
$$$$
x=2.74 \mathrm{ft}
$$$$
M_{\chi}=R_{1} \chi-\left(w_{D}+w_{L}\right) \chi^{2} / 2
$$$$
=16,321(2.74)-(410+5,547) 2.74^{2} / 2
$$$$
=22,355 \mathrm{ft}-1 \mathrm{~b} \text { or } 268,255 \mathrm{in} .-1 \mathrm{~b}
$$ 
Determine the total depth ( $t$ ) of Beam BI:

$$
\begin{aligned}
d & =\left(M_{x} / K b\right)^{0.5} \text { and } t=d+1.5 \mathrm{in.} \text { (cover) Using } b=12 \mathrm{in} . \\
& =[268,255 /(583 \times 12)]^{0.5}=6.2 \mathrm{in} . \text { Use } d=6.5 \mathrm{in} . \\
t & =6.5+1.5=8.0 \mathrm{in} .
\end{aligned}
$$

Determine the total area of reinforcing steel $\left(A_{s}\right)$ required to reinforce Beam $\mathrm{Bl}$.

$$
\begin{aligned}
A_{S} & =M_{x} / f_{s} J d \\
& =268,255 /[24,000 \times 0.789 \times 6.5]=2.18 \mathrm{in} .^{2}
\end{aligned}
$$

Five No. 6 bars have a total area of $5 \times 0.44=2.20$ in. ${ }^{2}$

Check the design calculations for Beam BI to ensure that the stresses developed in the beam are less than the allowable design stresses.

$$
\begin{aligned}
\rho & =A_{s} / b d \\
& =2.20 /(12 \times 6.5) \\
& =0.03 \\
k & =\left[2 \eta \rho+(\rho \eta)^{2}\right]^{0.5}-\rho \eta \\
& =\left[(2 \times 17.5 \times 0.03)+(0.03 \times 17.5)^{2}\right]^{0.5}-(0.03 \times 17.5) \\
& =[1.05+0.28]^{0.5}-0.53 \\
& =0.62 \\
J & =1-(k / 3) \\
& =1-(0.62 / 3) \\
& =0.79 \\
f_{s} & =M_{x} / A_{s} J d \\
& =268,255 /[2.2 \times 0.79 \times 6.5] \\
& =23,746 \mathrm{psi} \\
f_{c} & =2 \rho f_{s} / \mathrm{k} \leq 0.45 f_{p c} ? \\
& =[2 \times 0.03 \times 23,746] / 0.62 \leq 0.45 \times 5,200 ? \\
& =2,298 \mathrm{psi} \leq 2,340 \mathrm{psi} 0 \mathrm{KK}
\end{aligned}
$$


B.2.3 Design of Roof Slab Beam B2.

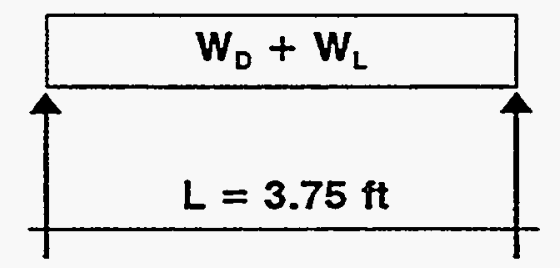

This beam is located on the short side of the opening to the manhole chimney. Use a uniform dead load of $410 \mathrm{lb} / \mathrm{ft}$ and a uniform live load of $5,547 \mathrm{lb} / \mathrm{ft}$ (total applied load is 5,957 (b/ft).

$R_{1}$

$\mathbf{R}_{2}$

$$
\begin{aligned}
R_{1}=R_{2}= & \left(w_{D}+w_{L}\right) 1 / 2 \\
& =(410+5,547) \times 3.75 / 2 \\
& =11,1691 \mathrm{~b} \\
M & =\left(w_{D}+w_{L}\right) I^{2} / 8 \\
& =\left[(410+5,547)(3.75)^{2}\right] / 8 \\
& =10,471 \mathrm{ft}-1 \mathrm{~b} \text { or } 125,655 \text { in. }-1 \mathrm{~b}
\end{aligned}
$$

Determine the total depth ( $t$ ) of Beam B2:

$$
\begin{aligned}
d & =(M / K b)^{0.5} \text { and } t=d+1.5 \text { in. (cover) Using } b=12 \mathrm{in} . \\
& =[125,655 /(583 \times 12)]^{0.5} \\
& =4.24 \mathrm{in.} \text { Use a minimum } d \text { of } 6.0 \mathrm{in} . \\
t & =6+1.5=7.5 \mathrm{in} .
\end{aligned}
$$

Determine the total area of reinforcing steel $\left(A_{S}\right)$ required to reinforce Beam $\mathrm{B} 2$.

$$
\begin{aligned}
A_{S} & =M / f_{s} J d \\
& =125,655 /(24,000 \times 0.798 \times 6)=1.11 \mathrm{in.}^{2}
\end{aligned}
$$

Three No. 6 bars have a total area of $3 \times 0.44=1.32$ in. ${ }^{2}$

Check the design calculations for Beam B2 to ensure that the stresses developed in the beam are less than the allowable design stresses.

$$
\begin{aligned}
\rho & =A_{S} / b d \\
& =1.32 /(12 \times 6) \\
& =0.02
\end{aligned}
$$




$$
\begin{aligned}
& \mathrm{k}=\left[2 \eta \rho+(\rho \eta)^{2}\right]^{0.5}-\rho \eta \\
& =\left[(2 \times 17.5 \times 0.02)+(0.02 \times 17.5)^{2}\right]^{0.5}-(0.02 \times 17.5) \\
& =[0.70+0.12]^{0.5}-0.35=0.56 \\
& J=1-(\mathrm{k} / 3) \\
& =1-(0.56 / 3) \\
& =0.81 \\
& f_{S}=M / A_{S} J d \\
& =125,655 /(1.32 \times 0.81 \times 6) \\
& =19,587 \mathrm{psi} \\
& f_{c}=2 \rho f_{s} / k \leq 0.45 f_{p C} \text { ? } \\
& =(2 \times 0.02 \times 19,587) / 0.56 \leq 0.45 \times 5,200 ? \\
& =1,399 \mathrm{psi} \leq 2,340 \mathrm{psi} \mathrm{OK}
\end{aligned}
$$

\section{B.2.4 Design of Roof Slab Beam B3.}

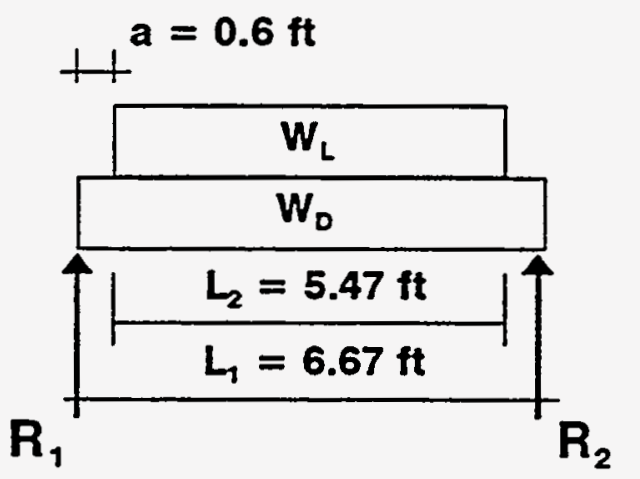

This beam runs parallel to Beam B1 and spans the center section of the roof. Design the entire slab as one large beam $(b=42$ in. $)$ Use a uniform dead load of $410 \quad 1 \mathrm{~b} / \mathrm{ft}^{2}$ $(1436 \mathrm{lb} / \mathrm{ft})$ and a uniform live load of $3796 \mathrm{lb} / \mathrm{ft}$. This section of the roof will not contain any rebars.

$$
\begin{aligned}
R_{1} & =R_{2}=R_{D}+R_{L}=W_{D} I_{1} / 2+W_{L} I_{2} / 2 \\
& =(1,436 \times 6.67) / 2+(3,796 \times 5.47) / 2 \\
& =15,1711 b \\
M & =w_{D} I_{1}^{2} / 8+R_{L}\left[a+\left(R_{L} / 2 w_{L}\right)\right] \\
& =1,436(6.67)^{2} / 8+10,382[0.6+(10,382 /(2 \times 3,796))] \\
& =7,986+20,426 \\
& =28,412 \mathrm{ft}-1 \mathrm{~b} \text { or } 340,944 \text { in. }-1 \mathrm{~b}
\end{aligned}
$$


Determine the total depth $(t)$ of Beam B3. Since this beam will not contain any rebar $t=d$.

$$
\begin{aligned}
d & =\left(6 \mathrm{M} / \mathrm{bF}_{\mathrm{T}}\right)^{0.5} \\
& =[(6 \times 340,944) /(42 \times 900)]^{0.5} \\
& =7.36 \mathrm{in} . \text { Use } \mathrm{d}=8.0 \mathrm{in} .
\end{aligned}
$$

For $d=8.0$ in.

$$
\begin{aligned}
\mathrm{F}_{\mathrm{T}} & =6 \mathrm{M} / \mathrm{bd}^{2} \leq 900 \mathrm{psi} ? \\
& =(6 \times 340,944) /\left(42 \times 8^{2}\right) \\
& =761 \mathrm{psi} \leq 900 \mathrm{psi} \mathrm{OK}
\end{aligned}
$$

B.2.5 Design of the Sidewalls.

$$
\begin{aligned}
& R_{1} \longrightarrow \text { The design of the walls will be } \\
& w=467 \mathrm{lb} / \mathrm{ft}^{2} \times 9 \mathrm{ft}=4,203 \mathrm{lb} / \mathrm{ft} \\
& \mathrm{M}=\mathrm{wl} \mathrm{l}^{2} / 8 \\
& =4,203 \times 7^{2} / 8 \\
& =25,743 \mathrm{ft}-\mathrm{lb} \text { or } 308,920 \mathrm{in.}-1 \mathrm{~b}
\end{aligned}
$$

Determine the total depth $(t)$ of the wall. Since this beam will not contain any rebar $t=d$.

$$
\begin{aligned}
d & =\left(6 \mathrm{M} / \mathrm{bF}_{\mathrm{T}}\right)^{0.5} \\
& =[(6 \times 308,920) /(108 \times 900)]^{0.5} \\
& =4.37 \mathrm{in.} \quad \text { Use } \mathrm{d}=4.5 \mathrm{in} .
\end{aligned}
$$

For $d=4.5$ in.

$$
\begin{aligned}
\mathrm{F}_{\mathrm{T}} & =6 \mathrm{M} / \mathrm{bd}^{2} \leq 900 \mathrm{psi} ? \\
& =(6 \times 308,920) /\left(108 \times 4.5^{2}\right) \\
& =848 \mathrm{psi} \leq 900 \mathrm{psi} \underline{\mathrm{OK}}
\end{aligned}
$$




\section{B.3 Design Summary}

In general, the design requires that the sidewalls have a minimum thickness of $4.5 \mathrm{in}$. and that the roof slab has a minimum thickness of 8.0 in. Number 6 reinforcing bars will be used around the opening to the manhole chimney to help transfer loads and to help minimize deflections and creep. 